Universidade de São Paulo

Instituto de Astronomia, Geofísica e Ciências Atmosféricas

Departamento de Astronomia

Edgar Bueno dos Santos

\title{
Modelagem numérica da dinâmica do manto na borda da litosfera continental em margens divergentes
}

São Paulo 

Edgar Bueno dos Santos

\section{Modelagem numérica da dinâmica do manto na borda da litosfera continental em margens divergentes}

Dissertação apresentada ao Departamento de Geofísica do Instituto de Astronomia, Geofísica e Ciências Atmosféricas da Universidade de São Paulo como requisito parcial para a obtenção do título de Mestre em Ciência.

Versão Corrigida. O original encontra-se disponível na Unidade.

Área de Concentração: Geofísica Orientador: Prof. Dr. Victor Sacek

São Paulo 



\section{Agradecimentos}

Gostaria de agradecer primeiramente ao meu orientador Prof. Dr. Victor Sacek por toda a dedicação e paciência. Sei que além de um excelente orientador eu ganhei um grande amigo. Obrigado.

Agradeço ao PRH-19 da Agência Nacional do Petróleo, Gás Natural e Biocombustíveis pela concessão da bolsa de mestrado e pelo apoio financeiro para a realização desta pesquisa.

Aos professores, funcionários, e alunos do IAG que de alguma forma contribuíram para o desenvolvimento deste trabalho.

Aos meus amigos e colegas do IF por todas as "aventura" que passamos juntos pela graduação.

Agradeço ao Benix, Gianee, Xpray e Lille por todos os momentos de diversão que tivemos nos últimos anos. I would also like to thank Morewynn for the friendship and for all the patience taking my English questions. Aos meus primos, em especial ao Douglas e Lucas por todos estes anos de amizade, e ainda mais especial ao Douglas por todas as correções/traduções em que já contribuiu.

Agradeço aos meus pais Valter e Nelci por todo o amor, carinho e educação que me foi dado. Por sempre acreditarem no meu potencial e fazerem de tudo para que eu pudesse chegar onde cheguei.

Ao meu irmão Henrique, por sempre estar disposto a me ajudar e compartilhar suas experiências e me guiar durante todos esses anos. Aos meus sobrinhos Olívia e Antônio que com toda a sua inocência trouxeram tantos momentos felizes para esta família. 


\section{Resumo}

O presente trabalho tem como objetivo estudar a dinâmica do manto superior em margens continentais através do uso de modelos numéricos que simulam processos convectivos e condutivos no tempo geológico, avaliando-se como a incorporação da convecção no estudo da história de subsidência de margens continentais difere do resultado obtido através de modelos puramente condutivos. Como primeiros testes, foram realizadas comparações dos resultados numéricos com soluções analíticas para diferentes valores do número de Rayleigh, verificando-se a validade das soluções computacionais. Também foi feita uma análise da estabilidade da litosfera no tempo geológico para diferentes perfis de viscosidade, servindo como base para a escolha dos parâmetros reológicos do manto para os modelos no contexto de margens divergentes. A partir dos cenários numéricos que melhor reproduziram a estrutura da litosfera terrestre, novos cenários foram criados para simular a evolução térmica e isostática de margens continentais. Como exemplo, utilizou-se dados geofísicos e geológicos extraídos da literatura para a bacia sedimentar do Golfo do Leão, no sudeste da França, com o objetivo de comparar a evolução geodinâmica do presente modelo numérico com outros modelos publicados na literatura. Observou-se que o efeito convectivo astenosférico preserva a estrutura térmica aquecida da margem estirada por mais tempo em comparação com o modelo puramente condutivo. Isso implica que, possivelmente, outros fatores também devem ser levados em consideração como o efeito da geometria tridimensional da margem do Golfo do Leão que pode contribuir para um aumento da subsidência da margem em relação ao modelo obtido no presente trabalho. Adicionalmente, constatou-se que a convecção mantélica pode induzir tensões na base da litosfera que a deslocam dinamicamente ao longo do tempo geológico, podendo influenciar a evolução estratigráfica das bacias sedimentares marginais. São apresentados cerca de 60 cenários geodinâmicos 
mostrando como a variação da estrutura reológica do manto influencia a evolução térmica da litosfera e consequentemente, a história de subsidência da margem. 


\section{Abstract}

This work aims to study the dynamics of the upper mantle in continental margins by using numerical models that simulate convective and conductive processes in geological time scale. It was evaluated the contribution of convection and conduction for subsidence history of sedimentary basins. As first tests, simple numerical scenarios with different Rayleigh number were compared with analytic solutions, verifying the validate of the computational solutions. These numerical experiments were followed by the analysis of the lithospheric stability in the geological time scale for different values of viscosity. These experiments were used as a base for the choice of the rheological parameters of the mantle for the models in the context of divergent margins. From the numerical scenarios that better reproduced the lithospheric structure of the Earth, new scenarios were created to simulate the thermal and isostatic evolution of continental margins. As an example, geophysical and geological data extracted from the literature for the sedimentary basin of the Gulf of Lion, Southeastern France, were compared with the results of different geodynamic models published in the literature and with the numerical scenarios obtained in the present work. We observed that the effect of the astenospheric convection preserves the thermal structure of the stretched margin for a long time in comparison with purely conductive models. This implies that, possibly, other processes must be taken into account, such as the effect of the three-dimensional geometry of the Gulf of Lion margin that may contribute to a higher subsidence of the margin than the one obtained in the present work. Additionally, it was observed that mantle convection may induce stress at the base of the lithosphere that dynamically moves it in the geological time, and may influence the stratigraphic evolution of sedimentary basins. It is presented about 60 scenarios showing how the variation of the rheological structure of the mantle is taken into account in the 
thermal evolution of the lithosphere and consequently in the subsidence history of the margin. 


\section{Lista de Figuras}

2.1 Representação esquemática do modelo de Sleep (1971). O continente é soerguido por processos externos. A porção soerguida é afinada pela erosão. Com o resfriamento término, há subsidência do continente soerguido, voltando a sua posição inicial e assim é formada uma bacia sedimentar. Figura extraída de Stüwe (2002). . . . . . . . . . . . . . . . .

2.2 Representação do modelo de Mckenzie (1978). A seção inicial da litosfera possui uma espessura uniforme (L), e o perfil de temperatura é linear com a profundidade. A litosfera é instantaneamente estirada por um fator $\beta$ e então afinada por um fator $1 / \beta$. A área abaixo da litosfera afinada é preenchida pelo manto astenosférico, com temperatura igual a da base da litosfera. O resfriamento provoca uma subsidência térmica e o perfil de temperatura volta a o seu perfil inicial. Extraída de Buck (1986). . . . . .

2.3 Seção crustal do modelo bidimensional de Steckler e Watts (1980). Os valores em cada bloco são os valores estimados de $\beta$. A linha espessa representa o afinamento crustal da margem no momento do estiramento. Extraída de Steckler e Watts (1980). . . . . . . . . . . . . . . . . .

2.4 Subsidência tectônica pela raiz quadrada do tempo. As linhas contínuas representam a subsidência teórica calculada pelo modelo de Mckenzie (1978). As linhas tracejadas representam a subsidência calculada pelo modelo bidimensional de Steckler \& Watts. A linha dupla representa a subsidência observada por dados de poço. Extraída de Steckler \& Watts (1980). . . . . 
2.5 Geometria da temperatura inicial do rifte. $W_{r}$ representa a comprimento de metade do rifte e $W_{t}$ o comprimento da região de transição entre a região não-estirada e a região de estiramento máximo $\left(\beta_{\max }\right)$. Extraída de Buck

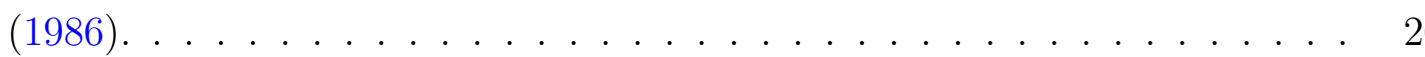

2.6 Curvas de temperatura e soerguimento sub-aéreo. Curvas de temperatura estão espaçadas de $200^{\circ} \mathrm{C}$.Extraída de Allen e Allen (2005). . . . . . . . . .

2.7 Comparação entre a elevação sub-aérea para um caso condutivo e um caso com a presença de processos convectivos para as mesmas condições iniciais. Extraída de Buck (1986). . . . . . . . . . . . . . . . . . .

2.8 a) Perfil de temperatura para a litosfera não-estirada e estirada (linha tracejada). b) Mapa do fator de estiramento $(\beta)$ variando de 1 a 3 . Extraída de Sacek e Ussami (2013). . . . . . . . . . . . . . . . . . . . . . . . 28

2.9 Movimento vertical de $\mathrm{A}$ (azul) e $\mathrm{C}$ (vermelho) relativo a $\mathrm{B}$ (verde) e o perfil de viscosidade inicial para cada modelo. $E$ e $V$ são respectivamente a energia e o volume de ativação e $\eta_{0}$ a viscosidade de referência. Extraída de Sacek \& Ussami (2013). . . . . . . . . . . . . . . . . . . . . . .

2.10 Comparação da sedimentação da Bacia de Santos entre os dados preditos, obtidos a partir do modelo 3D desenvolvido (linhas contínuas) e observados em poços (pontos). Extraída de Sacek e Ussami (2013). . . . . . . . . . . . 30

3.1 Diagrama do fluxo de calor em uma caixa retangular. Extraída de Turcotte e Schubert (2014). . . . . . . . . . . . . . . . . .

6.1 Célula de Convecção bidimensional num fluido aquecido por baixo. Extraída de Turcotte e Schubert (2014) . . . . . . . . . . . . . . . . .

6.2 Curva de $R a_{c r}$ em relação a $2 \pi b / \lambda$. Os pontos acima da curva vermelha estão no regime instável(advecção) e os abaixo da curva no regime estável

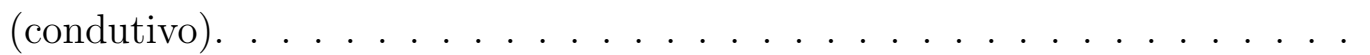

6.3 Curvas do módulo da velocidade máxima por iteração. O Ra de cada um dos modelos esta indicado na sua respectiva curva. . . . . . . . . . . .

6.4 Modelo com $R a=0.6 \times 10^{3}$ na iteração 2000. As isotermas paralelas indicam que estão ocorrendo apenas processos condutivos. . . . . . . . . . . . . 
6.5 Modelo com $R a=2.0 \times 10^{3}$ na iteração 2000. As isotermas mais profundas no meio e mais rasas nas bordas indicam a ocorrência de advecção. . . . . .

6.6 Curva de $R a_{c r}$ em relação a $2 \pi b / \lambda$. Os pontos acima da curva vermelha estão no regime instável(advecção) e os abaixo da curva no regime estável

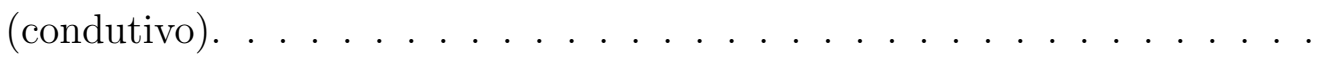

6.7 Curva de $R a_{c r}$ em relação a $2 \pi b / \lambda$. Os pontos acima da curva vermelha estão no regime instável(advecção) e os abaixo da curva no regime estável (condutivo). A seta indica para qual modelo o ponto mais a direita esta representando. . . . . . . . . . . . . . . . . . . . 54

6.8 Modelo com $R a=2.0 \times 10^{3}$ e $\lambda / 2$ em diversos instantes da simulação. . . .

7.1 Configuração do perfil de temperatura inicial utilizado para os modelos. A base se encontra a uma temperatura de $1800^{\circ} \mathrm{C}$. Foi utilizado um gride de 38025 nós. . . . . . . . . . . . . . . . . . . . . . .

7.2 Seção 2D da configuração do perfil de temperatura inicial utilizado para os modelos. A base se encontra a uma temperatura de $1800^{\circ} \mathrm{C}$. . . . . . . . . 60

7.3 Comparação entre dois perfis de viscosidade para valores de $\eta_{0}$ diferentes. . 61

7.4 Comparação entre dois perfis de viscosidade para valores diferentes de $V^{\prime}$. . 61

7.5 (a) Perfil de Viscosidade e (b) Curva de evolução temporal para o modelo com $\eta_{0}=5 \times 10^{20} \mathrm{~Pa} \cdot \mathrm{s}, E^{\prime}=30$ e $V^{\prime}=0$.

7.6 (a) Perfil de Viscosidade e (b) Curva de evolução temporal para o modelo com $\eta_{0}=3 \times 10^{20} \mathrm{~Pa} \cdot \mathrm{s}, E^{\prime}=20$ e $V^{\prime}=5 \ldots \ldots \ldots$

7.7 (a) Perfil de Viscosidade e (b) Curva de evolução temporal para o modelo $\operatorname{com} \eta_{0}=1 \times 10^{20} \mathrm{~Pa} \cdot \mathrm{s}, E^{\prime}=20$ e $V^{\prime}=5$.

7.8 Profundidade da isoterma de $1300^{\circ} \mathrm{C}$ para todos os modelos que obtiveram uma litosfera estável durante o tempo de simulação. . . . . . . . . . . . . .

8.1 Representação esquemática da isoterma da litosfera não estirada e a litosfera

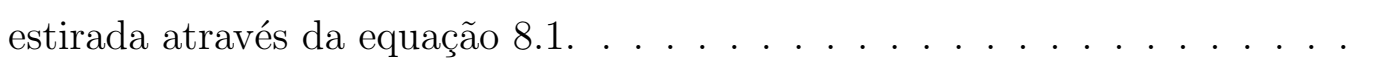

8.2 Perfil do fator de estiramento $\beta$. Estão representadas as posições das três estações utilizados por Steckler e Watts (1980). . . . . . . . . . . . . . 
8.3 Comparação das curvas de subsidência entre os modelos de Mckenzie (1978), Steckler e Watts (1980) e os apresentados neste trabalho para o modelo com

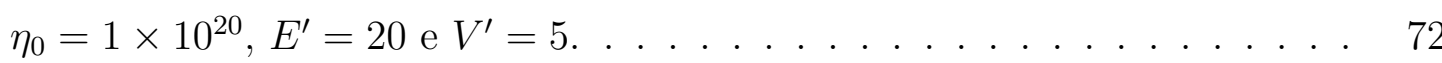

8.4 Estrutura térmica e campo de velocidades para o modelo com $\eta_{0}=1 \times 10^{20}$,

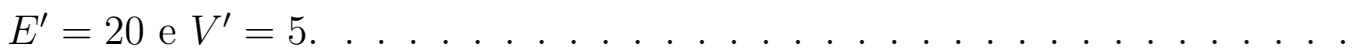

8.5 Comparação das curvas de subsidência entre os modelos de Mckenzie (1978), Steckler e Watts (1980) e os apresentados neste trabalho para o modelo com $\eta_{0}=4 \times 10^{20}, E^{\prime}=20$ e $V^{\prime}=7.5 \ldots \ldots \ldots \ldots \ldots \ldots$

8.6 Estrutura térmica e campo de velocidades para o modelo com $\eta_{0}=4 \times 10^{20}$,

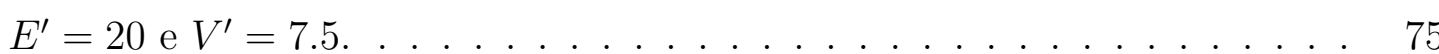

8.7 Comparação das curvas de subsidência entre os modelos de Mckenzie (1978), Steckler e Watts (1980) e os apresentados neste trabalho para o modelo com $\eta_{0}=5 \times 10^{20}, E^{\prime}=20$ e $V^{\prime}=7.5 \ldots \ldots \ldots \ldots \ldots \ldots$

8.8 Estrutura térmica e campo de velocidades para o modelo com $\eta_{0}=5 \times 10^{20}$, $E^{\prime}=20$ e $V^{\prime}=7.5 \ldots \ldots \ldots \ldots \ldots \ldots \ldots$

8.9 Comparação das curvas de subsidência entre os modelos de Mckenzie (1978), Steckler e Watts (1980) e os apresentados neste trabalho para o modelo com $\eta_{0}=3 \times 10^{20}, E^{\prime}=30$ e $V^{\prime}=5 \ldots \ldots \ldots \ldots$

8.10 Estrutura térmica e campo de velocidades para o modelo com $\eta_{0}=3 \times 10^{20}$, $E^{\prime}=30$ e $V^{\prime}=5$

8.11 Geologia de um perfil através do Golfo de Leão. Modificada de Steckler e Watts (1980).

A.1 Curvas de subsidência para o modelo com $\eta_{0}=4 \times 10^{20}, E^{\prime}=30$ e $V^{\prime}=7.5 . \quad 94$

A.2 Estrutura térmica e campo de velocidades para o modelo com $\eta_{0}=4 \times 10^{20}$, $E^{\prime}=30$ e $V^{\prime}=7.5$. Os vetores de velocidade foram reescalonados a cada intervalo de tempo e apenas fornecem uma representação qualitativa da tendência do movimento. . . . . . . . . . . . . . . . . . 95

A.3 Curvas de subsidência para o modelo com $\eta_{0}=3 \times 10^{20}, E^{\prime}=30$ e $V^{\prime}=7.5 . \quad 96$ 
A.4 Estrutura térmica e campo de velocidades para o modelo com $\eta_{0}=3 \times 10^{20}$, $E^{\prime}=30$ e $V^{\prime}=7.5$. Os vetores de velocidade foram reescalonados a cada intervalo de tempo e apenas fornecem uma representação qualitativa da tendência do movimento. . . . . . . . . . . . . . . . . . . . 97

A.5 Curvas de subsidência para o modelo com $\eta_{0}=1 \times 10^{20}, E^{\prime}=30$ e $V^{\prime}=0$.

A.6 Estrutura térmica e campo de velocidades para o modelo com $\eta_{0}=1 \times 10^{20}$, $E^{\prime}=30$ e $V^{\prime}=0$. Os vetores de velocidade foram reescalonados a cada intervalo de tempo e apenas fornecem uma representação qualitativa da tendência do movimento. . . . . . . . . . . . . . . . . . .

A.7 Curvas de subsidência para o modelo com $\eta_{0}=1 \times 10^{20}, E^{\prime}=30$ e $V^{\prime}=5$.

A.8 Estrutura térmica e campo de velocidades para o modelo com $\eta_{0}=1 \times 10^{20}$, $E^{\prime}=30$ e $V^{\prime}=5$. Os vetores de velocidade foram reescalonados a cada intervalo de tempo e apenas fornecem uma representação qualitativa da tendência do movimento. . . . . . . . . . . . . . . . . . . . . 101

A.9 Curvas de subsidência para o modelo com $\eta_{0}=5 \times 10^{20}, E^{\prime}=20$ e $V^{\prime}=5 . \quad 102$

A.10 Estrutura térmica e campo de velocidades para o modelo com $\eta_{0}=5 \times 10^{20}$, $E^{\prime}=20$ e $V^{\prime}=5$. Os vetores de velocidade foram reescalonados a cada intervalo de tempo e apenas fornecem uma representação qualitativa da tendência do movimento. . . . . . . . . . . . . . . . . . . . 103

A.11 Curvas de subsidência para o modelo com $\eta_{0}=4 \times 10^{20}, E^{\prime}=20$ e $V^{\prime}=5 . \quad 104$

A.12 Estrutura térmica e campo de velocidades para o modelo com $\eta_{0}=4 \times 10^{20}$, $E^{\prime}=20$ e $V^{\prime}=5$. Os vetores de velocidade foram reescalonados a cada intervalo de tempo e apenas fornecem uma representação qualitativa da tendência do movimento. . . . . . . . . . . . . . . 105

A.13 Curvas de subsidência para o modelo com $\eta_{0}=3 \times 10^{20}, E^{\prime}=20$ e $V^{\prime}=5 . \quad 106$

A.14 Estrutura térmica e campo de velocidades para o modelo com $\eta_{0}=3 \times 10^{20}$, $E^{\prime}=20$ e $V^{\prime}=5$. Os vetores de velocidade foram reescalonados a cada intervalo de tempo e apenas fornecem uma representação qualitativa da tendência do movimento. . . . . . . . . . . . . . . . . . . 107

A.15 Curvas de subsidência para o modelo com $\eta_{0}=1 \times 10^{20}, E^{\prime}=20$ e $V^{\prime}=0 . \quad 108$ 
A.16 Estrutura térmica e campo de velocidades para o modelo com $\eta_{0}=1 \times 10^{20}$, $E^{\prime}=20$ e $V^{\prime}=0$. Os vetores de velocidade foram reescalonados a cada intervalo de tempo e apenas fornecem uma representação qualitativa da tendência do movimento. . . . . . . . . . . . . . . . . . . . . . 109 


\section{Lista de Tabelas}

7.1 Valores utilizados para os modelos numéricos. Foram realizados modelos com todas as combinações possíveis entre esses três parâmetros. Os valores de $E^{\prime}$ e $V^{\prime}$ apresentados são adimensionais. . . . . . . . . . . . . . . . . . 60

7.2 Profundidade da Isoterma de $1300^{\circ} \mathrm{C}$ para os modelos estáveis com $E^{\prime}=20$. Os modelos que não obtiveram uma litosfera estável durante a simulação foram representados com um traço. . . . . . . . . . . . . . . . . . . . 64

7.3 Profundidade da Isoterma de $1300^{\circ} \mathrm{C}$ para os modelos estáveis com $E^{\prime}=30$. Os modelos que não obtiveram uma litosfera estável durante a simulação foram representados com um traço. . . . . . . . . . . . . . . .

8.1 Valores dos parâmetros utilizados para o cálculo da subsidência. Estes valores foram baseados em valores apresentados por Schubert et al. (2001). 


\section{Sumário}

1. Introdução . . . . . . . . . . . . . . . . . . . . . . . . . . . . 19

2. Subsidência de Bacias Sedimentares . . . . . . . . . . . . . . . . . . . . . . . 21

2.1 Modelo de Sleep (1971) . . . . . . . . . . . . . . . . . . . . 21

2.2 Modelo de Mckenzie (1978) f . . . . . . . . . . . . . . . . . 22

2.3 Modelo de Steckler \& Watts (1980) . . . . . . . . . . . . . . . . . 24

2.4 Modelo de Buck (1986) . . . . . . . . . . . . . . . . . . . . . 25

2.5 Modelos numéricos 3D da Dinâmica Mantélica em Margens Divergentes . . 26

2.6 CitcomCU . . . . . . . . . . . . . . . . . . . 29

3. Transferência de Calor . . . . . . . . . . . . . . . . . . . . . . . . . 31

3.1 Tipos de Transferência de Calor . . . . . . . . . . . . . . . 31

3.2 Lei de Fourier . . . . . . . . . . . . . . . . . . . . . . . . . . . 32

3.3 Condução de Calor no Estado Estacionário . . . . . . . . . . . . . . . . . . 32

3.4 Condução de Calor Dependente do Tempo . . . . . . . . . . . . . . . . . . . 34

4. Dinâmica de Fluidos . . . . . . . . . . . . . . . . . . . . . . . . . . . . . . . . . 37

4.1 Equação de Continuidade . . . . . . . . . . . . . . . . . . . . . 37

4.2 Equação de Euler . . . . . . . . . . . . . . . . . . . . . . . . . . . . . . . . . . . 38

4.3 Equação de movimento de um fluido viscoso . . . . . . . . . . . . . . . . . 39

4.4 Equação de Energia . . . . . . . . . . . . . . . . . . . . . . 40

4.5 Aproximação de um Líquido Anelástico Truncado . . . . . . . . . . . . . . 41

4.6 Adimensionalização . . . . . . . . . . . . . . . . . . . . . . . . . . . . . . . 42 
5. Reologia das Rochas . . . . . . . . . . . . . . . . . . . . . . . 45

5.1 Introdução . . . . . . . . . . . . . . . . . . . . . 45

5.2 Dependência da Viscosidade com a Temperatura . . . . . . . . . . . . . 46

5.3 Dependência da Viscosidade com a Profundidade . . . . . . . . . . . . . 47

6. Problema com Solução Analítica . . . . . . . . . . . . . . . . . . . . . . . 49

7. Estabilidade da Litosfera Continental . . . . . . . . . . . . . . . . . . . . . . . 57

7.1 Adimensionalização da Equação de Arrhenius . . . . . . . . . . . . . . 57

7.2 Análise de Estabilidade da Litosfera . . . . . . . . . . . . . . . . . . . . 58

8. Efeito dos Processos Convectivos da Astenosfera na Subsidência de Bacias de Margens Divergentes . . . . . . . . . . . . . . . . . . . . 67

8.1 Estiramento da Litosfera . . . . . . . . . . . . . . . . . . . . . . 67

8.2 Cálculo da Subsidência . . . . . . . . . . . . . . . . . . . . . . . . . . 69

8.3 Comparação da Taxa de Subsidência com os Modelos Puramente Condutivos 70

8.4 Discussão . . . . . . . . . . . . . . . . . . . . . . . . . . 81

9. Conclusão . . . . . . . . . . . . . . . . . . . . . . . 85

Apêndice

A. Subsidência e Estrutura Térmica dos Modelos com Litosfera Inicial Entre 120 - 270

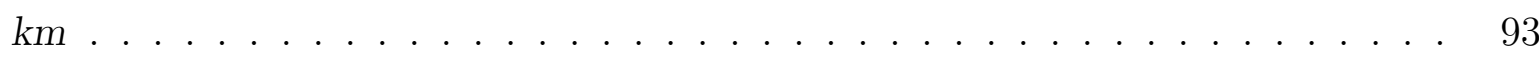


Capítulo 1

\section{Introdução}

A evolução de margens divergentes está diretamente relacionada com a dinâmica interna do planeta. Após o processo de rifteamento, a litosfera afinada resfria-se ao longo do tempo geológico através da condução térmica de calor para a superfície durante a formação da margem continental. Esse resfriamento induz uma progressiva subsidência da margem continental devido a contração térmica da litosfera. Adicionalmente, processos convectivos no manto astenosférico afetam o estado térmico da litosfera, e consequentemente, a subsidência de margens continentais.

A complexa interação entre a condução térmica e o transporte de calor por convecção mantélica dificilmente pode ser tratada através de solução analítica de equações diferenciais. Desse modo, o uso de modelos numéricos torna-se fundamental para a quantificação desses processos. Mas, apesar de ser evidente a presença de convecção no manto astenosférico, um elemento fundamental para a existência de tectônica de placas no nosso planeta, poucos modelos numéricos geodinâmicos exploram a convecção em suas formulações no estudo de evolução de margens divergentes.

Dada a escassez de modelos numéricos, o presente trabalho tem como objetivo estudar a dinâmica mantélica em margens continentais através do uso de modelos numéricos que incorporam não apenas a condução térmica, mas a convecção astenosférica e sua influência na base da litosfera. Esse estudo poderá contribuir para o entendimento dos fatores que influenciam a história de subsidência da margem continental.

O Capítulo 2 apresenta uma revisão bibliográfica dos modelos já existentes para a formação de bacias sedimentares de margens divergentes. Desse modo, foi possível identificar a importância de se utilizar modelos mais complexos para se investigar a evolução de bacias sedimentares. 
No Capítulo 3, foram estudados alguns dos processos térmicos presentes no interior da Terra, principalmente sobre a condução térmica, de modo que se tenha uma melhor compreensão da estrutura térmica no interior da Terra.

Para se compreender os processos de convecção presentes no manto, realizou-se um estudo sobre a dinâmica de fluidos, identificando assim, as equações que regem seu movimento, descrito no Capítulo 4, seguido pelo Capítulo 5 sobre o estudo da reologia do manto terrestre.

No Capítulo 6 é apresentada a comparação de resultados numé-ricos para diferentes valores de número de Rayleigh $R a$ com soluções analíticas, verificando-se a validade das soluções computacionais. Esse estudo preliminar permitiu verificar como certos parâmetros físicos influenciam o regime convectivo no manto terrestre.

No Capítulo 7 é apresentado alguns modelos numéricos, com a finalidade de analisar a estabilidade da litosfera. Este estudo foi utilizado como base para os modelos no contexto de margens divergentes presentes no Capítulo 8, auxiliando na escolha de parâmetros como viscosidade, energia de ativação e volume de ativação, fornecendo um perfil de temperatura estabilizado para a litosfera continental.

No Capítulo 8 são discutidos os efeitos dos processos convectivos presentes no manto astenosférico sobre a evolução de margens divergentes, comparando com modelos puramente condutivos presentes na literatura. Observou-se que o efeito convectivo astenosférico preserva a estrutura térmica aquecida da margem estirada por mais tempo em comparação com o modelo puramente condutivo. Adicionalmente, constatou-se que a convecção mantélica pode induzir tensões na base da litosfera que a deslocam dinamicamente ao longo do tempo geológico, podendo influenciar a evolução estratigráfica das bacias sedimentares marginais. São apresentados cenários de como a variação reológica do manto influencia a evolução térmica da litosfera, e consequentemente, a história de subsidência de margens. 
Capítulo 2

\section{Subsidência de Bacias Sedimentares}

A compreensão e quantificação dos mecanismos que induzem o soerguimento ou a subsidência da superfície terrestre são fundamentais para o entendimento da formação e evolução de bacias sedimentares.

Pode-se diferenciar dois tipos de subsidência em bacias sedimentares ao longo de margens divergentes; subsidência tectônica e a subsidência total. A subsidência total é a soma da subsidência tectônica e a subsidência induzida pela carga do sedimentos derivados da erosão dos continentes, representando a variação vertical total sofrida pela superfície. Já a componente tectônica é a subsidência originada por mecanismos tectônicos e independe de carga sedimentar sobre a crosta terrestre (Stüwe, 2002), como por exemplo os processos térmicos na litosfera e variações na espessura crustal.

Nas últimas quatro décadas diversos modelos foram propostos para explicar a evolução de bacias sedimentares em margens divergentes. Neste capítulo serão apresentados alguns destes modelos.

\subsection{Modelo de Sleep (1971)}

Sleep (1971) foi o primeiro a propor um modelo quantitativo para a formação e evolução de bacias sedimentares de margens divergentes. Em seu modelo ele propôs que inicialmente ocorreria um soerguimento do continente devido a expansão térmica. Esta porção soerguida passa a sofrer erosão, resultando em um afinamento crustal. Por fim, quando o soerguimento termina o continente volta a sua estrutura térmica original através da perda de calor para a superfície, e dessa forma ocorreria a formação de uma bacia sedimentar rasa. A Figura 2.1 possui uma representação esquemática do modelo de Sleep. 


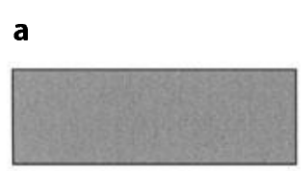

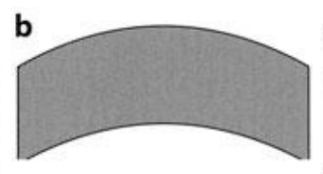

Uplift

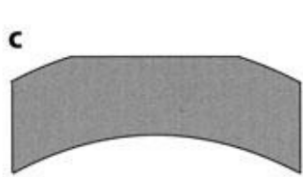

Erosion

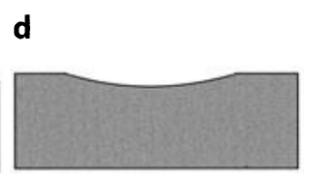

Subsidence

Figura 2.1: Representação esquemática do modelo de Sleep (1971). O continente é soerguido por processos externos. A porção soerguida é afinada pela erosão. Com o resfriamento término, há subsidência do continente soerguido, voltando a sua posição inicial e assim é formada uma bacia sedimentar. Figura extraída de Stüwe (2002).

O modelo de Sleep (1971) apresentou resultados quantitativos importantes, que forneceram boas aproximações para a taxa de subsidência de bacias sedimentares. Entretanto, nunca foram encontradas evidências de que tenham ocorrido erosões tão grandes capazes de explicar o afinamento crustal nessas bacias (Ziegler, 1975; Mckenzie, 1978).

\subsection{Modelo de Mckenzie (1978)}

A primeira explicação satisfatória para a existência da subsidência tectônica foi dada por Mckenzie (1978). Em seu modelo, McKenzie propôs que a subsidência tectônica ocorre inicialmente por um processo mecânico devido ao estiramento uniforme da litosfera, seguido de uma subsidência térmica prolongada devido a perda de calor para a superfície. Tal modelo assume que a perda de calor se dá apenas por condução térmica de calor e ocorre exclusivamente na direção vertical sendo portanto, um modelo 1D.

O manto astenosférico sob a litosfera, que tem um comportamento fluido no tempo geológico, resfria-se em contato com a base da litosfera podendo ser agregado a sua base, tornando-se mais rígida e resultando no espessamento da litosfera.

A Figura 2.2 apresenta uma representação do modelo de McKenzie. Inicialmente temse uma seção inicial da litosfera com espessura uniforme $(L)$, e com o perfil de temperatura linear com a profundidade. A litosfera é estirada por um fator de estiramento litosférico $\beta$, e desse modo a nova espessura da litosfera afinada é dada por $L / \beta$. A região abaixo da litosfera afinada é então preenchida pelo material mais quente presente na astenosfera. Através da condução de calor ocorre o resfriamento térmico, devido a perda de calor da litosfera para a superfície. Este resfriamento faz com que ocorra a subsidência térmica fazendo com que o perfil de temperatura volte ao seu estado inicial. 


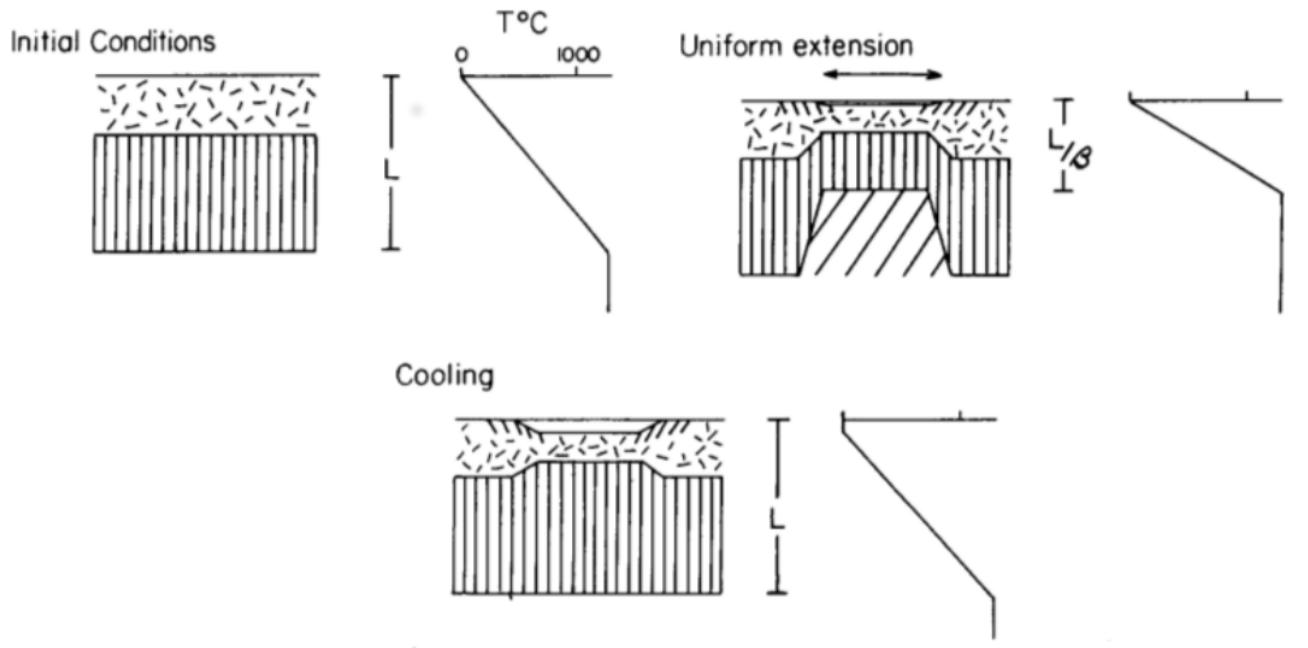

Figura 2.2: Representação do modelo de Mckenzie (1978). A seção inicial da litosfera possui uma espessura uniforme (L), e o perfil de temperatura é linear com a profundidade. A litosfera é instantaneamente estirada por um fator $\beta$ e então afinada por um fator $1 / \beta$. A área abaixo da litosfera afinada é preenchida pelo manto astenosférico, com temperatura igual a da base da litosfera. O resfriamento provoca uma subsidência térmica e o perfil de temperatura volta a o seu perfil inicial. Extraída de Buck (1986).

Através deste modelo foi possível prever a taxa de subsidência de bacias sedimentares, assim como o fluxo térmico do embasamento para a bacia sedimentar ao longo do tempo, informação fundamental para a avaliação do potencial petrolífero de uma bacia, o que consagrou o modelo na indústria de petróleo.

Entretanto o modelo de Mckenzie (1978) é um modelo bastante simplificado para explicar toda a complexidade da evolução de uma bacia marginal, visto que ele assume um estiramento uniforme para a crosta e o manto litosférico, e que o rifte ocorre instantaneamente.

Assim, outros modelos foram de grande contribuição para o estudo da subsidência de bacias sedimentares em margens divergentes. Royden e Keen (1980) construíram um modelo de duas camadas para estudar a influência de se considerar um estiramento nãouniforme, ou seja, o fator de estiramento do manto litosférico difere do fator de estiramento crustal. Royden e Keen (1980) aplicaram seu modelo na margem continental do leste do Canadá, onde os parâmetros de estiramento indicavam que o manto litosférico havia sido consideravelmente mais estirado do que a crosta e, desse modo, eles foram capazes de avaliar a evolução térmica da região.

Jarvis e Mckenzie (1980) incorporaram um modelo em que o estiramento ocorre numa 


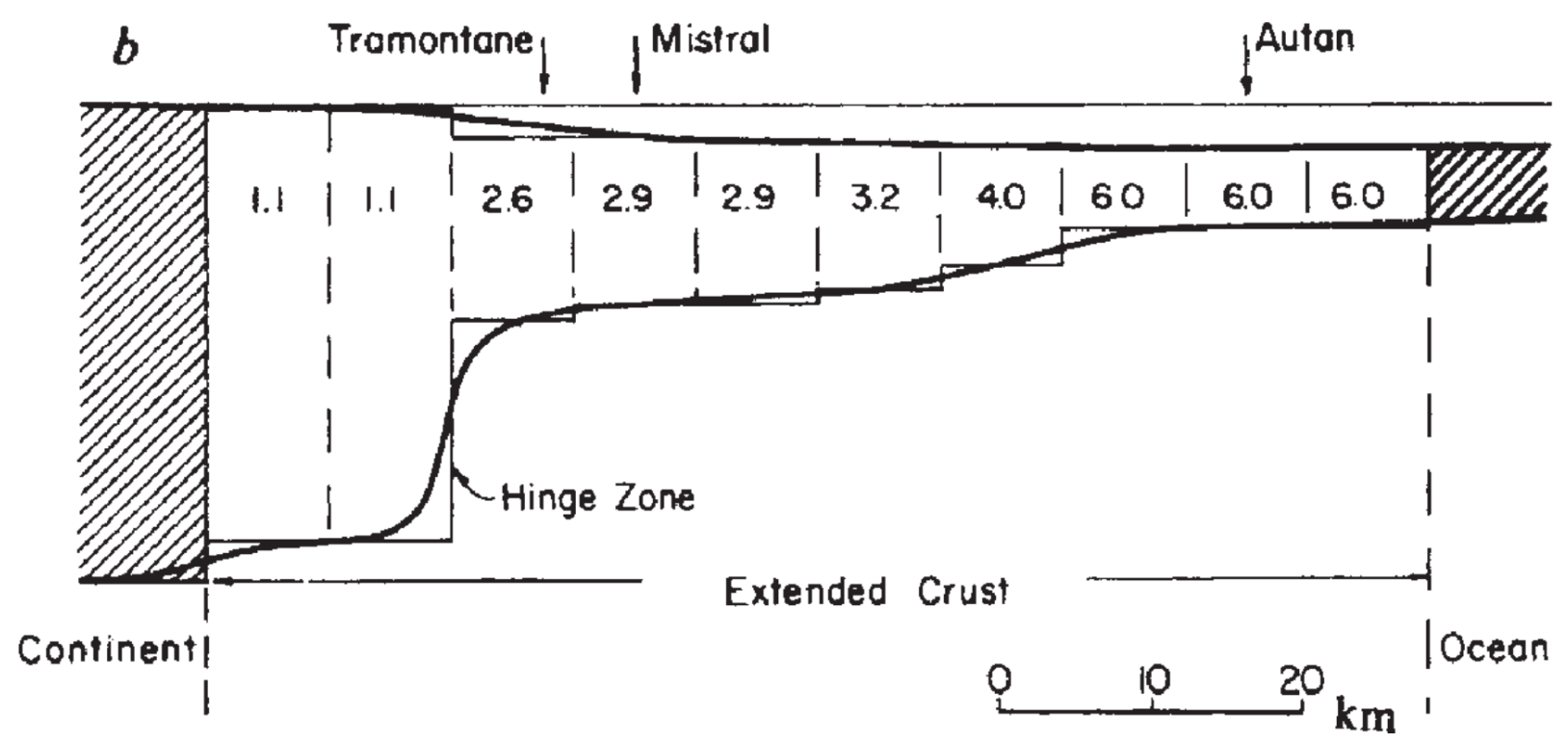

Figura 2.3: Seção crustal do modelo bidimensional de Steckler e Watts (1980). Os valores em cada bloco são os valores estimados de $\beta$. A linha espessa representa o afinamento crustal da margem no momento do estiramento. Extraída de Steckler e Watts (1980).

taxa finita, ou seja, o rifteamento não é instantâneo como no modelo de Mckenzie (1978), mostrando que os dois modelos resultam em cenários geológicos muito próximos quando a fase de estiramento litosférico é inferior a $\sim 20$ milhões de anos.

\subsection{Modelo de Steckler \& Watts (1980)}

Steckler e Watts (1980) apresentaram um modelo numérico bidimensional para o estudo da condução térmica no interior da litosfera, mostrando que a variação lateral da espessura da litosfera pode induzir mudanças expressivas na evolução térmica da litosfera e, consequentemente, na taxa de subsidência de bacias sedimentares.

A Figura 2.3 apresenta uma seção crustal do modelo bidimensional utilizado por Steckler e Watts (1980). Os valores apresentados em cada bloco são os valores estimados de $\beta$. A linha mais espessa representa o afinamento crustal da margem no momento do estiramento litosférico.

A Figura 2.4 apresenta uma comparação entre o modelo de Mckenzie (1978) e os resultados obtidos pelo modelo bidimensional proposto por Steckler e Watts (1980). É possível observar que o modelo de McKenzie (linha contínua), necessita de valores de $\beta$ muito elevados para explicar a subsidência observada. No caso do poço de Tramontane (Figura 2.3) isto fica ainda mais claro: segundo o modelo de Mckenzie, seria necessário um valor de 

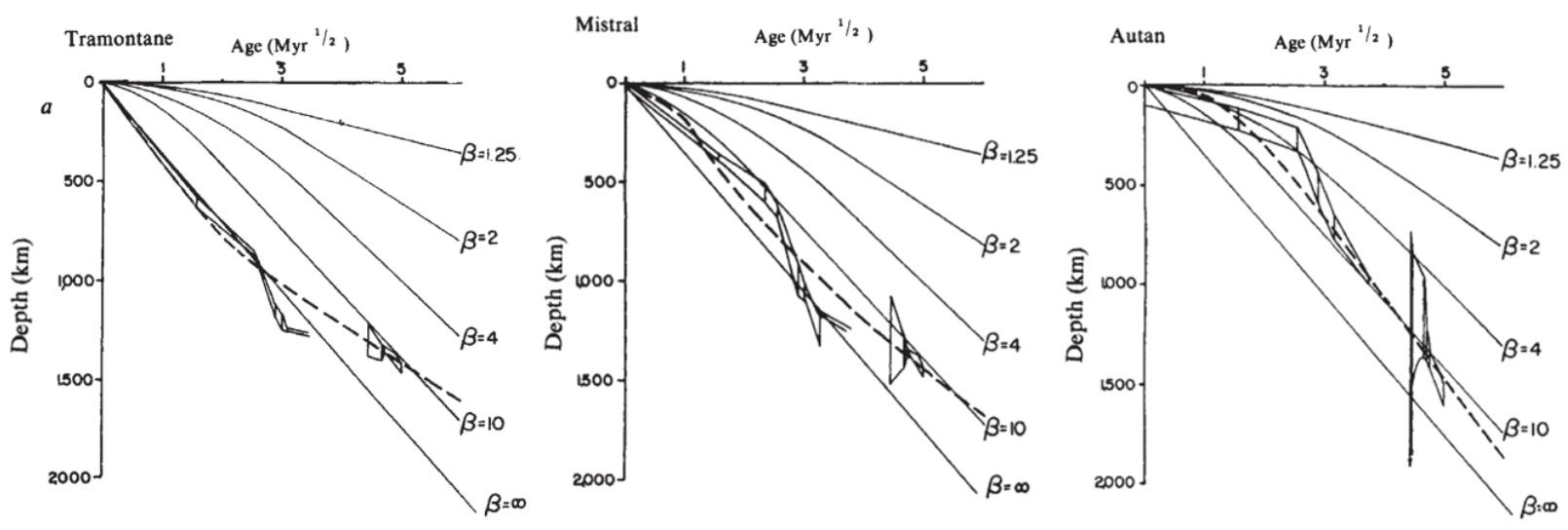

Figura 2.4: Subsidência tectônica pela raiz quadrada do tempo. As linhas contínuas representam a subsidência teórica calculada pelo modelo de Mckenzie (1978). As linhas tracejadas representam a subsidência calculada pelo modelo bidimensional de Steckler \& Watts. A linha dupla representa a subsidência observada por dados de poço. Extraída de Steckler \& Watts (1980).

$\beta=\infty$, o que equivaleria a ausência de crosta continental. No modelo de Steckler e Watts (1980), a perda de calor por condução lateral induz um aumento na taxa de subsidência da bacia sedimentar que não poderia ser explicado adequadamente pelo modelo de Mckenzie (1978).

Desse modo Steckler \& Watts mostraram que o modelo 1D proposto por McKenzie apresenta limitações, sendo necessário, em alguns casos, considerar a variação lateral da espessura, bem como a perda de calor por condução pelas laterais do modelo.

\subsection{Modelo de Buck (1986)}

Outro processo que controla a subsidência de margens divergentes é a convecção do manto astenosférico abaixo da litosfera, cujo vigor é dependente da viscosidade do manto. Variações laterais na espessura da litosfera ao longo das margens continentais podem induzir células de convecção de pequena escala na astenosfera (King e Anderson, 1998), resultando no aumento do fluxo térmico para a base da litosfera afinada (Lucazeau et al., 2008).

Buck (1986) mostrou que convecções de pequena escala no manto induzidas pelo gradiente de temperatura lateral podem contribuir para o soerguimento das bordas do rifte. Em seu modelo Buck utilizou um perfil de temperatura inicial do rifte seguindo a geometria apresentada na Figura 2.5. Nesta figura $W_{r}$ representa a comprimento de metade do 


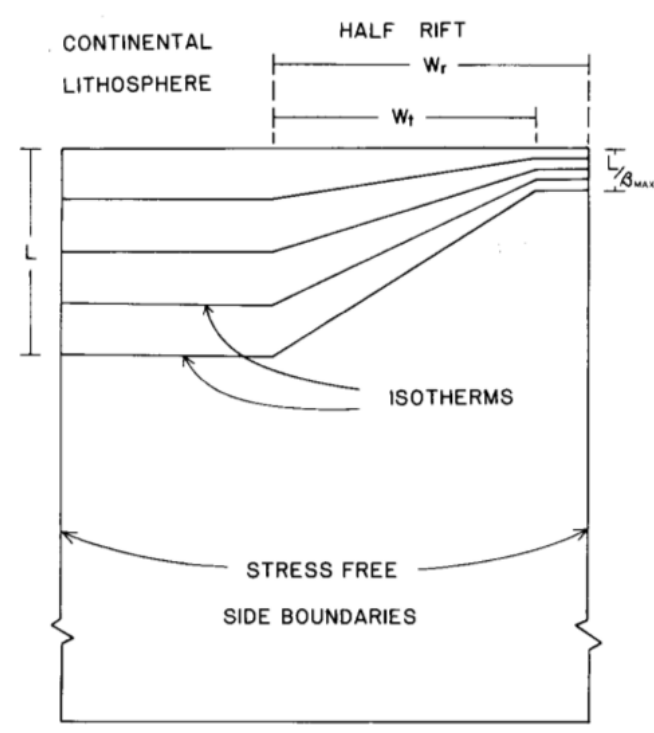

Figura 2.5: Geometria da temperatura inicial do rifte. $W_{r}$ representa a comprimento de metade do rifte e $W_{t}$ o comprimento da região de transição entre a região não-estirada e a região de estiramento máximo $\left(\beta_{\max }\right)$. Extraída de Buck (1986).

rifte e $W_{t}$ o comprimento da região de transição entre a região não-estirada e a região de estiramento máximo $\left(\beta_{\max }\right)$.

Na Figura 2.6 tem-se as curvas de temperatura, e o soerguimento sub-aéreo obtidos em um dos modelos estudados por Buck. É possível observar que devido aos processos de convecção presentes no modelo, as bordas da litosfera em torno do rifte estão sendo aquecidas, e este aquecimento causa o soerguimento nas bordas dos riftes.

Buck verificou que as convecções de pequena escala tem um papel importante na história da subsidência de bacias sedimentares, e que essas convecções podem ser responsáveis pelo soerguimento das bordas dos riftes. Na Figura 2.7 isto fica ainda mais claro. Nesta figura tem-se uma comparação entre a elevação sub-aérea obtida por um modelo puramente condutivo e outro modelo com convecções de pequena escala. Os dois modelos partiram das mesmas condições de temperaturas iniciais, e o modelo puramente condutivo só foi capaz de gerar um soerguimento de cerca de $40 \%$ do que o modelo que considera os processos de convecção. 

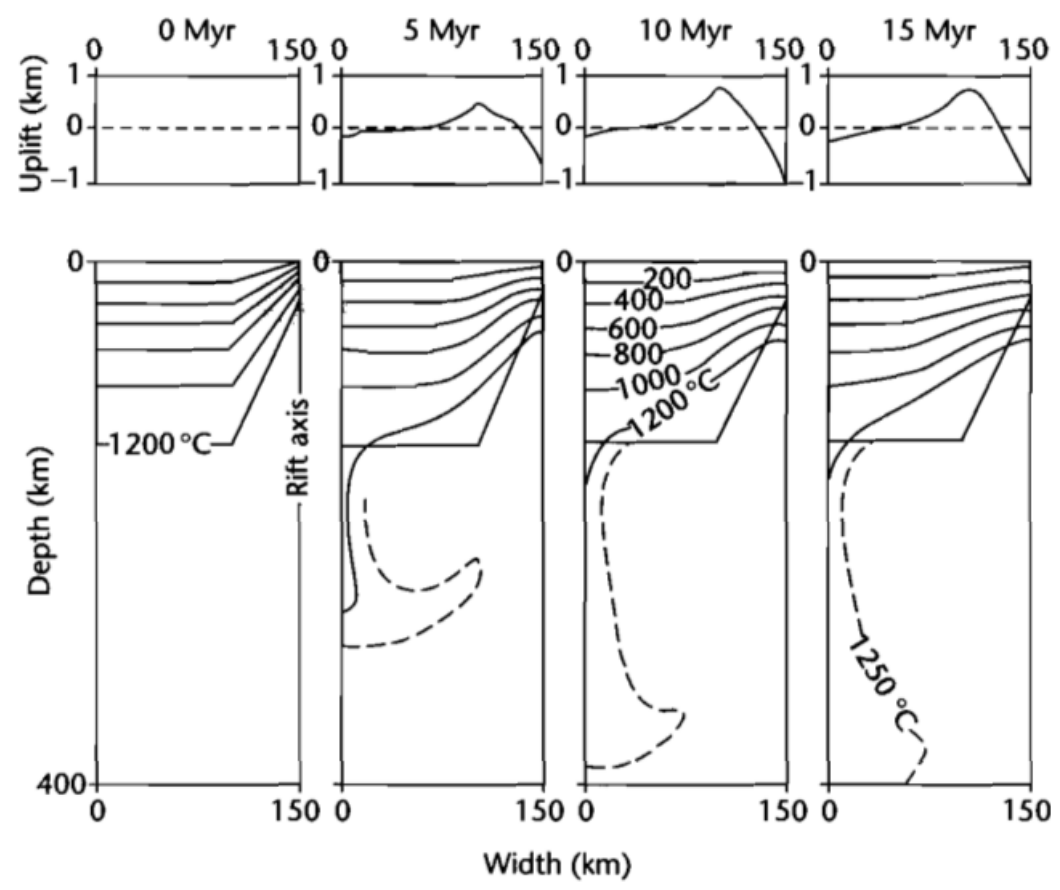

Figura 2.6: Curvas de temperatura e soerguimento sub-aéreo. Curvas de temperatura estão espaçadas de $200^{\circ} \mathrm{C}$.Extraída de Allen e Allen (2005).

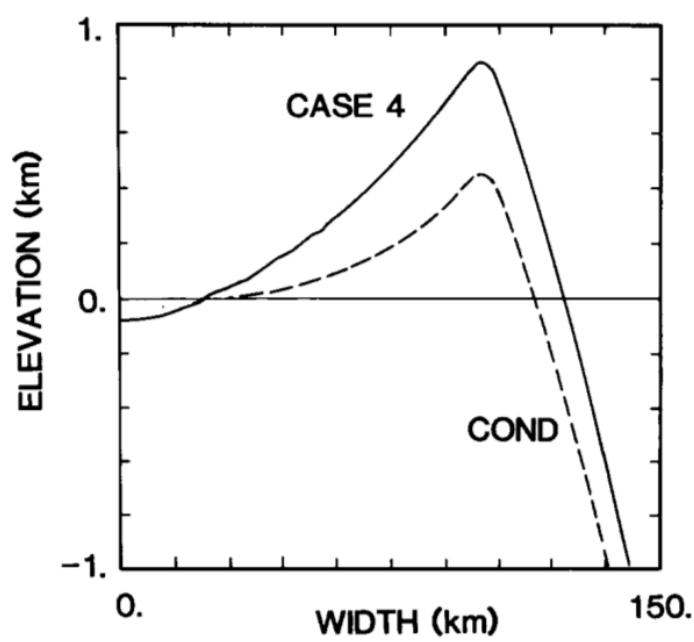

Figura 2.7: Comparação entre a elevação sub-aérea para um caso condutivo e um caso com a presença de processos convectivos para as mesmas condições iniciais. Extraída de Buck (1986). 

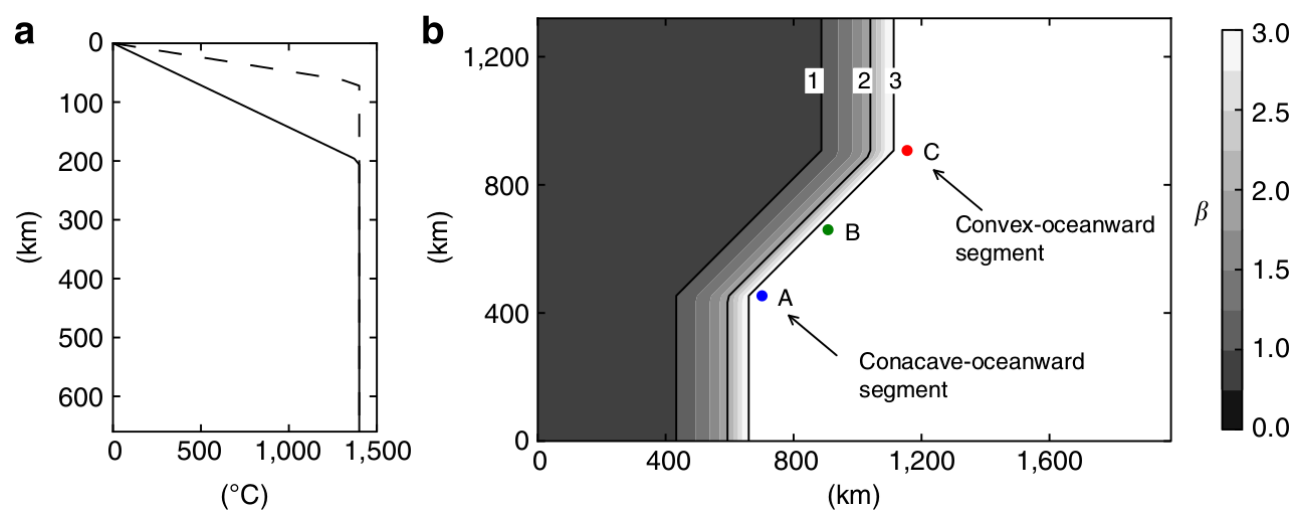

Figura 2.8: a) Perfil de temperatura para a litosfera não-estirada e estirada (linha tracejada). b) Mapa do fator de estiramento $(\beta)$ variando de 1 a 3 . Extraída de Sacek e Ussami (2013).

\subsection{Modelos numéricos 3D da Dinâmica Mantélica em Margens Divergentes}

Trabalhos mais recentes mostraram como a geometria 3D da margem pode influenciar a história de subsidência das bacias marginais (Farrington et al., 2010; Braun et al., 2013; Sacek e Ussami, 2013). Sacek e Ussami (2013) mostraram como a curvatura da margem poderia induzir subsidência diferencial da mesma, devido ao efeito combinado da condução térmica 3D e processos convectivos no manto.

A Figura 2.8a apresenta o perfil de temperatura para a litosfera não-estirada (linha contínua) e para a litosfera estirada (linha tracejada), utilizados por Sacek \& Ussami. Este perfil de temperatura assume uma variação linear da temperatura com a profundidade até a base da litosfera, e assume um valor constante para a astenosfera. Na Figura $2.8 \mathrm{~b}$ tem-se um mapa do fator de estiramento $\beta$ variando entre 1 e 3 . Os pontos $\mathrm{A}, \mathrm{B}$ e $\mathrm{C}$ representam os pontos onde foi estudada a história de subsidência da margem.

Ainda observando a Figura 2.8b é possível verificar a geometria da margem curva assumida para este modelo. O ponto A se encontra em uma região côncava da margem enquanto o ponto $\mathrm{C}$ se encontra numa região convexa. O ponto B foi colocado entre os pontos A e C para ser usado como referência na análise da subsidência diferencial na margem.

A Figura 2.9 apresenta o movimento vertical relativo entre os pontos A e C em relação a B no tempo. São apresentados cinco modelos (a-e) indo do mais viscoso (a) para o menos viscoso (e). Com isso foi possível observar que uma margem côncava sofre uma maior 

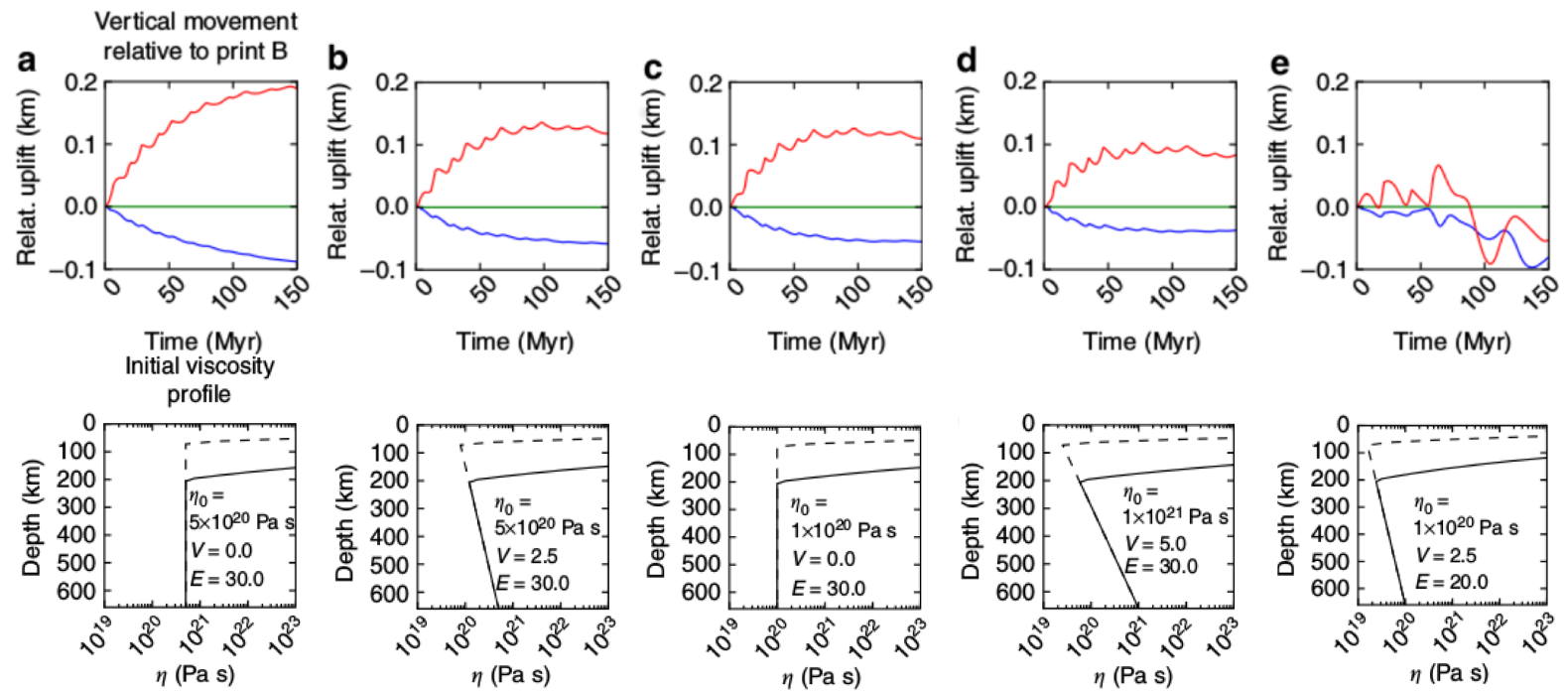

Figura 2.9: Movimento vertical de A (azul) e C (vermelho) relativo a B (verde) e o perfil de viscosidade inicial para cada modelo. $E$ e $V$ são respectivamente a energia e o volume de ativação e $\eta_{0}$ a viscosidade de referência. Extraída de Sacek \& Ussami (2013).

subsidência pois o resfriamento pela condução lateral de calor é mais eficiente do que na região convexa. Isto é facilmente observado na Figura 2.9a, onde o modelo apresenta uma viscosidade mais alta e a condução térmica prevalece. Observou-se também que a convecção de pequena escala é maior na região côncava. Uma convecção mais vigorosa produz um aquecimento mais eficiente da margem, diminuindo assim a taxa de subsidência. É possível visualizar este efeito nas Figuras 2.9b-d, onde são apresentados modelos menos viscosos e, portanto, com uma maior contribuição dos movimentos de convecção. Já na Figura 2.9e é apresentado um modelo de baixa viscosidade. Neste caso, a convecção vigorosa supera a condução de calor e a subsidência não apresenta depedência da sua posição em relação a margem curva.

Sacek e Ussami (2013) utilizaram este conjunto de modelos para mostrar como a geometria da margem sudeste do Brasil influenciou a subsidência da Bacia de Santos. Eles utilizaram a viscosidade apresentada no modelo da Figura 2.9c, apenas assumindo que a transição entre $\beta=1$ e $\beta=3$ seja mais estreita.

A Figura 2.10 apresenta a comparação entre a sedimentação predita pelo modelo (linhas contínuas) e os dados de poços (pontos). Apesar de pequenas discrepâncias entre a espessura de sedimentos dos dados observados e da espessura calculada pelo modelo, Sacek e Ussami (2013) mostraram que variações regionais na sedimentação podem estar 


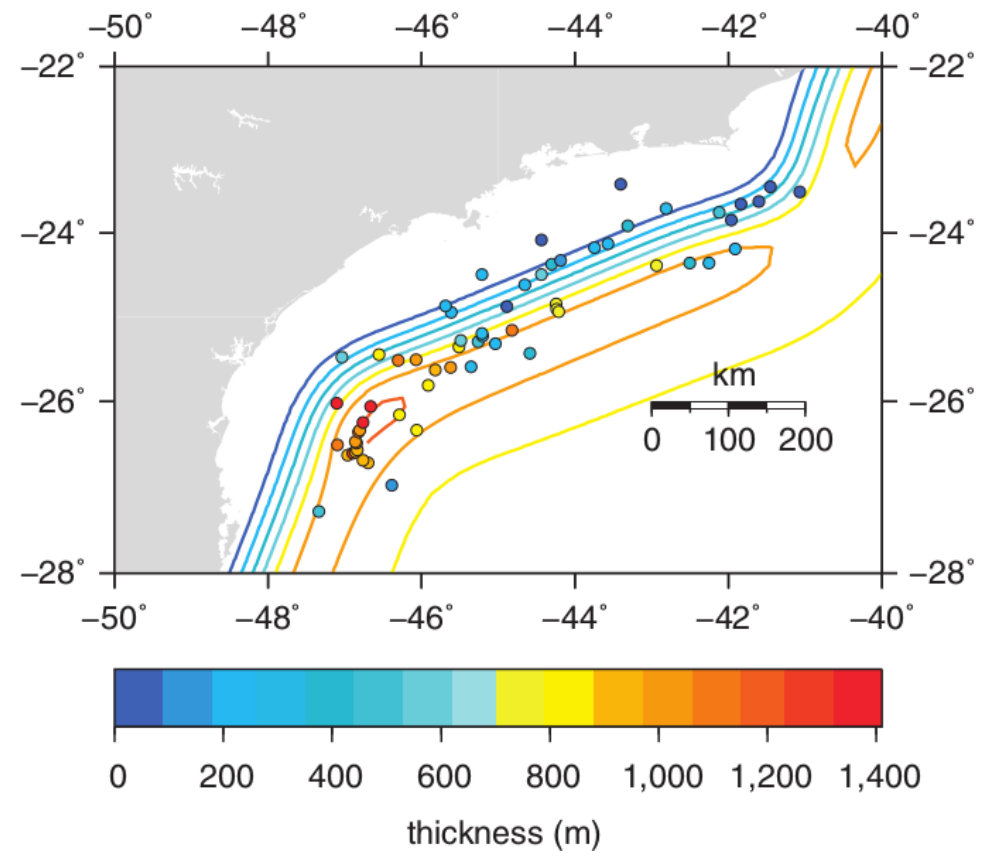

Figura 2.10: Comparação da sedimentação da Bacia de Santos entre os dados preditos, obtidos a partir do modelo 3D desenvolvido (linhas contínuas) e observados em poços (pontos). Extraída de Sacek e Ussami (2013).

associadas a geometria da margem combinada com a dinâmica do manto terrestre.

\subsection{CitcomCU}

Neste trabalho será utilizado o modelo numérico CitcomCU (California Institute of Technology Convection in the Mantle) desenvolvido por Moresi e Gurnis (1996) e Zhong (2006) utilizando o métodos dos elementos finitos para a resolução de equações diferenciais. Este código é distribuído gratuitamente pela CIG (Computational Infrastructure for Geodynamics).

Esse código numérico é capaz de gerar modelos termoquímicos de convecção no manto em 3D. Ele permite variar propriedades físicas do manto como viscosidade, condutividade térmica e condições iniciais de temperatura e condições de contorno para a temperatura e velocidade. 
Capítulo 3

\section{Transferência de Calor}

Sabe-se, através de estudos teóricos e práticos, que a reologia de sólidos é uma função dependente da temperatura (Turcotte e Schubert, 2014). A reologia das rochas mantélicas está diretamente relacionada com a temperatura em função da profundidade, que por sua vez é dependente da taxa na qual o interior da Terra perde calor pela superfície. Desse modo, para que seja possível compreender o comportamento mecânico da Terra é necessário entender a sua estrutura térmica. Neste capítulo, serão introduzidas as equações básicas da transferência de calor através da condução térmica.

\subsection{Tipos de Transferência de Calor}

Existem três mecanismos para a transferência de calor, são eles a condução, a convecção e a radiação. A transferência de calor por condução é um processo difusivo e ocorre através da transmissão passo a passo da energia cinética de uma molécula quando ela se choca com outras moléculas. Assim para que possa ocorrer a condução de calor é necessário a existência de um gradiente de temperatura. A condução de calor ocorre sem que se perceba movimento da matéria em escala macroscópica

Diferentemente da condução térmica, a convecção térmica é associada a movimentos no meio material. Ela ocorre quando um fluido mais quente entra em uma região de menor temperatura, e desse modo aquece esta região. Analogamente quando um fluido mais frio entra em uma região mais quente ele resfriará a região, produzindo deslocamento de massa.

Já a transferência de calor por radiação térmica é dada por meio de ondas eletromagnéticas emitidas por corpos aquecidos. Como exemplos deste tipo de transferência de calor temos o a radiação térmica do Sol e de lâmpadas incandescentes. 
No interior dos planetas rochosos, o livre caminho das ondas eletromagnéticas é muito pequeno, sendo absorvido pela rocha e retransmitido essencialmente por condução térmica. Assim, o transporte de calor no interior do planeta pode ser representado essencialmente pela condução e convecção térmica, sendo razoável desprezar-se a radiação térmica para o estudo da dinâmica térmica do planeta.

\subsection{Lei de Fourier}

A lei de Fourier, também conhecida como a lei da condução térmica é o princípio para o transporte de calor por condução. Tal lei estabelece que o fluxo de calor atráves de um material é proporcional ao gradiente negativo de temperatura

$$
q=-k \operatorname{grad}(T)
$$

ou na forma tensorial

$$
q_{i}=-k \frac{d T}{d x_{i}}
$$

onde $k$ é o coeficiente de condutividade térmica. O sinal negativo em 3.2 é devido ao fato de que o calor flui na direção da diminuição da temperatura.

\subsection{Condução de Calor no Estado Estacionário}

Consideremos uma caixa retangular com espessuras infinitesimais $\delta x_{1}, \delta x_{2}$ e $\delta x_{3}$ como mostrado na Figura 3.1. Pode-se escrever o fluxo de calor em cada uma das direções como $q_{x_{i}}$. A taxa na qual o calor flui para dentro da caixa pela direção $x_{i}$ pode ser expressa como $q_{x_{i}}\left(x_{i}\right) \delta x_{j} \delta x_{k}$ e a taxa pela qual o calor flui para fora da caixa na mesma direção como $q_{x_{i}}\left(x_{i}+\delta x_{i}\right) \delta x_{j} \delta x_{k}$. Assim, o fluxo de calor saindo da caixa pode ser escrito como

$$
\begin{aligned}
& {\left[q_{x_{1}}\left(x_{1}+\delta x_{1}\right)-q_{x_{1}}\left(x_{1}\right)\right] \delta x_{2} \delta x_{3}+} \\
+ & {\left[q_{x_{2}}\left(x_{2}+\delta x_{2}\right)-q_{x_{2}}\left(x_{2}\right)\right] \delta x_{1} \delta x_{3}+} \\
+ & {\left[q_{x_{3}}\left(x_{3}+\delta x_{3}\right)-q_{x_{3}}\left(x_{3}\right)\right] \delta x_{1} \delta x_{2} }
\end{aligned}
$$

ou na forma tensorial

$$
\left[q_{x_{i}}\left(x_{i}+\delta x_{i}\right)-q_{x_{i}}\left(x_{i}\right)\right] \delta x_{j} \delta x_{k}
$$




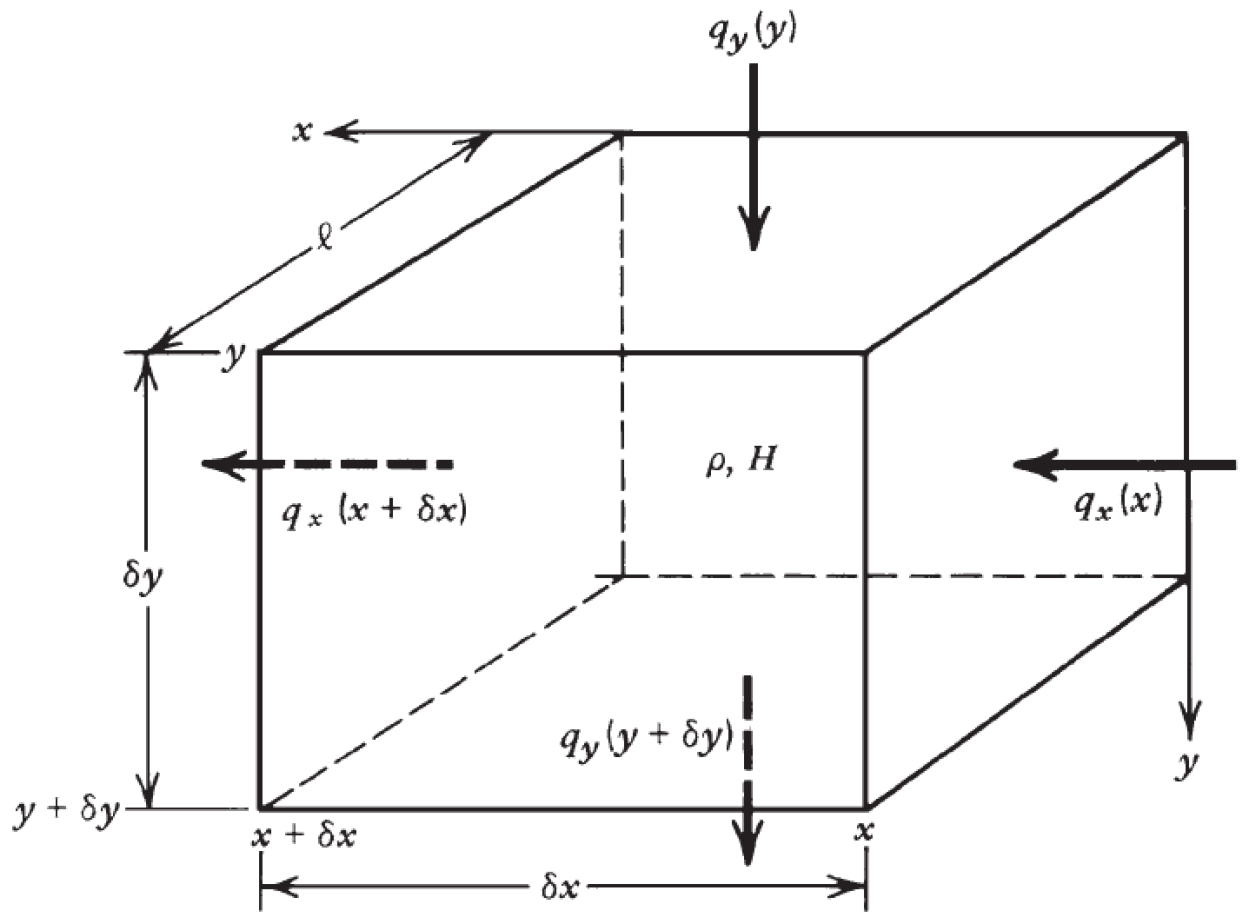

Figura 3.1: Diagrama do fluxo de calor em uma caixa retangular. Extraída de Turcotte e Schubert (2014).

Como $\delta x_{1}, \delta x_{2}$ e $\delta x_{3}$ são infinitesimais podemos expandir os termos $q_{x_{i}}\left(x_{i}+\partial x_{i}\right)$ através da série de Taylor. Desse modo, podemos escrever os termos como

$$
q_{x_{i}}\left(x_{i}+\delta x_{i}\right)=q_{x_{i}}\left(x_{i}\right)+\delta x_{i} \frac{\partial q_{i}}{\partial x_{i}}+\ldots
$$

Utilizando a aproximação pela série de Taylor dada por 3.5 em 3.4 obtemos

$$
q_{x_{i}}\left(x_{i}+\delta x_{i}\right)-q_{x_{i}}\left(x_{i}\right)=\frac{\partial q_{x_{i}}}{\partial x_{i}} \delta x_{i} \delta x_{j} \delta x_{k}
$$

substituindo 3.2 na equação acima, temos:

$$
\delta x_{i} \delta x_{j} \delta x_{k}\left[-k \frac{\partial}{\partial x_{i}}\left(\frac{\partial T}{\partial x_{i}}\right)\right]
$$

A equação 3.1 fornece o fluxo que esta saindo da caixa retangular, por unidade de tempo e por unidade de área. Como estamos tratando de um caso estacionário ou seja, sem variações no fluxo ou temperatura no decorrer do tempo, se o fluxo saindo da caixa é não nulo, este calor deve ser gerado internamente. Dessa forma, se considerarmos $H$ como 
sendo a taxa de produção de calor por unidade de massa e volume, então o calor gerado internamente é dado por $\rho H \delta x_{i} \delta x_{j} \delta x_{k}$. Assim, a partir de 3.1 temos

$$
\begin{aligned}
\delta x_{i} \delta x_{j} \delta x_{k}\left[-k \frac{\partial}{\partial x_{i}}\left(\frac{\partial T}{\partial x_{i}}\right)\right] & =\rho H \delta x_{i} \delta x_{j} \delta x_{k} \\
-k \frac{\partial}{\partial x_{i}}\left(\frac{\partial T}{\partial x_{i}}\right) & =\rho H
\end{aligned}
$$

caso não tenham fontes de calor dentro da caixa temos $H=0$ e a equação se resume a equação de Laplace

$$
\frac{\partial}{\partial x_{i}}\left(\frac{\partial T}{\partial x_{i}}\right)=0
$$

\subsection{Condução de Calor Dependente do Tempo}

Na seção anterior obtivemos uma equação que representa a condução térmica de calor para um estado estacionário, entretanto muitos dos problemas geológicos envolvendo condução térmica são dependentes do tempo. Desse modo, é necessário encontrarmos uma relação para a condução térmica dependente do tempo.

Partindo de 3.8, considera-se um caso em que não há produção de calor no interior da caixa $(H=0)$. Assim, é necessário que ocorra uma diminuição na temperatura do meio para que a conservação de energia não seja violada. Essa diminuição de temperatura é proporcional a $\partial T / \partial t$, sendo então $c$ o calor específico do meio, um elemento de volume dessa caixa $\delta x_{i} \delta x_{j} \delta x_{k}$ necessita de um fluxo de energia por unidade de tempo dado por

$$
-\rho c \frac{\partial T}{\partial t} \delta x_{i} \delta x_{j} \delta x_{k}
$$

o sinal negativo indica que a temperatura da caixa esta diminuindo já que o fluxo de calor esta saindo da caixa, para manter essa taxa de diminuição da temperatura. Assim, devemos somar a equação acima ao lado direito de 3.8, obtendo assim

$$
k \frac{\partial}{\partial x_{i}}\left(\frac{\partial T}{\partial x_{i}}\right)=\rho c \frac{\partial T}{\partial t}
$$

esta equação é conhecida como a equação de difusão e comumente pode ser escrita como

$$
\frac{\partial T}{\partial t}=\kappa \frac{\partial}{\partial x_{i}}\left(\frac{\partial T}{\partial x_{i}}\right)
$$

onde $\kappa$ é a difusividade térmica e é dada por

$$
\kappa=\frac{k}{\rho c}
$$


A equação do transporte de calor apresentada em 3.13 é valida em um meio em que a convecção térmica pode ser desprezada, como na litosfera que se comporta essencialmente como um sólido no tempo geológico. Porém, para representar adequadamente o transporte de calor no manto astenosférico, deve-se incorporar a convecção térmica, modificando-se a equação do calor. Esta modificação na equação do transporte de calor juntamente com a formulação matemática da dinâmica de fluidos serão apresentadas no próximo capítulo. 
Capítulo 4

\section{Dinâmica de Fluidos}

É sabido que o manto terrestre sub-litosférico se comporta como um fluido em escalas de tempo geológicas (Schubert et al., 2001). Dessa forma, para que seja possível estudar os processos convectivos no manto terrestre, é necessário um conhecimento sobre a mecânica de fluidos. Nesse capítulo, serão introduzidas as equações básicas que regem o movimento de um fluido.

\subsection{Equação de Continuidade}

Consideremos um volume $V$ do espaço. A massa de fluido presente neste volume pode ser escrita como:

$$
\int_{V} \rho d V
$$

onde $\rho$ é a densidade do fluido dada em função da posição $x_{j}(j=1,2,3)$. A massa de fluido por unidade de tempo passando através de um elemento $d \boldsymbol{s}$ da superfície em torno de $V$ pode ser expressa por $\rho \boldsymbol{v} \cdot d \boldsymbol{s}$, e a direção de $d \boldsymbol{s}$ é ao longo da normal. Por convenção, assumimos $d \boldsymbol{s}$ com a normal apontando para fora, e portanto, $d \boldsymbol{s}$ é positivo se o fluido esta saindo do volume $V$, e negativo se o fluido esta entrando em $V$. Desse modo, para obtermos a massa total de fluido saindo do volume $V$ por unidade de tempo devemos integrar em toda a superfície fechada no entorno de $V$, assim temos:

$$
\oint \rho v_{i} d s_{i}
$$


A variação da massa contida no volume $V$ pode ser escrita como

$$
-\frac{\partial}{\partial t} \int \rho d V
$$

o sinal negativo indica que a massa está saindo do volume $V$. Assim, de (4.2) e (4.3) temos:

$$
\frac{\partial}{\partial t} \int \rho d V=-\oint \rho v_{i} d s_{i}
$$

A integral de superfície pode ser transformada em uma integral de volume pelo teorema do Divergente

$$
\oint \rho v_{i} d s_{i}=\int \frac{\partial}{\partial x_{i}}\left(\rho v_{i}\right) d V
$$

e assim temos

$$
\int\left[\frac{\partial \rho}{\partial t}+\frac{\partial}{\partial x_{i}}\left(\rho v_{i}\right)\right] d V=0
$$

Como essa integral deve ser verdade para qualquer volume, o integrando deve ser nulo. Portanto

$$
\frac{\partial \rho}{\partial t}+\frac{\partial}{\partial x_{i}}\left(\rho v_{i}\right)=0
$$

Está é a equação de continuidade, ou também chamada de conservação de massa

\subsection{Equação de Euler}

Consideremos agora um volume no fluido. A força total agindo sobre este volume é dada pela integral da pressão, tomada sobre a superfície no entorno do volume. Em termos matemáticos:

$$
-\oint p d s
$$

Podemos novamente utilizar o teorema do Divergente e transformar está integral em uma integral de volume

$$
-\oint p d s=-\int \operatorname{grad}(p) d V
$$

Podemos dizer então que uma força $-\boldsymbol{g r a d}(p)$ age em uma unidade de volume do fluido. Desse modo, podemos escrever a segunda lei de Newton para um elemento de volume do fluido igualando-se a força $-\boldsymbol{g} \boldsymbol{r a d}(p)$, com a massa por unidade de volume ( $\rho$, densidade) vezes a aceleração $(d \boldsymbol{v} / d t)$, assim temos: 


$$
\rho \frac{d \boldsymbol{v}}{d t}=-\boldsymbol{g r a d}(p)
$$

ou na forma tensorial

$$
\rho \frac{d v_{i}}{d t}=-\frac{\partial p}{\partial x_{i}}
$$

A derivada do lado esquerdo da equação acima não representa a variação da velocidade de um ponto fixo no espaço, e sim a variação de um dado elemento do fluido conforme ele se move pelo espaço. Podemos escrever está derivada como

$$
\frac{d v_{i}}{d t}=\frac{\partial v_{i}}{\partial t}+v_{k} \frac{\partial v_{i}}{\partial x_{k}}
$$

Substituindo (4.12) em (4.11) obtemos

$$
\frac{\partial v_{i}}{\partial t}=-v_{k} \frac{\partial v_{i}}{\partial x_{k}}-\frac{1}{\rho} \frac{\partial p}{\partial x_{i}}
$$

A equação acima é a equação de movimento do fluido, conhecida também como Equação de Euler.

\subsection{Equação de movimento de um fluido viscoso}

Até agora consideramos apenas o caso de um fluido ideal, sem viscosidade. A equação de continuidade (4.7) é válida para qualquer fluido, entretanto a equação de Euler (4.13) necessita de algumas alterações quando estamos lidando com fluidos viscosos.

Quando se trata de um fluido viscoso, devemos levar em consideração a fricção interna entre partículas do fluido, função da viscosidade do meio. Desse modo, devemos somar essa contribuição devido a viscosidade na equação de movimento do fluido.

$$
\rho\left(\frac{\partial v_{i}}{\partial t}+v_{k} \frac{\partial v_{i}}{\partial x_{k}}\right)=-\frac{\partial p}{\partial x_{i}}+\frac{\partial \sigma_{i k}^{\prime}}{\partial x_{k}}
$$

O tensor $\sigma_{i k}^{\prime}$ é chamado de tensor de tensão de viscosidade. Este tensor é usualmente escrito como (Landau e Lifshitz, 1987):

$$
\sigma_{i k}^{\prime}=\eta\left(\frac{\partial v_{i}}{\partial x_{k}}+\frac{\partial v_{k}}{\partial x_{i}}-\frac{2}{3} \delta_{i k} \frac{\partial v_{l}}{\partial x_{l}}\right)
$$

onde $\eta$ é a viscosidade do fluido. Podemos escrever o segundo termo da equação como: 


$$
\frac{\partial \sigma_{i k}^{\prime}}{\partial x_{k}}=\frac{\partial}{\partial x_{i}}\left[\eta\left(\frac{\partial v_{i}}{\partial x_{k}}+\frac{\partial v_{k}}{\partial x_{i}}-\frac{2}{3} \frac{\partial v_{l}}{\partial x_{l}}\right)\right]
$$

Logo, a equação de movimento para um fluido viscoso pode ser escrita como:

$$
\rho\left(\frac{\partial v_{i}}{\partial t}+v_{k} \frac{\partial v_{i}}{\partial x_{k}}\right)=-\frac{\partial p}{\partial x_{i}}+\frac{\partial}{\partial x_{i}}\left[\eta\left(\frac{\partial v_{i}}{\partial x_{k}}+\frac{\partial v_{k}}{\partial x_{i}}-\frac{2}{3} \frac{\partial v_{l}}{\partial x_{l}}\right)\right]
$$

Esta é a forma geral da equação do movimento de um fluido viscoso, também conhecida como equação de Navier-Stokes (Landau e Lifshitz, 1987).

\subsection{Equação de Energia}

Fazendo uso da lei de conservação da energia, precisamos levar em consideração todos os ganhos e perdas de energia $E$ que ocorrem em um determinado volume $V$ do fluido por unidade de tempo. Assim temos:

$$
\frac{\partial}{\partial t} \int_{V} \rho E d V=\int_{S} v_{i} \sigma_{i k} d S_{j}+\int_{V} \rho v_{i} F_{i} d V-\int_{S} k \frac{\partial T}{\partial x_{k}} d S_{k}-\int_{S} \rho E v_{k} d S_{k}+\int_{V} \rho H d V
$$

O primeiro termo do lado direito da equação (4.18) é a taxa do trabalho realizado na região das bordas. Já o segundo termo representa o trabalho realizado por forças externas em cada elemento do fluido contido em $V$. No terceiro termo temos a taxa de condução de calor através da superfície $S$ do volume $V$, e $k$ é o coeficiente de condução de calor. O quarto termo é a taxa em que a energia sofre convecção através de $S$ pelo movimento predominante. E por último temos a taxa de energia obtida por fontes internas de calor (por exemplo, calor por decaimento de elementos radioativos). Podemos escrever o primeiro termo da seguinte forma:

$$
\int_{S} v_{i} \sigma_{i k} d S_{j}=\frac{1}{2} \frac{\partial}{\partial t} \int_{V} \rho v_{i}^{2} d V+\frac{1}{2} \int_{S} \rho v_{i}^{2} v_{k} d S_{k}-\int_{V} \rho v_{i} F_{i} d V+\int_{V} \Phi d V
$$

sendo $\Phi=\frac{\partial v_{i}}{\partial x_{k} \sigma_{i k}}$ é chamada de função de dissipação viscosa, e $F_{i}$ é uma força externa agindo no fluido.

A energia $E$ pode ser escrita como:

$$
E=\frac{1}{2} u_{i}^{2}+c_{V} T
$$

onde $c_{V}$ é o coeficiente de calor específico com volume constante e $T$ é a temperatura. Desse modo podemos escrever o quarto termo da equação (4.18) da seguinte forma: 


$$
-\int_{S} \rho E v_{k} d S_{k}=-\int_{S} \rho\left(\frac{1}{2} u_{i}^{2}+c_{V} T\right) v_{k} d S_{k}=-\frac{1}{2} \int_{S} \rho u^{2} i u_{k} d S_{k}-\int_{V} \frac{\partial}{\partial x_{k}}\left(\rho v_{k} c_{V} T\right) d V
$$

Utilizando o teorema do divergente podemos escrever o terceiro termo da equação (4.18) como

$$
\int_{S} k \frac{\partial T}{\partial x_{k}} d S_{k}=\int_{V} \frac{\partial}{\partial x_{k}}\left(k \frac{\partial T}{\partial x_{k}}\right) d V
$$

Substituindo (4.19), (4.21) e (4.22) em (4.18):

$$
\int_{V} \frac{\partial}{\partial t}\left(\rho c_{V} T\right) d V=\int_{V} \frac{\partial}{\partial x_{k}}\left(k \frac{\partial T}{\partial x_{k}}\right) d V+\int_{V} \Phi d V-\int_{V} \frac{\partial}{\partial x_{k}}\left(\rho c_{V} T v_{k}\right) d V+\int_{V} \rho H d V
$$

Como a equação acima deve ser válida para qualquer volume $V$, temos:

$$
\frac{\partial}{\partial t}\left(\rho c_{V} T\right)+\frac{\partial}{\partial x_{k}}\left(\rho c_{V} T v_{k}\right)=\frac{\partial}{\partial x_{k}}\left(k \frac{\partial T}{\partial x_{k}}\right)+\Phi+\rho H
$$

podemos também escrever a equação acima em termos de $c_{P}$

$$
\rho c_{P}\left(\frac{\partial T}{\partial t}+v_{k} \frac{\partial T}{\partial x_{k}}\right)-\alpha T\left(\frac{\partial p}{\partial t}+v_{k} \frac{\partial p}{\partial x_{k}}\right)=\frac{\partial}{\partial x_{k}}\left(k \frac{\partial T}{\partial x_{k}}\right)+\Phi+\rho H
$$

E está é a equação de conservação de energia para um fluido.

\subsection{Aproximação de um Líquido Anelástico Truncado}

O modelo numérico CitcomCU considera o manto como sendo anelástico, compressível e viscoso através da aproximação de um líquido anelástico truncado (Truncated Anelastic Liquid Approximation).

Nestas aproximações, a densidade é considerada como uma função apenas do espaço, usualmente da profundidade $\rho\left(x_{3}\right)$, e não do tempo. Desse modo a derivada temporal da equação de continuidade pode ser negligenciada.

Além disso, as variações na densidade decorrentes de efeitos da pressão são ordens de grandeza menores do que aqueles decorrentes da temperatura. Dessa forma, o termo da pressão nas forças de empuxo é desprezado na equação do momento. 
Para o termo de aquecimento/resfriamento adiabático da equação de energia, é utilizada a pressão hidrostática ao invés de se utilizar a pressão total, dessa forma o termo se torna proporcional apenas a velocidade vertical $v_{3}$ (Ismail-Zadeh e Tackley, 2014).

\subsection{Adimensionalização}

As leis da física não podem variar de acordo com a unidade que estamos utilizando para as quantidades físicas. Dito isso, é importante expressar as três equações de conservação em termos de quantidades adimensionais, ou seja, estabelecer uma relação entre as quantidades dimensionais e adimensionais, e verificar o que ocorre nas equações de conservação quando aplicamos estas relações.

As equações de conservação (4.7), (4.17) e (4.25), quando aplicamos a aproximação de um líquido anelástico truncado podem ser escritas como:

$$
\begin{gathered}
\frac{\partial \rho v_{i}}{\partial x_{i}}=0 \\
-\frac{\partial p}{\partial x_{i}}+\frac{\partial}{\partial x_{i}}\left[\eta\left(\frac{\partial v_{i}}{\partial x_{k}}+\frac{\partial v_{k}}{\partial x_{i}}-\frac{2}{3} \frac{\partial v_{l}}{\partial x_{l}}\right)\right]+\delta \rho F_{i}=0 \\
\rho c_{P}\left(\frac{\partial T}{\partial t}+v_{k} \frac{\partial T}{\partial x_{k}}\right)=-\alpha T \rho g v_{3}+\rho c_{P} \frac{\partial}{\partial x_{k}}\left(k \frac{\partial T}{\partial x_{k}}\right)+\Phi+\rho H
\end{gathered}
$$

Somou-se um termo $\delta \rho F_{i}$ na equação de conservação do momento que representa a ação de uma força externa no fluido, neste caso representando a força gravitacional devido a variações de densidade do fluido. Assumiu-se $F=g \hat{x}_{3}$, sendo $g$ a aceleração da gravidade. Podemos então escrever $\delta \rho F_{i}$ como:

$$
\delta \rho F_{i}=-\rho g \alpha\left(T-T_{0}\right)
$$

Vamos definir as constantes adimensionais como sendo: 


$$
\begin{array}{r}
x_{i}=x_{i}^{\prime} l_{0} \\
v_{i}=v_{i}^{\prime} \frac{k_{0}}{l_{0}} \\
t=t^{\prime} \frac{l_{0}^{2}}{k_{0}} \\
\rho=\rho^{\prime} \rho_{0} \\
\alpha=\alpha^{\prime} \alpha_{0} \\
g=g^{\prime} g_{0} \\
\eta=\eta^{\prime} \eta_{0} \\
k=k^{\prime} k_{0} \\
p=p^{\prime} \frac{\eta_{0} k_{0}}{l_{0}^{2}} \\
c_{P}=c_{P}^{\prime} c_{P 0} \\
T_{0}=\Delta T T_{0}^{\prime} \\
T=\Delta T\left(T^{\prime}-T_{0}^{\prime}\right) \\
H=\frac{k_{0}}{l_{0}^{2}} c_{P 0} \Delta T H^{\prime}
\end{array}
$$

onde os termos com as linhas são os termos adimensionais. Aplicando as relações acima nas equações de conservação obtemos:

$$
\begin{gathered}
\frac{\partial \rho^{\prime} v_{i}^{\prime}}{\partial x_{i}^{\prime}}=0 \\
-\frac{\partial p^{\prime}}{\partial x_{i}^{\prime}}+\frac{\partial}{\partial x_{i}^{\prime}}\left[\eta^{\prime}\left(\frac{\partial v_{i}^{\prime}}{\partial x_{k}^{\prime}}+\frac{\partial v_{k}^{\prime}}{\partial x_{i}^{\prime}}-\frac{2}{3} \frac{\partial v_{l}^{\prime}}{\partial x_{l}^{\prime}}\right)\right]+R_{a} \rho^{\prime} g^{\prime} \alpha^{\prime} T^{\prime} \delta_{i 3}=0 \\
\rho^{\prime} c_{P}^{\prime}\left(\frac{\partial T^{\prime}}{\partial t^{\prime}}+v_{k}^{\prime} \frac{\partial T^{\prime}}{\partial x_{k}^{\prime}}\right)=-D_{i}\left(T^{\prime}+T_{0}^{\prime}\right) \alpha^{\prime} \rho^{\prime} g^{\prime} v_{3}^{\prime}+\rho^{\prime} c_{P}^{\prime} k^{\prime} \frac{\partial^{2} T}{\partial x_{k}^{2}}+\frac{D_{i}}{R_{a}} \Phi^{\prime}+\rho^{\prime} H^{\prime}
\end{gathered}
$$

E essas são as equações de conservação para quantidades adimensionais, onde $R_{a}$ e $D_{i}$ são, respectivamente o número de Rayleigh e o número de dissipação dados por:

$$
R_{a}=\frac{\rho_{0} g_{0} \alpha_{0} \Delta T l_{0}^{3}}{k_{0} \eta_{0}}
$$

e

$$
D_{i}=\frac{\alpha_{0} g_{0} l_{0}}{c_{P 0}}
$$


Neste trabalho assumiu-se que $\Phi^{\prime}$ e $H^{\prime}$ são nulos, por simplicidade. 
Capítulo 5

\section{Reologia das Rochas}

\subsection{Introdução}

Sabe-se que as rochas quando submetidas a pressão atmosférica e a temperatura ambiente possuem um comportamento rígido. Entretanto, estudos mostraram (Ranalli, 1995) que as rochas se comportam como um material dúctil quando submetidas a grandes pressões e temperaturas. Desse modo, um estudo da reologia das rochas crustais e mantélicas é necessário para que seja possível entender a dinâmica interna da Terra.

A reologia para sólidos cristalinos pode apresentar um comportamento linear ou nãolinear, dependendo da temperatura, pressão, granulação e o nível de tensão ao qual a rocha esta associada (Ricard, 2015). Existem diversos mecanismos de deformação subsólida presentes no manto terrestre, como o arrasto por difusão ou por deslocamento, que podem ser representadas como um fluido que flui no tempo geológico com viscosidade $\eta$ dada pela seguinte equação de Arrhenius:

$$
\eta=A J_{2}^{-n} d^{m} \exp \left(\frac{E^{*}+p V^{*}}{R T}\right)
$$

onde $E^{*}$ e $V^{*}$ são a energia de ativação e o volume de ativação por mol, $p$ e $T$ são a pressão e a temperatura, $R$ é a constante dos gases, $d$ é o tamanho dos grãos, $m$ é o expoente do tamanho do grão, $J_{2}$ é a segunda invariante do tensor deviatórico, $n$ é o expoente de tensão, e o coeficiente $A$ é um coeficiente que varia dependendo da quantidade de água, material fundido e da mineralogia. O segundo invariante $J_{2}$ do tensor deviatórico pode ser escrito como

$$
J_{2}=\frac{1}{6}\left[\left(\sigma_{11}-\sigma_{22}\right)^{2}+\left(\sigma_{22}-\sigma_{33}\right)^{2}+\left(\sigma_{33}-\sigma_{11}\right)^{2}\right]
$$

e $\sigma_{i i}$ são as componentes principais do tensor de tensões $\boldsymbol{\sigma}$. Entretanto, neste trabalho vamos tratar de uma viscosidade dependente apenas da temperatura e da profundidade. 
Assumiremos também que não há variação significativa no tamanho dos grãos, ou seja, $d$ é constante e que não ocorra arrasto por deslocamento $(n=0)$, resultando em um fluido Newtoniano, ou seja, a viscosidade independe do estado de tensão no manto. Assim, a equação 5.3 se reduz a

$$
\eta=\eta_{0} \exp \left(\frac{E^{*}+p V^{*}}{R T}\right)
$$

onde $\eta_{0}$ é a viscosidade inicial. Optou-se por esta simplificação pois estas são as componentes que possuem maior contribuição para a variação da viscosidade.

\subsection{Dependência da Viscosidade com a Temperatura}

A viscosidade do manto astenosférico apresenta uma relação muito forte com a temperatura. Valores típicos para a viscosidade do manto são da ordem de $10^{18}-10^{20} \mathrm{~Pa} \cdot \mathrm{s}$ (Turcotte e Schubert, 2014), sendo de 4 até 6 ordens de grandeza menores do que a viscosidade da litosfera.

Quando existe uma forte dependência da viscosidade com a temperatura a definição do número de Rayleigh, que é um número adimensional que controla o comportamento de um fluido qualquer, se torna um tanto quanto arbitrária. Assim, para que seja possível caracterizar a convecção é necessário conhecer a razão da variação das viscosidades máxima e mínima $\eta_{\max } / \eta_{\min }$ (Ricard, 2015). Para uma razão da viscosidade menor do que 100, obtém-se um padrão similar ao apresentado por uma convecção com a viscosidade uniforme. Solomatov (1995) mostrou que quando a viscosidade da litosfera é 3000 vezes maior do que a viscosidade da astenosfera a superfície é imóvel. Quando a razão da viscosidade esta entre 100-3000, a litosfera se deforma lentamente e são formadas grandes células de convecção (Ricard, 2015).

Christensen (1984) entre outros autores estudou a convecção através de modelos com a viscosidade dependentes da temperatura. Como a litosfera é mais fria e portanto, mais rígida do que a astenosfera, dificulta a perda de calor para superfície e assim ocorre um aumento na temperatura média do manto astenosférico. A convecção obtida através de uma reologia dependente apenas da temperatura não é uma boa aproximação para a convecção mantélica da Terra. Nesse regime quando a temperatura é muito alta a superfície será congelada e ficará estagnada, e apesar da litosfera terrestre apresentar uma alta viscosidade, ela ainda apresenta movimentação devido a tectônica de placas. Christensen $(1996,1997)$ 
utilizou uma reologia dependente da temperatura, entretanto para considerar o movimento das placas litosféricas ele estabeleceu uma velocidade para a superfície do modelo.

Além disso, a dependência da viscosidade com a temperatura atua na auto regulação da dinâmica do interior do planeta (Tozer, 1972). Quando a convecção é muito intensa o planeta perde mais calor do que o que é gerado através do decaimento radioativo. Assim, a temperatura interna vai diminuindo e consequentemente a viscosidade aumenta. Esse aumento da viscosidade fará com que a transferência de calor seja reduzida. Já quando a convecção é pequena, o calor radiogênico gerado é maior do que o calor perdido pela transferência térmica. Isso faz com que a astenosfera fique mais quente, diminuindo consequentemente, a viscosidade.

\subsection{Dependência da Viscosidade com a Profundidade}

A dependência da viscosidade com a profundidade esta intimamente relacionada com o volume de ativação visto que para um valor muito baixo de $V^{*}$ a variação da viscosidade com a temperatura pode ser negligenciada. Para valores típicos do volume de ativação da ordem de $10^{-5} \mathrm{~m}^{3} \mathrm{~mol}^{-1}$ espera-se um grande aumento na viscosidade quando se extrapola para as pressões na interface manto-núcleo, entretanto medir a viscosidade a grandes pressões e temperaturas é uma tarefa difícil (Ricard, 2015).

A profundidade juntamente com o volume de ativação atuam na contramão da temperatura. Assim como o aumento da temperatura tende a diminuir a viscosidade e, desse modo, aumentar a convecção a profundidade aumenta a pressão aumentando assim a viscosidade o que faz com que a convecção seja menos vigorosa. O balanço entre as componentes é o que permite que não ocorram grandes variações na viscosidade do manto.

O aumento da viscosidade com a profundidade permite explicar a estabilidade relativa dos hot-spots, pois com o aumento da viscosidade temos um manto inferior que se move mais lentamente, e com menor convecção, permitindo assim a fixação do hot-spot.

Outra consequência da dependência da viscosidade com a profundidade é a ocorrência de anomalias térmicas de larga escala presentes em grandes profundidades. 
Capítulo 6

\section{Problema com Solução Analítica}

Para iniciar os testes numéricos, adotou-se um modelo simples que possuísse solução analítica. Dito isso, optou-se por utilizar o modelo com solução analítica apresentado por Turcotte e Schubert (2014). Este modelo é composto por uma célula de convecção bidimensional de espessura $b$ e comprimento $\lambda$ em um fluido aquecido pela base à temperatura $T_{1}$ e topo mantido à temperatura $T_{0}$. A Figura 6.1 apresenta uma representação esquemática deste modelo.

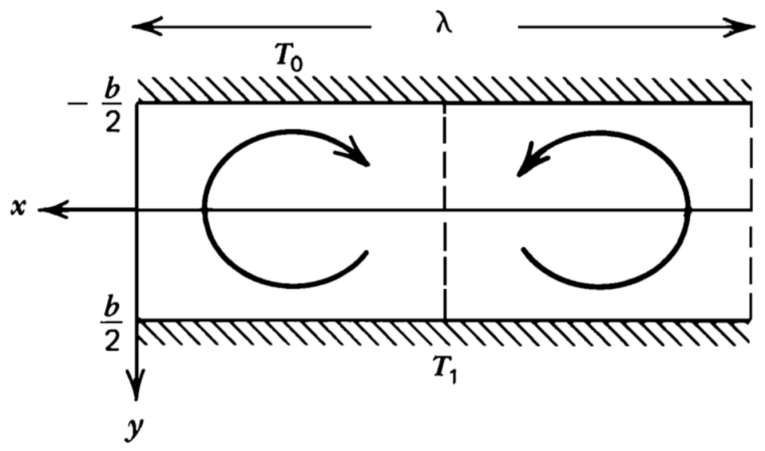

Figura 6.1: Célula de Conveç̧ão bidimensional num fluido aquecido por baixo. Extraída de Turcotte e Schubert (2014).

Se assumirmos que na condição inicial ocorre apenas a condução térmica, o perfil de temperatura inicial pode ser escrito como:

$$
T=T^{\prime}+\frac{\left(T_{1}-T_{0}\right)}{2}+\frac{T_{1}-T_{0}}{b} y
$$

As equações de conservação $(4.43,4.44$ e 4.45$)$ definidas no capítulo anterior para este modelo se resumem a:

$$
\frac{\partial v_{i}^{\prime}}{\partial x_{i}^{\prime}}=0
$$




$$
\begin{gathered}
-\frac{\partial p^{\prime}}{\partial x_{i}^{\prime}}+\eta^{\prime}\left(\frac{\partial^{2} v_{i}^{\prime}}{\partial x_{k}^{\prime 2}}\right)+\rho^{\prime} g^{\prime} \alpha_{v}^{\prime} T^{\prime} \delta_{i z}=0 \\
\frac{\partial T^{\prime}}{\partial t^{\prime}}+\frac{v_{k}^{\prime}}{b}\left(T_{1}-T_{0}\right)=k^{\prime} \frac{\partial^{2} T}{\partial x_{k}^{2}}
\end{gathered}
$$

Ao resolver as equações acima para $T^{\prime}$ obtém-se:

$$
T^{\prime}=T_{0}^{\prime} \cos \left(\frac{\pi y}{b}\right) \cos \left(\frac{2 \pi x}{\lambda}\right) e^{\alpha^{\prime} t}
$$

onde $\alpha^{\prime}$ é um fator conhecido como taxa de crescimento. Este fator pode ser escrito como:

$$
\frac{\alpha^{\prime} b^{2}}{\kappa}=\frac{R a \frac{4 \pi^{2} b^{2}}{\lambda^{2}}-\left(\pi^{2}+\frac{4 \pi^{2} b^{2}}{\lambda^{2}}\right)^{3}}{\left(\pi^{2}+\frac{4 \pi^{2} b^{2}}{\lambda^{2}}\right)^{2}}
$$

onde $R a$ assim como na equação 4.46 é expressa por:

$$
R a=\frac{\rho_{0} g \alpha_{v} \Delta T b^{3}}{\eta \kappa}
$$

onde $\Delta T=T_{1}-T_{0}$.

Se $\alpha^{\prime}>0$ as perturbações aumentarão e assim teremos o início da convecção. Ao analisarmos a equação (6.6) observa-se que isso só ocorre quando $\alpha^{\prime}=R a_{c r}$. Assim, o número de Rayleigh que define o início da convecção é dado por:

$$
R a \geq \frac{\left(\pi^{2}+\frac{4 \pi^{2} b^{2}}{\lambda^{2}}\right)^{3}}{\frac{4 \pi^{2} b^{2}}{\lambda^{2}}}=R a_{c r}
$$

onde $b$ é a espessura do modelo e $\lambda$ é o comprimento.

Desse modo o $R a_{c r}$ delimita a interface de estabilidade/instabilidade. A Figura 6.2 apresenta uma curva de $R a_{c r}$ em relação a $2 \pi b / \lambda$. Desse modo, os pontos situados acima da curva representam pontos no regime instável (com a presença de advecção) e os abaixo da curva se situam no regime estável (modelos puramente condutivos).

Para que fosse possível verificar se os modelos estavam realmente em um regime de convecção ou condução, foi feita uma análise da velocidade de cada elemento do modelo. A Figura 6.3 apresenta um gráfico com as curvas da velocidade máxima de cada modelo pela iteração. Os números de $R a$ utilizados em cada um dos modelos se encontra sobre a respectiva curva na Figura 6.3.

A partir da Figura 6.3, vemos que os modelos com $R a<0.8 \times 10^{3}$ não apresentam convecção, pois a velocidade máxima desses modelos decresce no decorrer da simulação. 


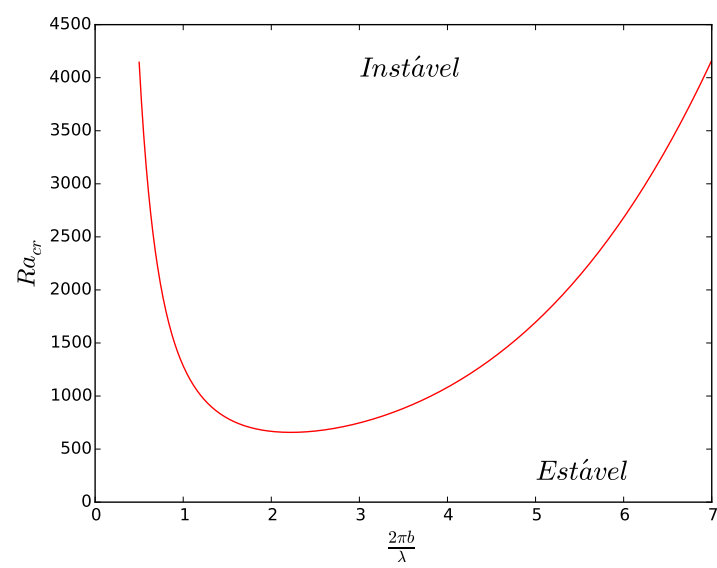

Figura 6.2: Curva de $R a_{c r}$ em relação a $2 \pi b / \lambda$. Os pontos acima da curva vermelha estão no regime instável(advecção) e os abaixo da curva no regime estável (condutivo).

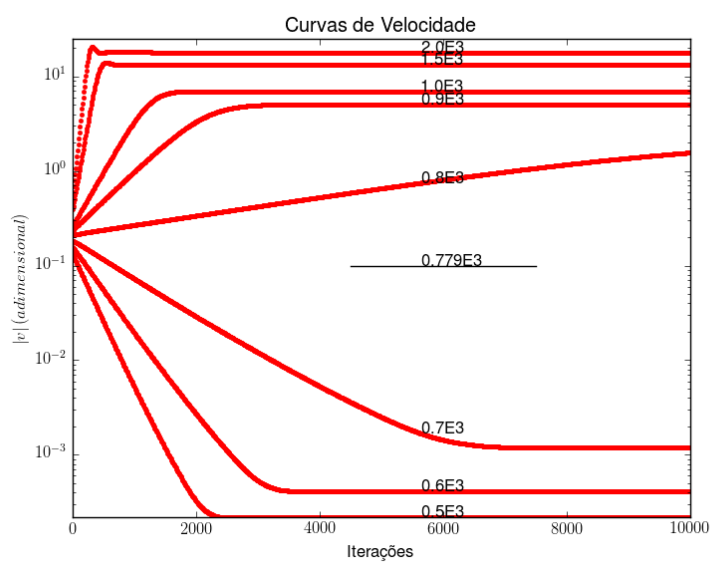

Figura 6.3: Curvas do módulo da velocidade máxima por iteração. O $R a$ de cada um dos modelos esta indicado na sua respectiva curva.

Já para os modelos com $R a \geq 0.8 \times 10^{3}$ verifica-se que com o passar do tempo os modelos mantém uma velocidade máxima que cresce com o decorrer do tempo, indicando assim a presença de convecção.

As Figuras 6.4 e 6.5 apresentam as isotermas, bem como os vetores de velocidade para dois modelos distintos. O modelo da Figura 6.4 possui isotermas paralelas e como se pode verificar pela Figura 6.3 que a velocidade de seus elementos é praticamente nula. Essas duas características indicam que este modelo está no regime dominantemente condutivo. Já na Figura 6.5 é possível verificar que as isotermas são mais profundas no centro do modelo e mais rasas nas bordas. Através da Figura 6.3 podemos verificar que a velocidade máxima deste modelo não é nula, crescendo progressivamente no início da simulação numérica. Estes fatores indicam que tal modelo apresenta movimentos de convecção. Além disso, 


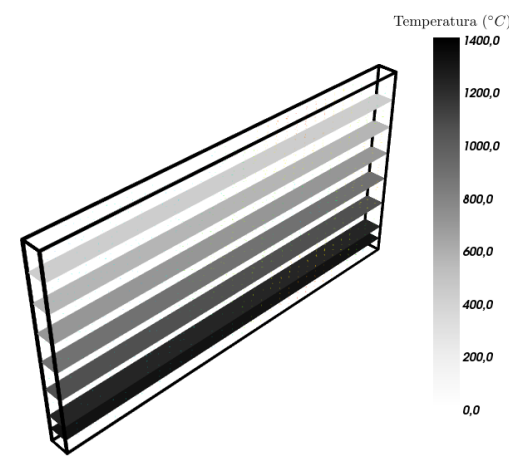

Figura 6.4: Modelo com $R a=0.6 \times 10^{3}$ na iteração 2000. As isotermas paralelas indicam que estão ocorrendo apenas processos condutivos.

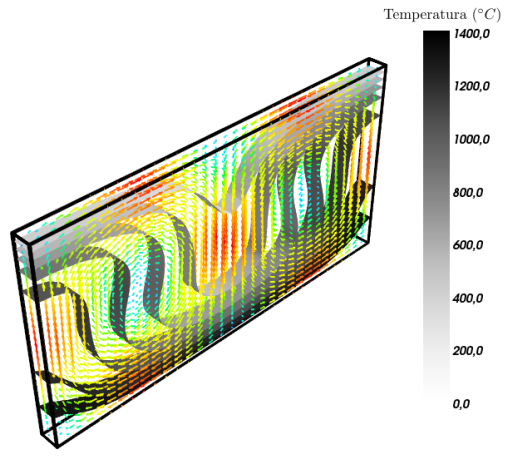

Figura 6.5: Modelo com $R a=2.0 \times 10^{3}$ na iteração 2000. As isotermas mais profundas no meio e mais rasas nas bordas indicam a ocorrência de advecção.

analisando as setas na Figura 6.5 que indicam a direção da tangente da velocidade naquele ponto, é possível verificar que o material mais frio está descendo pelo centro do modelo, enquanto o material aquecido está subindo pelas bordas do modelo.

Desse modo, foi possível identificar em todos os modelos se eles pertenciam ao regime puramente condutivo, ou se pertenciam ao regime com a presença de convecção. Na Figura 6.6 tem-se um gráfico similar ao gráfico apresentado na Figura 6.2, com a diferença de que foram adicionados os pontos representando cada um dos modelos estudados. Verificou-se assim que todos os modelos se comportaram de acordo com o previsto, exceto pelo ponto mais a direita do gráfico.

Neste ponto, foram utilizados os mesmos parâmetros utilizados no modelo com $R a=$ $2.0 \times 10^{3}$. Sendo que, neste caso, a única diferença é que foi adotado um $\lambda$ com a metade do valor. $\mathrm{O}$ valor de $\lambda$ corresponde ao comprimento, horizontal, do modelo. Dessa forma, quando escolhemos um valor de $\lambda$ menor, estamos utilizando uma caixa menor em nosso modelo.

Neste caso, o que ocorreu é que no início da simulação estão tentando ser formadas duas células de convecção, como as apresentadas na Figura 6.1, entretanto esse processo é abortado e o sistema se rearranja formando apenas uma célula convectiva. Assim, este modelo está apenas refletindo metade do modelo com $R a=2.0 \times 10^{3}$, como indicado na Figura 6.7. 


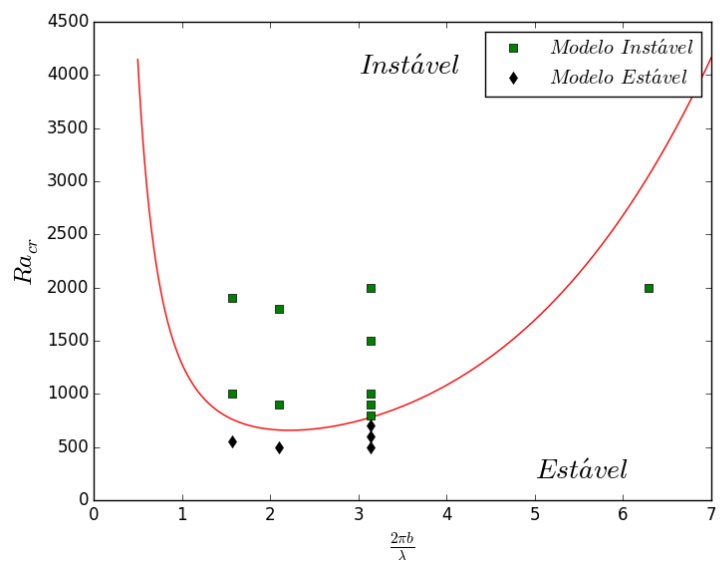

Figura 6.6: Curva de $R a_{c r}$ em relação a $2 \pi b / \lambda$. Os pontos acima da curva vermelha estão no regime instável(advecção) e os abaixo da curva no regime estável (condutivo).

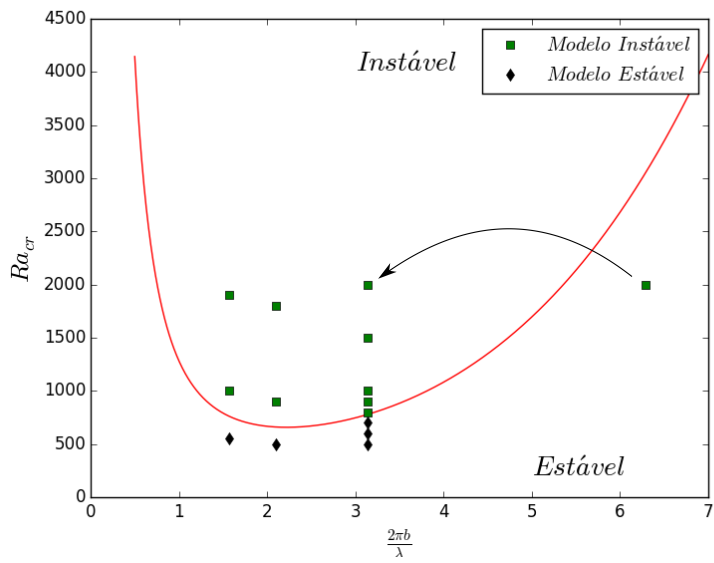

Figura 6.7: Curva de $R a_{c r}$ em relação a $2 \pi b / \lambda$. Os pontos acima da curva vermelha estão no regime instável(advecção) e os abaixo da curva no regime estável (condutivo). A seta indica para qual modelo o ponto mais a direita esta representando.

Isto ocorre pois esta análise de estabilidade/instabilidade mostra apenas a tendência convectiva do modelo para um intervalo de tempo pequeno, não sendo válido para longos períodos. De fato, é possível verificar que nos instantes iniciais o modelo tenta ajustar as duas células de convecção (6.8a-c), e que no decorrer do tempo ele se reajusta formando apenas uma grande célula de convecção (6.8d-i). 


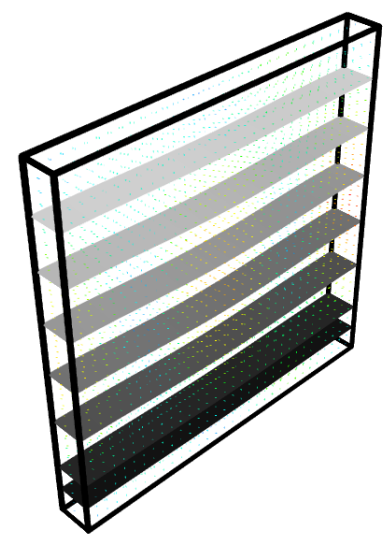

(a) Condição Inicial.

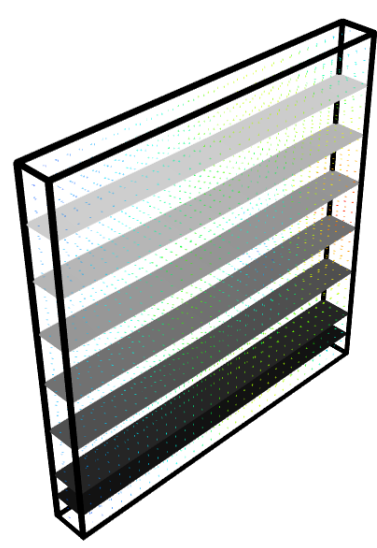

(d) 100 iterações.

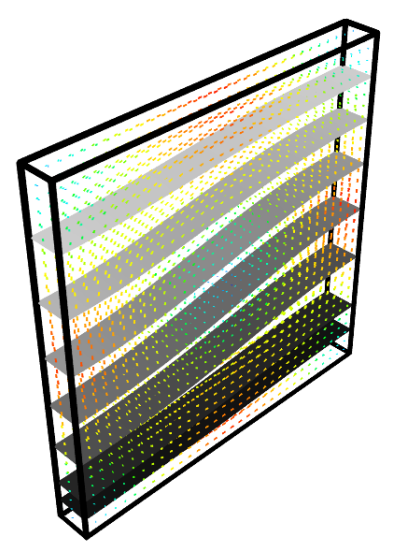

(g) 300 iterações.

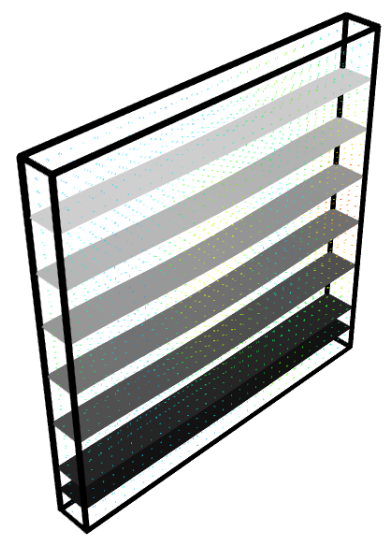

(b) 40 iterações.

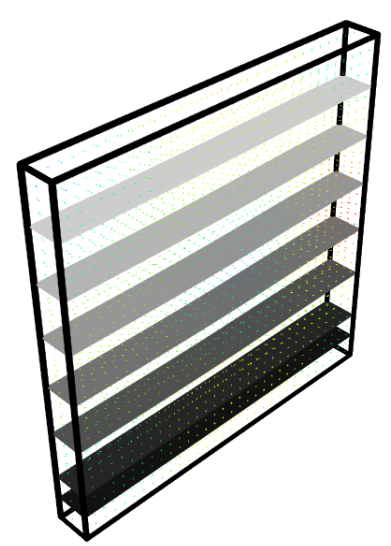

(e) 150 iterações.

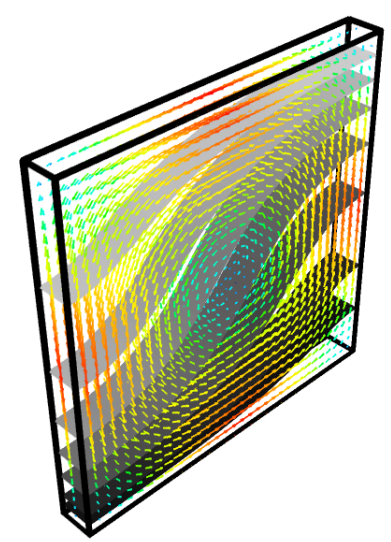

(h) 400 iterações.

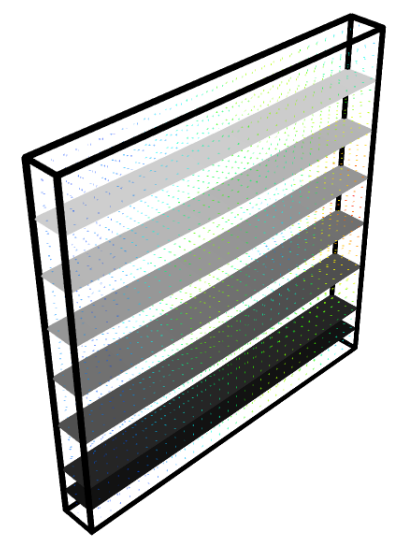

(c) 80 iterações.

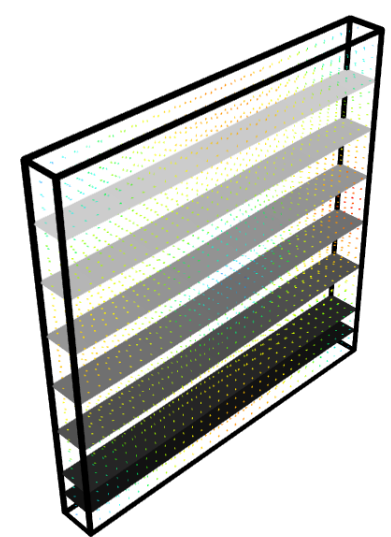

(f) 200 iterações.

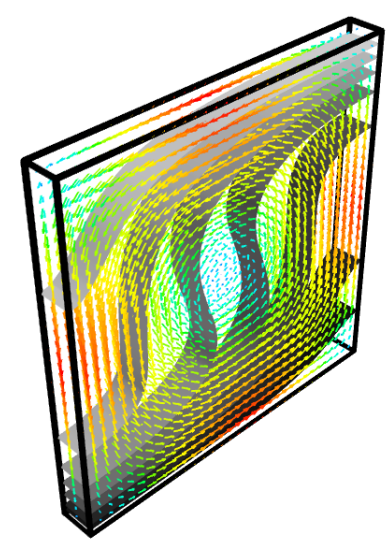

(i) 500 iterações.

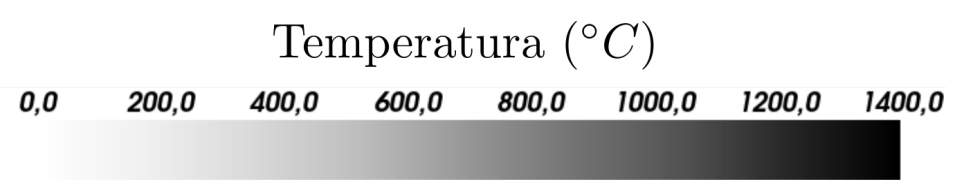

Figura 6.8: Modelo com $R a=2.0 \times 10^{3}$ e $\lambda / 2$ em diversos instantes da simulação. 
Capítulo 7

\section{Estabilidade da Litosfera Continental}

Doin et al. (1997) mostraram que a espessura em que a litosfera, tanto oceânica quanto continental, se estabiliza está intimamente relacionada com o número de Rayleigh $R a$ e a reologia utilizada. Nesse trabalho, eles verificaram que apenas modelos em que a viscosidade da astenosfera possuía uma forte dependência com a pressão e temperatura conseguiam reproduzir litosferas capazes de se estabilizar em profundidades compatíveis com os valores observados $(100-200 \mathrm{~km})$, sendo que valores relativamente altos para a viscosidade astenosférica resultava, ao longo de centenas de milhões de anos, em uma litosfera irreal atingindo mais de $500 \mathrm{~km}$.

Desse modo, é importante a obtenção de um modelo onde se tenha a garantia de que a configuração térmica inicial para litosfera não estirada esteja em equilíbrio, não sofrendo variações significativas na espessura para intervalos de tempo inferiores à idade máxima de margens divergentes $(<200 \mathrm{Ma})$.

\subsection{Adimensionalização da Equação de Arrhenius}

Neste trabalho foi utilizada uma reologia Newtoniana dependente da pressão e temperatura. A partir da equação de Arrhenius (equação 5.3) pode-se redefinir a viscosidade como sendo

$$
\eta=\eta_{0} \times \exp \left(\frac{E^{*}+p V^{*}}{R T_{k}}\right)
$$

onde $\eta$ é a viscosidade, $\eta_{0}$ é a viscosidade na base do modelo, $E^{*}$ e $V^{*}$ são respectivamente, a energia e o volume de ativação por mol, $p$ é a pressão, $T_{k}$ é a temperatura em Kelvin e $R$ é a constante universal dos gases. 
Considerando-se somente os termos dentro da exponencial

$$
\frac{E^{*}+p V^{*}}{R T_{k}}
$$

é possível adimensionalizar a temperatura através da relação 4.41, desse modo:

$$
T_{k}=\Delta T\left(T^{\prime}+T_{0}^{\prime}\right)
$$

onde $T_{0}^{\prime}$ é a temperatua adimensional do topo do modelo, $T^{\prime}$ é a temperatura adimensional, e $\Delta T$ é a variação de temperatura entre o topo e a base do modelo. Pode-se também escrever a pressão como $p=\rho g z$, onde $\rho$ é a densidade, $g$ é a aceleração da gravidade e $z$ é a profundidade, desse modo a equação (7.2) pode ser escrita da seguinte forma:

$$
\frac{E^{*}+\rho g z V^{*}}{R \Delta T\left(T^{\prime}+T_{0}^{\prime}\right)}
$$

Realizando algumas mudanças de variáveis é possível reescrever a equação acima como

$$
\frac{E^{\prime}+V^{\prime} z / D}{T^{\prime}+T_{0}^{\prime}}=\frac{E^{\prime}+V^{\prime} z / D}{\frac{T_{c}}{\Delta T}+T_{0}^{\prime}}
$$

onde $E^{\prime}$ é a energia de ativação adimensional, $V^{\prime}$ é o volume de ativação adimensional, $T_{c}$ a temperatura em graus Celsius e $D$ é a espessura do modelo, onde $E^{\prime}, V^{\prime}$ e $T_{0}^{\prime}$ são dados por

$$
\begin{gathered}
E^{\prime}=\frac{E^{*}}{R \Delta T} \\
V^{\prime}=\frac{\rho g D V^{*}}{R \Delta T}
\end{gathered}
$$

e

$$
T_{0}^{\prime}=\frac{T_{0}}{\Delta T}
$$

\subsection{Análise de Estabilidade da Litosfera}

Foram realizados diversos modelos numéricos com o software CitcomCU a fim de se avaliar a influência dos parâmetros que governam as equações da dinâmica do manto, sendo estes a viscosidade da base $\left(\eta_{0}\right)$, a energia de ativação $\left(E^{\prime}\right)$ e o volume de ativação $\left(V^{\prime}\right)$, bem como encontrar a melhor combinação desses parâmetros, para que possam ser utilizados como ponto de partida para os modelos no contexto de margens divergentes.

Em todos os testes apresentados aqui considerou-se um modelo de caixa simples, como pode ser verificado na Figura 7.1 , com a base do modelo a uma temperatura de $1800^{\circ} \mathrm{C}$ 


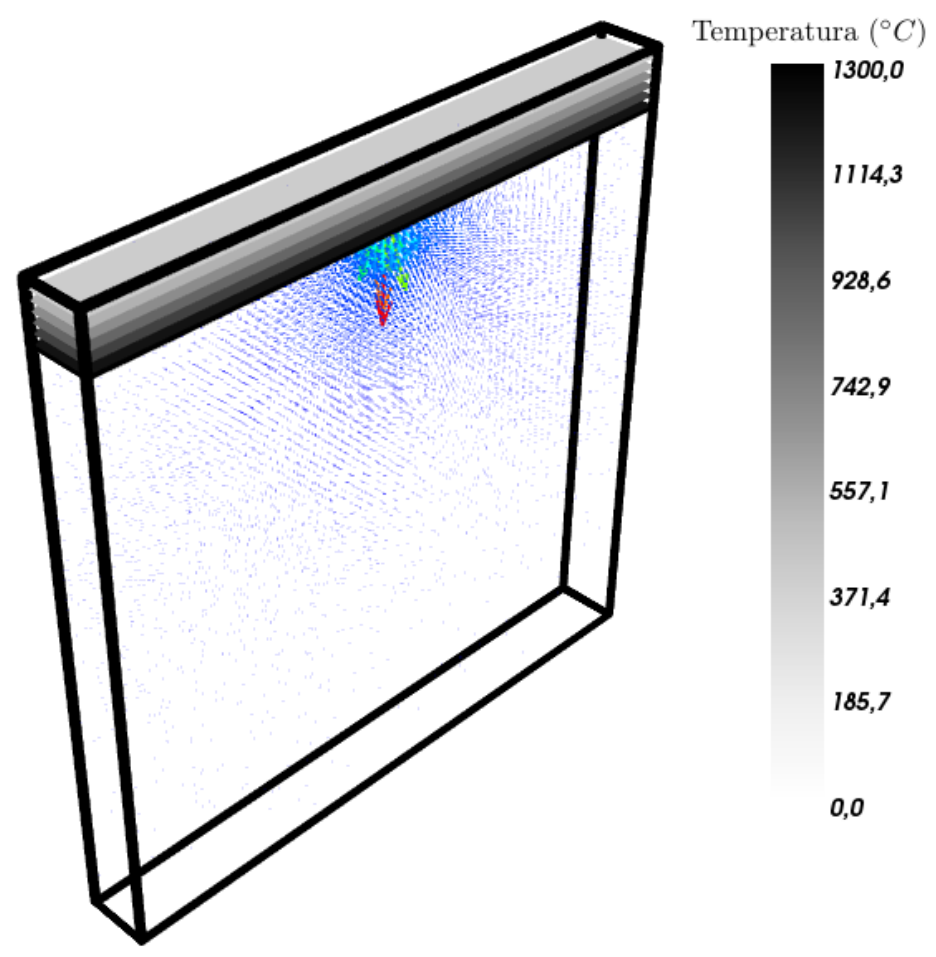

Figura 7.1: Configuração do perfil de temperatura inicial utilizado para os modelos. A base se encontra a uma temperatura de $1800^{\circ} \mathrm{C}$. Foi utilizado um gride de 38025 nós.

e o topo a $0^{\circ} \mathrm{C}$. Além disso foi adotada uma profundidade de $660 \mathrm{~km}$, e de $660 \mathrm{~km}$ para o comprimento da caixa. Os valores adotados foram baseados em dados apresentados por Schubert et al. (2001), e representam valores estimados para a interface onde ocorre mudanças na mineralogia do manto astenosférico com a transformação do Espinélio em Peroviskta. A temperatura estimada para esta interface de transição é de $2000 \pm 250 \mathrm{~K}$.

Os modelos foram feitos com um gride de 65x9x65 $(x, y, z)$ num total de 38025 nós. A escolha de apenas nove nós na direção y foi feita a fim de que se observa-se o comportamento do modelo apenas em duas dimensões. Na Figura 7.2 se encontra uma seção 2D da configuração de temperatura inicial utilizada em nossos modelos.

Como é possível observar na Figura 7.2 foi adotada uma variação linear da temperatura na parte superior (aproximadamente $80 \mathrm{~km}$ de profundidade), esta porção representa a espessura inicial da litosfera, e uma temperatura constante até a base do modelo. Foi adicionada uma pequena perturbação na temperatura no centro do modelo, como se pode perceber através dos vetores de velocidade presentes na Figura 7.1. Esta perturbação é necessária para o início da convecção, garantindo que o modelo convirja, visto que todas as isotermas são paralelas. 


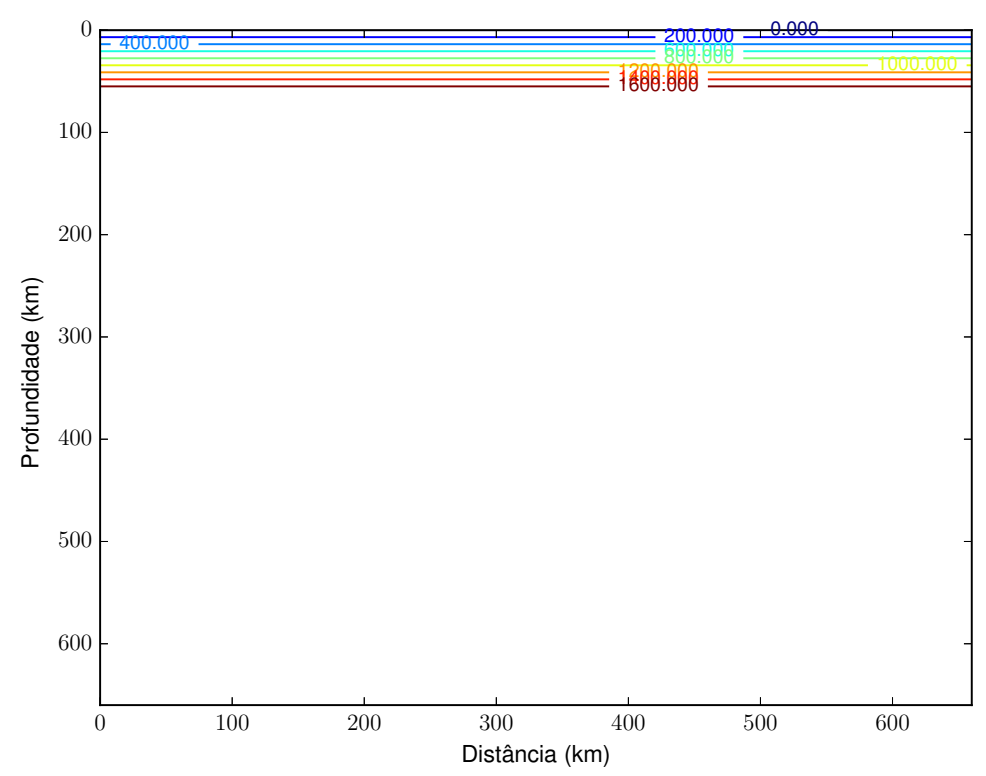

Figura 7.2: Seção 2D da configuração do perfil de temperatura inicial utilizado para os modelos. A base se encontra a uma temperatura de $1800^{\circ} \mathrm{C}$.

Realizou-se testes para diversos valores de viscosidade, energia de ativação e volume de ativação. Os valores utilizados estão apresentados na Tabela 7.1.

Tabela 7.1 - Valores utilizados para os modelos numéricos. Foram realizados modelos com todas as combinações possíveis entre esses três parâmetros. Os valores de $E^{\prime}$ e $V^{\prime}$ apresentados são adimensionais.

\begin{tabular}{lll}
\hline$E^{\prime}$ & $V^{\prime}$ & $\eta_{0}(\mathrm{~Pa} \cdot \mathrm{s})$ \\
\hline 20 & 0 & $5 \times 10^{19}$ \\
30 & 5 & $1 \times 10^{20}$ \\
- & 7.5 & $3 \times 10^{20}$ \\
- & 10 & $4 \times 10^{20}$ \\
- & 12.5 & $5 \times 10^{20}$ \\
- & 15 & - \\
\hline
\end{tabular}

Foram realizados modelos com todas as combinações possíveis entre os três parâmetros apresentados na Tabela 7.1, totalizando assim 60 modelos diferentes.

Desse modo, foi possível identificar a influência de cada um desses parâmetros na viscosidade do modelo. A Figura 7.3 apresenta uma comparação entre o perfil de viscosidade inicial entre dois modelos com valores de $\eta_{0}$ diferentes.

Através da Figura 7.3 pode-se observar que a viscosidade $\eta_{0}$ provoca uma translação 

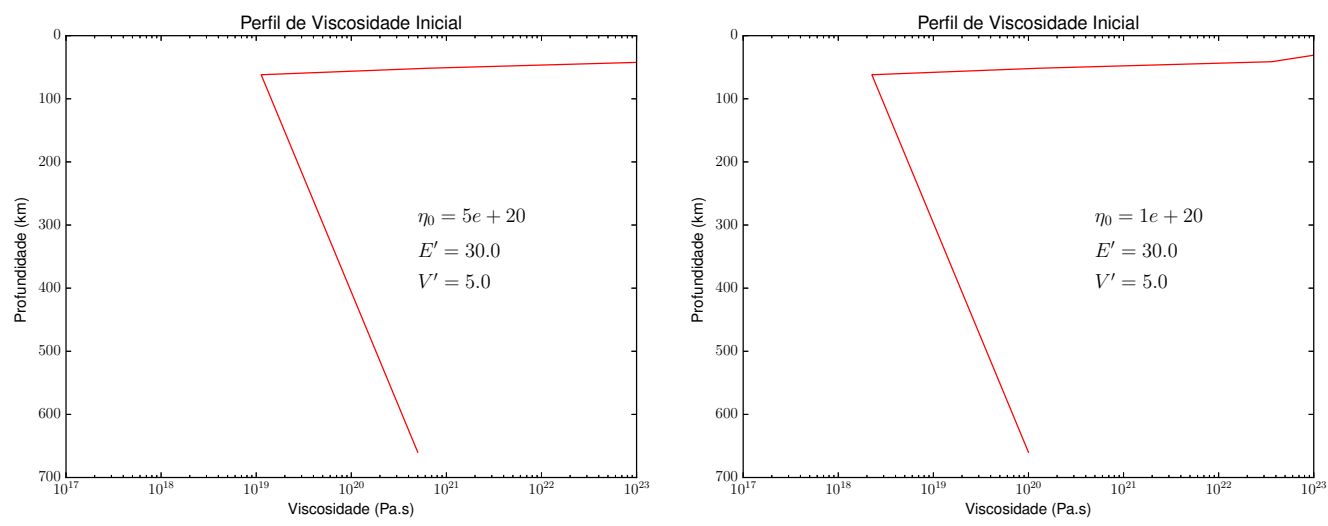

Figura 7.3: Comparação entre dois perfis de viscosidade para valores de $\eta_{0}$ diferentes.
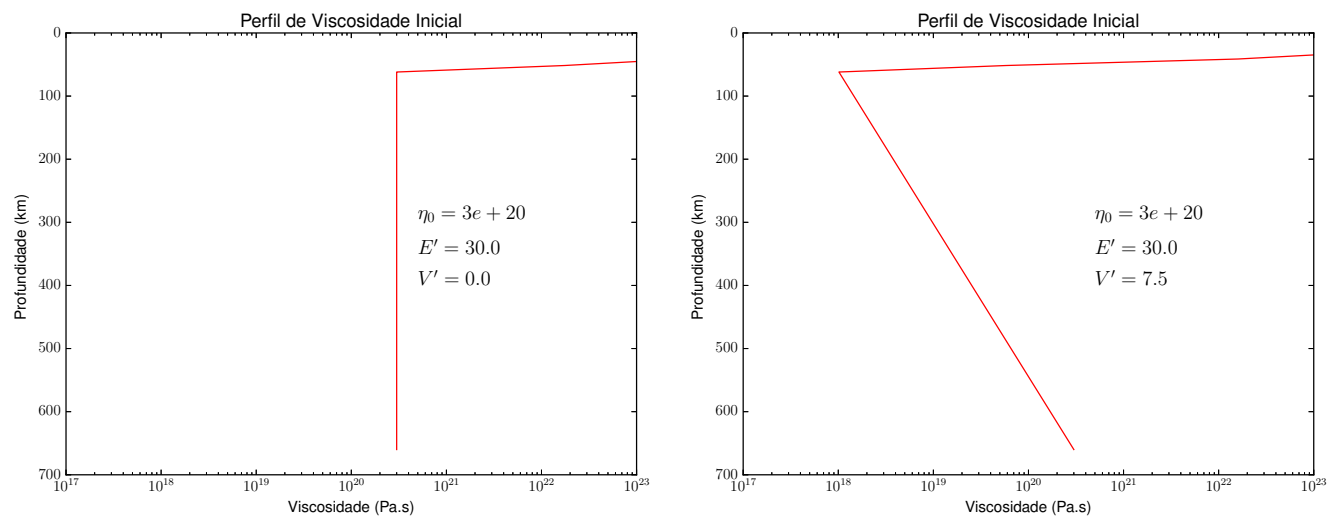

Figura 7.4: Comparação entre dois perfis de viscosidade para valores diferentes de $V^{\prime}$.

em todo o perfil, assim, valores de $\eta_{0}$ menores diminuem a viscosidade do modelo como um todo.

A Figura 7.4 apresenta uma comparação entre os perfis de viscosidade inicial de dois modelos com volumes de ativação $\left(V^{\prime}\right)$ diferentes. Verifica-se que o volume de ativação é o responsável pela dependência da viscosidade em relação a profundidade, ou mais especificamente, pela pressão. Pode-se observar que quando aumentamos o volume de ativação, a viscosidade no interior do modelo diminui e atinge seu mínimo a $80 \mathrm{~km}$ de profundidade, que é a profundidade da litosfera adotada como modelo inicial, ou seja, a viscosidade é mínima na base da litosfera.

Para cada modelo foi gerada uma curva de evolução temporal da temperatura média pela profundidade. Esta temperatura média foi calculada horizontalmente, ou seja, para uma determinada profundidade, calculou-se a temperatura média entre todos os pontos situados nesta profundidade. Também foram feitos perfis da viscosidade inicial em relação a profundidade. A Figura 7.5 apresenta estas curvas para um modelo com $\eta_{0}=5 \times 10^{20}$ $\mathrm{Pa} \cdot \mathrm{s}, E^{\prime}=30$ e $V^{\prime}=0$. 


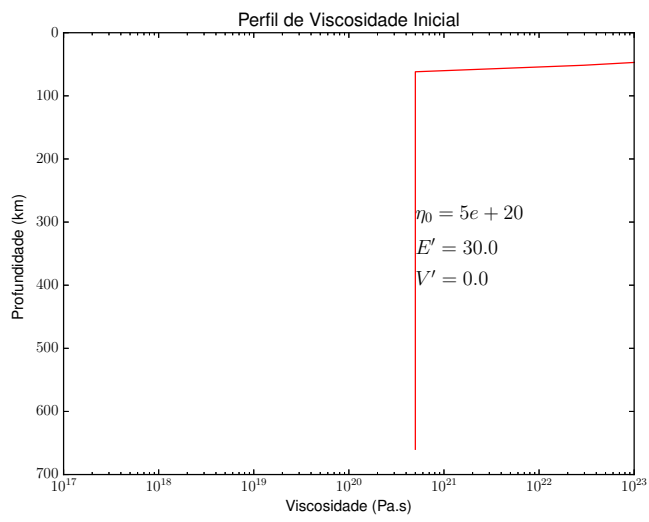

(a)

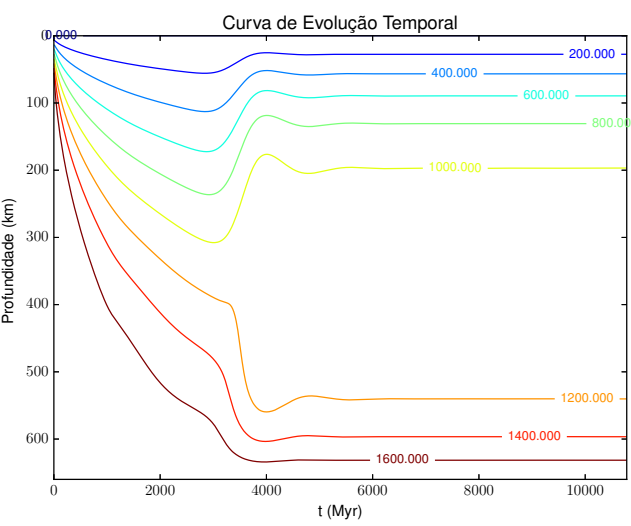

(b)

Figura 7.5: (a) Perfil de Viscosidade e (b) Curva de evolução temporal para o modelo com $\eta_{0}=$ $5 \times 10^{20} \mathrm{~Pa} \cdot \mathrm{s}, E^{\prime}=30$ e $V^{\prime}=0$.

A Figura 7.5 permite obter uma estimativa da espessura em que a litosfera se estabiliza no decorrer do tempo. Segundo Schubert et al. (2001) a litosfera pode ser definida por rochas que não se deformam em mais de $1 \%$ em $10^{8}$ yr à tensão típicas do manto (1 MPa), sendo que este limite para a base da litosfera é usualmente marcado por uma isoterma, por exemplo de 1400 K. É importante destacar que este valor não é bem fixado, e neste trabalho o limite térmico entre litosfera e astenosfera será assumido como sendo a isoterma de $1300^{\circ} \mathrm{C}$. Assim, para o modelo apresentado na Figura 7.5 observa-se que a litosfera se espessou até a base do modelo, sendo irreal em comparação com os valores observados no planeta Terra.

Na Figura 7.6, encontra-se as curvas de evolução temporal e o perfil de viscosidade para um modelo com $\eta_{0}=3 \times 10^{20} \mathrm{~Pa} \cdot \mathrm{s}, E^{\prime}=20$ e $V^{\prime}=5$. A partir desta figura verifica-se que a litosfera está estabilizada a uma profundidade de aproximadamente $200 \mathrm{~km}$.

Nas Figuras 7.5 e 7.6 é possível identificar dois gradientes térmicos em seus extremos e uma porção central com temperatura praticamente constante, o que está de acordo com o observado por Petersen et al. (2010).

Na Figura 7.7 se encontram o perfil de viscosidade e a evolução temporal do modelo com $\eta_{0}=1 \times 10^{20} \mathrm{~Pa} \cdot \mathrm{s}, E^{\prime}=20$ e $V^{\prime}=5$. Esse foi o modelo em que se obteve a litosfera estável mais fina, sendo que a espessura da litosfera foi calculada em $129 \mathrm{~km}$.

Para facilitar a comparação entre todos os modelos estimou-se a profundidade da isoterma de $1300^{\circ} \mathrm{C}$ para todos os modelos em que foi possível obter uma litosfera estabilizada após o início da simulação numérica (Figura 7.8). Todos os modelos foram simulados por 


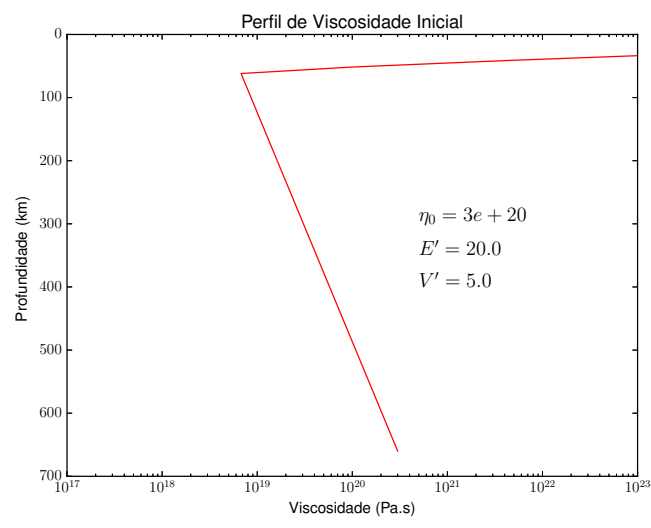

(a)

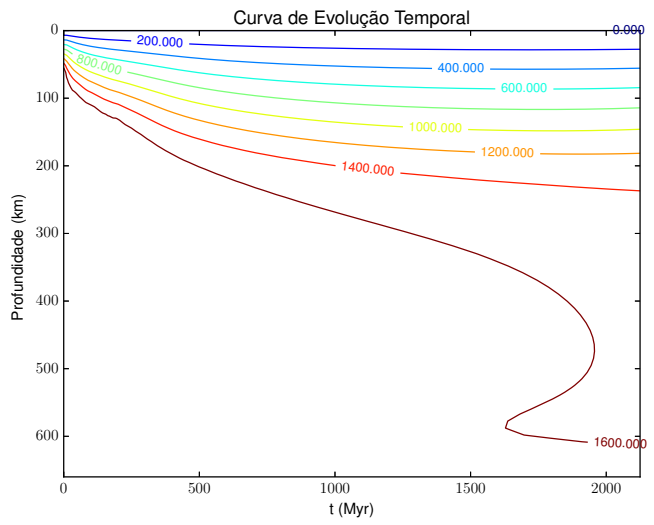

(b)

Figura 7.6: (a) Perfil de Viscosidade e (b) Curva de evolução temporal para o modelo com $\eta_{0}=$ $3 \times 10^{20} \mathrm{~Pa} \cdot \mathrm{s}, E^{\prime}=20$ e $V^{\prime}=5$.

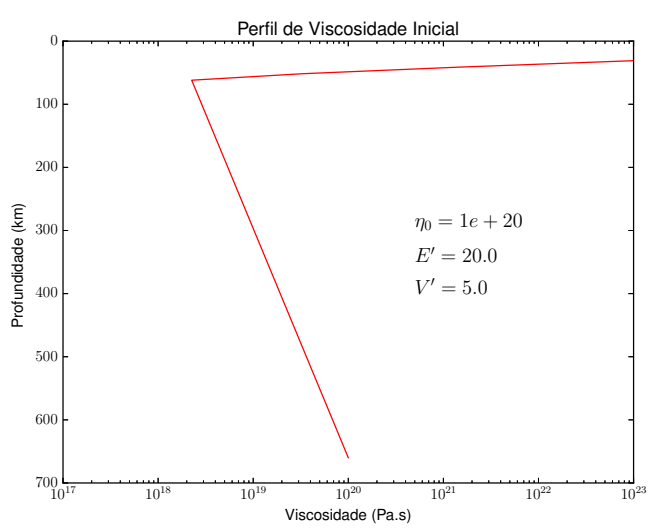

(a)

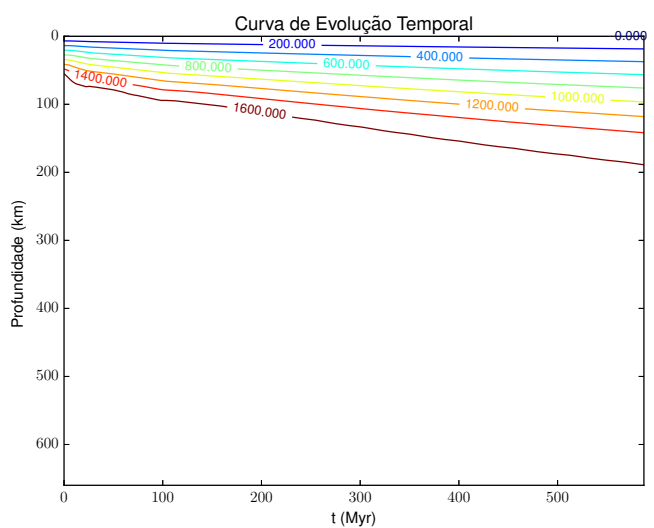

(b)

Figura 7.7: (a) Perfil de Viscosidade e (b) Curva de evolução temporal para o modelo com $\eta_{0}=$ $1 \times 10^{20} \mathrm{~Pa} \cdot \mathrm{s}, E^{\prime}=20$ e $V^{\prime}=5$. 


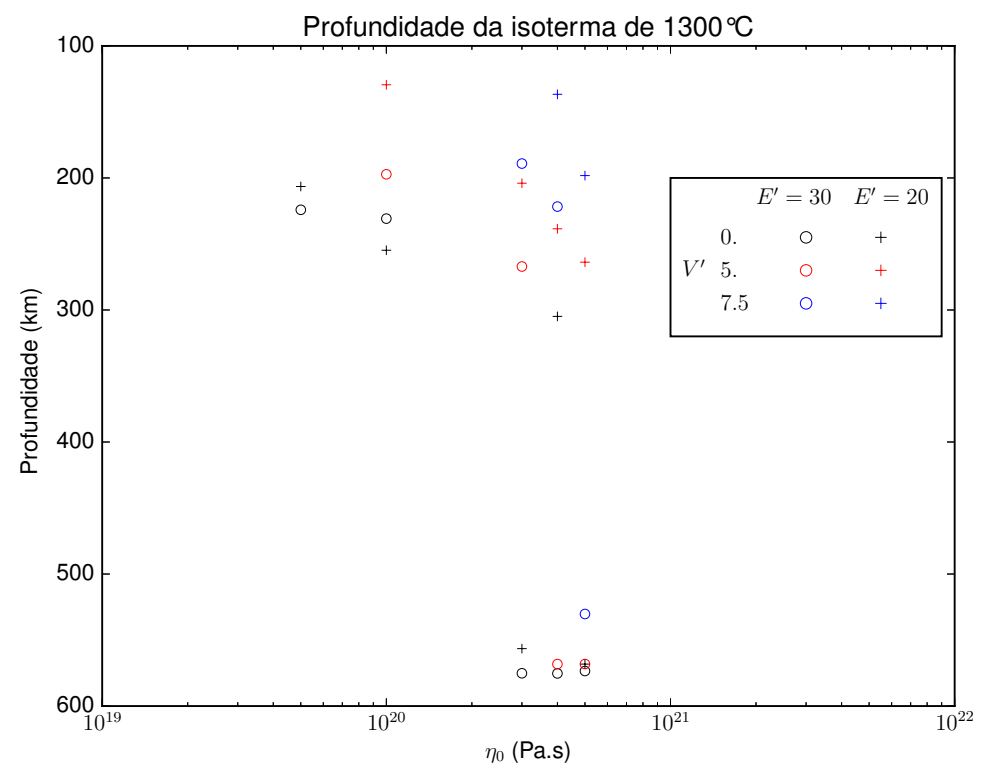

Figura 7.8: Profundidade da isoterma de $1300^{\circ} \mathrm{C}$ para todos os modelos que obtiveram uma litosfera estável durante o tempo de simulação.

10000 iterações, porém a escala de tempo varia de acordo com o perfil de viscosidade inicial do modelo. Isso ocorre pois o software calcula internamente o passo de tempo de modo a garantir a convergência da solução numérica, variando entre as simulações.

As Tabelas 7.2 e 7.3 apresentam os valores obtidos para a profundidade da isoterma de $1300^{\circ} \mathrm{C}$ para os modelos que atingiram uma litosfera estável. Os modelos que não obtiveram uma litosfera estável durante o tempo de simulação foram representados com um traço. Para os modelos com viscosidade muita baixa, não foi possível obter uma litosfera estável pois o passo de tempo para estes modelos é muito pequeno e se torna inviável realizar a simulação até que se possa garantir que a litosfera alcance um regime estável.

Tabela 7.2 - Profundidade da Isoterma de $1300^{\circ} \mathrm{C}$ para os modelos estáveis com $E^{\prime}=20$. Os modelos que não obtiveram uma litosfera estável durante a simulação foram representados com um traço.

\begin{tabular}{|l|llllll}
\multicolumn{1}{c}{} & \multicolumn{7}{c}{$\eta_{0}(\mathrm{~Pa} \cdot \mathrm{s})$} \\
\cline { 2 - 7 }$V^{\prime}$ & $5 \times 10^{19}$ & $1 \times 10^{20}$ & $3 \times 10^{20}$ & $4 \times 10^{20}$ & $5 \times 10^{20}$ \\
\hline 0 & $206 \mathrm{~km}$ & $254 \mathrm{~km}$ & $556 \mathrm{~km}$ & $304 \mathrm{~km}$ & $568 \mathrm{~km}$ \\
5 & - & $129 \mathrm{~km}$ & $203 \mathrm{~km}$ & $238 \mathrm{~km}$ & $263 \mathrm{~km}$ \\
7.5 & - & - & - & $136 \mathrm{~km}$ & $198 \mathrm{~km}$ \\
10 & - & - & - & - & - \\
12.5 & - & - & - & - & - \\
15 & - & - & - & - & -
\end{tabular}


Tabela 7.3 - Profundidade da Isoterma de $1300^{\circ} \mathrm{C}$ para os modelos estáveis com $E^{\prime}=30$. Os modelos que não obtiveram uma litosfera estável durante a simulação foram representados com um traço.

\begin{tabular}{|l|llllll}
\multicolumn{1}{c|}{} & \multicolumn{7}{c}{$\eta_{0}(\mathrm{~Pa} \cdot \mathrm{s})$} \\
\cline { 2 - 7 }$V^{\prime}$ & $5 \times 10^{19}$ & $1 \times 10^{20}$ & $3 \times 10^{20}$ & $4 \times 10^{20}$ & $5 \times 10^{20}$ \\
\hline 0 & $224 \mathrm{~km}$ & $230 \mathrm{~km}$ & $575 \mathrm{~km}$ & $575 \mathrm{~km}$ & $573 \mathrm{~km}$ \\
5 & - & $197 \mathrm{~km}$ & $267 \mathrm{~km}$ & $568 \mathrm{~km}$ & $568 \mathrm{~km}$ \\
7.5 & - & - & $189 \mathrm{~km}$ & $221 \mathrm{~km}$ & $530 \mathrm{~km}$ \\
10 & - & - & - & - & - \\
12.5 & - & - & - & - & - \\
15 & - & - & - & - & -
\end{tabular}

Através da Figura 7.8 é possível verificar que quando utiliza-se uma viscosidade menor para a base do modelo, a profundidade da isoterma de $1300^{\circ} \mathrm{C}$ também diminuirá.

Pode-se observar também, que valores menores de energia de ativação resultam em afinamento litosférico, isto ocorre, pois esta energia de ativação atua como uma barreira potencial, dificultando a existência de processos convectivos no manto astenosférico. No nível atômico, os movimentos de convecção do manto se dão por átomos migrando dentro dos cristais das rochas sob um certo campo de tensão. A este fenômeno é dado o nome de arrasto por difusão e é um dos processos responsáveis pelo comportamento fluido do manto.

Os espaços vazios por onde os átomos migram são originários de imperfeições na estrutura cristalina dos minerais. A energia $E^{\prime}$ é a energia mínima necessária para que um cristal consiga migrar da sua posição para um destes espaços vagos, sendo assim, quando se diminui o valor de $E^{\prime}$ facilita-se a ocorrência deste processo.

Analisando o volume de ativação $V^{\prime}$, observa-se que quando o volume de ativação é muito baixo, ocorre um espessamento da litosfera. Isso se dá pois quando o volume de ativação é muito pequeno, a viscosidade deixa de variar com a profundidade, e isso faz com que a viscosidade no interior do modelo seja muito alta dificultando assim a ocorrência de processos convectivos.

É importante notar que nestes modelos não estão inclusos o calor radiogênico do manto. Ao se considerar a contribuição desta componente, espera-se que todas as isotermas sejam elevadas. Apesar do manto possuir uma concentração de elementos radiogênicos muito menor do que na crosta terrestre, o calor gerado pelo decaimento desses elementos contribuirá 
para o aumento da temperatura interna da Terra. Também deve-se notar que os modelos não incorporam variações composicionais, sendo assim a viscosidade só possui dependência com a temperatura e pressão. 
Capítulo 8

\section{Efeito dos Processos Convectivos da Astenosfera na Subsidência de Bacias de Margens Divergentes}

Neste capítulo será apresentada a influência dos processos convectivos presentes no manto astenosférico, na subsidência de bacias sedimentares de margens divergentes.

Os modelos numéricos de bacias sedimentares de margens divergentes são amplamente utilizados pela indústria petrolífera. Entretanto, atualmente ainda são predominantemente utilizados modelos que consideram apenas a condução térmica de calor baseado em trabalhos como Mckenzie (1978) e Steckler e Watts (1980).

Como descrito no capítulo 2, o modelo de Mckenzie (1978) é um modelo simplista que incorpora apenas a condução térmica em uma dimensão. Steckler e Watts (1980) também desenvolveram um modelo puramente condutivo, entretanto eles consideraram a variação lateral de temperatura.

Para avaliar o efeito não apenas da condução térmica mas também da convecção mantélica, foram simulados cenários numéricos da dinâmica mantélica em uma representação bidimensional no contexto de margens divergentes, de modo que seja possível realizar uma comparação com outros modelos presentes na literatura (Mckenzie, 1978; Steckler e Watts, 1980).

\subsection{Estiramento da Litosfera}

Até o momento, todos os modelos deste trabalho foram simulados a partir de uma mesma estrutura térmica inicial, observando sua evolução temporal. Entretanto, para simular cenários no contexto de margens divergentes, é necessário que em um dado instante de tempo a litosfera sofra um estiramento. 


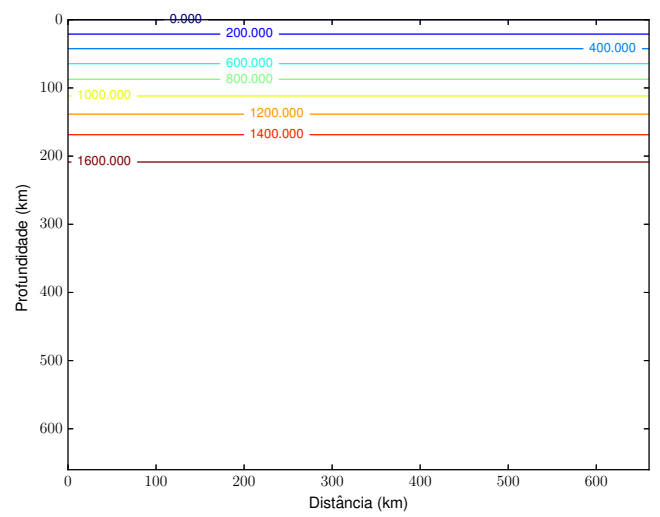

(a) Litosfera não estirada.

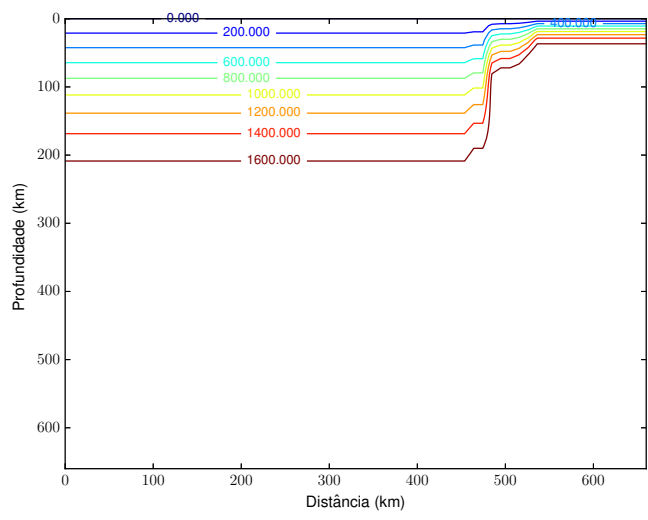

(b) Litosfera estirada.

Figura 8.1: Representação esquemática da isoterma da litosfera não estirada e a litosfera estirada através da equação 8.1 .

Este estiramento deve ser feito de maneira que a base da porção estirada da litosfera mantenha a mesma temperatura da base da litosfera não estirada. Isso pode ser realizado através de uma transformação linear dada pela seguinte equação

$$
\begin{array}{cl}
T(h)=T_{0}(h \beta) & , \quad 0 \leq h<\frac{L}{\beta} \\
T(h) & =T_{0}\left(h^{\prime}\right) \quad, \quad \frac{L}{\beta} \leq h<H
\end{array}
$$

onde $T(h)$ é a temperatura após a aplicação da transformação, $T_{0}(h)$ é a temperatura da estrutura térmica não estirada, $h$ é a profundidade, $H$ é a profundidade total do modelo, $\beta$ é o fator de estiramento, $L$ é a espessura da litosfera não estirada e $h^{\prime}$ é dado por

$$
h^{\prime}=\frac{H-L}{H-\frac{L}{\beta}}\left(h-\frac{L}{\beta}\right)+L
$$

A Figura 8.1 é uma representação esquemática de como essa transformação modifica a estrutura térmica inicial.

Para que a comparação entre os modelos apresentados neste trabalho, e os modelos apresentados por Mckenzie (1978) e por Steckler e Watts (1980) seja possível, é necessário que sejam utilizados o mesmo perfil do fator de estiramento $\beta$ utilizado por Steckler e Watts (1980), e a mesma espessura de litosfera utilizada por Mckenzie (1978) e Steckler e Watts (1980). A Figura 8.2 apresenta o perfil de $\beta$ utilizado, juntamente com a posição dos poços utilizados por Steckler e Watts (1980).

No capítulo 7, realizou-se um estudo sobre a estabilidade da litosfera, através da variação de parâmetros como a energia de ativação, o volume de ativação e a viscosidade inicial do modelo, verificando assim a profundidade na qual a litosfera se encontra. 


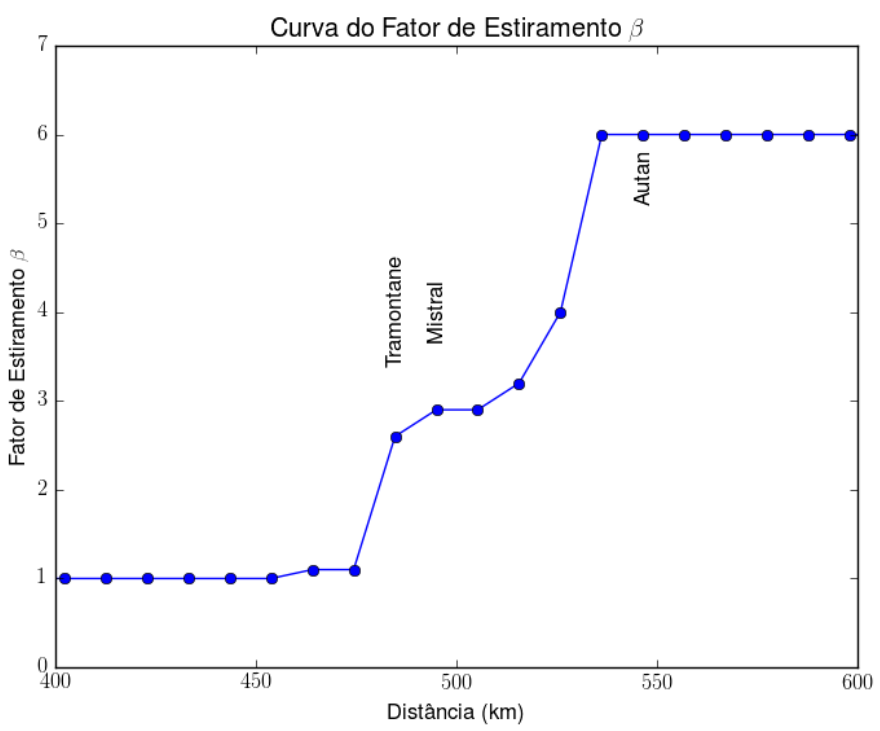

Figura 8.2: Perfil do fator de estiramento $\beta$. Estão representadas as posições das três estações utilizados por Steckler e Watts (1980).

Assim, com o auxílio da Figura 7.8 identificou-se os modelos que obtiveram espessura da litosfera da ordem de $125 \mathrm{~km}$ conforme foi utilizado por Mckenzie (1978) e Steckler e Watts (1980). Optou-se por utilizar todos os modelos que apresentaram espessura para a litosfera entre 120 km e $270 \mathrm{~km}$, valores razoáveis para a litosfera continental não estirada.

\subsection{Cálculo da Subsidência}

Para a obtenção da taxa de subsidência na margem estirada, calculou-se a compensação isostática local (Turcotte e Schubert, 2014) para cada uma das estações apresentadas no trabalho de Steckler e Watts (1980)

$$
w=\frac{\alpha \rho_{m}}{\left(\rho_{m}-\rho_{\text {sed }}\right)} \int\left(T_{1}-T_{2}\right) d h
$$

onde $T_{1}$ e $T_{2}$ são as temperaturas do modelo em dois instantes de tempo diferentes, $\rho_{m}$ e $\rho_{\text {sed }}$ são respectivamente a densidade do manto e a densidade dos sedimentos preenchendo a bacia, $\alpha$ é o coeficiente de expansão volumétrico e a integral é calculada entre o topo e a base do modelo para uma certa posição da margem. Neste trabalho considerou-se uma bacia preenchida com água com densidade $\rho_{w}$. Logo, a equação acima pode ser escrita como

$$
w=\frac{\alpha \rho_{m}}{\left(\rho_{m}-\rho_{w}\right)} \int\left(T_{1}-T_{2}\right) d h
$$


Tabela 8.1 - Valores dos parâmetros utilizados para o cálculo da subsidência. Estes valores foram baseados em valores apresentados por Schubert et al. (2001).

\begin{tabular}{ll}
\hline$\rho_{m}$ & $3300 \mathrm{~kg} / \mathrm{m}^{3}$ \\
$\rho_{w}$ & $1000 \mathrm{~kg} / \mathrm{m}^{3}$ \\
$H$ & $660 \mathrm{~km}$ \\
$\alpha$ & $3 \times 10^{-5} \mathrm{~K}^{-1}$ \\
\hline
\end{tabular}

A Tabela 8.1 apresenta os valores das constantes utilizados para os modelos. Os valores utilizados foram assumidos baseando-se nos valores apresentados em Schubert et al. (2001).

\subsection{Comparação da Taxa de Subsidência com os Modelos Puramente Condutivos}

Nas Figuras 8.3(a-c) apresentamos a comparação entre as curvas de subsidência obtidas por Mckenzie (1978) e Steckler e Watts (1980) com as obtidas para um modelo com $\eta_{0}=$ $1 \times 10^{20} \mathrm{~Pa} \cdot \mathrm{s}, E^{\prime}=20$ e $V^{\prime}=5$. A espessura inicial da litosfera para este modelo foi de $129 \mathrm{~km}$, um valor bem próximo do valor utilizado por Mckenzie (1978) e Steckler e Watts (1980). Através destas figuras verifica-se que o modelo que incorpora a presença de processos convectivos apresenta uma taxa de subsidência menor para todos os três poços. Esta redução na taxa de subsidência está relacionada com a presença de movimentos convectivos que mantém a base da litosfera aquecida por mais tempo.

Observa-se também que a taxa de subsidência não possui um perfil monotônico como nos modelos puramente condutivos, apresentando oscilações ao longo do tempo. Isto ocorre devido a perturbações na base da litosfera causadas pelos movimentos convectivos na astenosfera e estão relacionados com a topografia dinâmica no sentido que a convecção sob a litosfera afinada induz tensões na base da mesma, deslocando-a para cima e para baixo ao longo do tempo. Quanto menor a viscosidade da astenosfera, maior será o vigor da convecção, induzindo maiores perturbações na litosfera.

Como elas induzem deslocamentos para cima e para baixo, elas podem criar espaço de acomodação em um momento e em outro expor os sedimentos em ambiente sub-aéreo, induzindo erosão, criando uma discordância erosiva. Desse modo essas perturbações modificam a evolução estratigráfica da bacia (Petersen et al., 2010). 
As Figuras 8.4(a-d) apresentam a estrutura térmica e o campo de velocidades obtidos para o modelo em determinados instantes de tempo após o inicio da simulação. Através destas figuras pode-se verificar um aumento na temperatura na região mais próxima a margem. Isto pode explicar porque a variação na taxa de subsidência é mais expressiva nos poços mais próximos a margem do que no poço mais distal. Observa-se também a formação de uma célula de convecção induzida pelo gradiente horizontal de temperatura entre a litosfera estirada e não-estirada. O movimento desta célula de convecção é descendente próximo a borda do continente, levando o manto astenosférico frio para baixo, enquanto em uma porção mais distal há a subida de manto astenosférico aquecido para a base da litosfera continental afinada. O vigor desta célula decresce com a diminuição do contraste térmico horizontal.

As Figuras 8.5(a-c) apresentam a comparação entre as curvas de subsidência para um modelo com $\eta_{0}=4 \times 10^{20}, E^{\prime}=20$ e $V^{\prime}=7.5$. Este modelo partiu de uma litosfera com espessura inicial de $136 \mathrm{~km}$. Neste modelo, também é possível verificar que a presença de processos convectivos reduzem a taxa de subsidência da bacia sedimentar. Nas Figuras 8.6(a-d) são apresentadas as estruturas térmicas juntamente com o campo de velocidades para alguns instantes desse modelo. A célula convectiva presente abaixo da região estirada faz com que a base da litosfera esteja sempre em contato com um material mais quente, esse processo faz com que a base da litosfera fique aquecida por mais tempo diminuindo a taxa de subsidência

Na Figura 8.5(a) podemos perceber que a subsidência do modelo proposto aqui tende a ser maior do que a obtida por Steckler e Watts (1980) pois este poço é bem próximo a margem e sofre grande influência da condução lateral de calor porém, devido célula de convecção presente na astenosfera (Figuras 8.6(a-d)) ocorre uma diminuição na taxa de subsidência mesmo com uma litosfera mais espessa do que a utilizada por Steckler e Watts (1980).

A comparação das curvas de subsidência para o modelo com $\eta_{0}=5 \times 10^{20}, E^{\prime}=20$ e $V^{\prime}=7.5$ estão apresentadas nas Figuras 8.7(a-c). Este modelo foi simulado a partir de uma litosfera com espessura inicial de $198 \mathrm{~km}$.

Através da Figura 8.7(a) podemos verificar que a subsidência se deu de maneira mais rápida do que a calculada por Steckler e Watts (1980).

Nas Figuras 8.8(a-d) são apresentadas as estruturas térmicas juntamente com o campo 


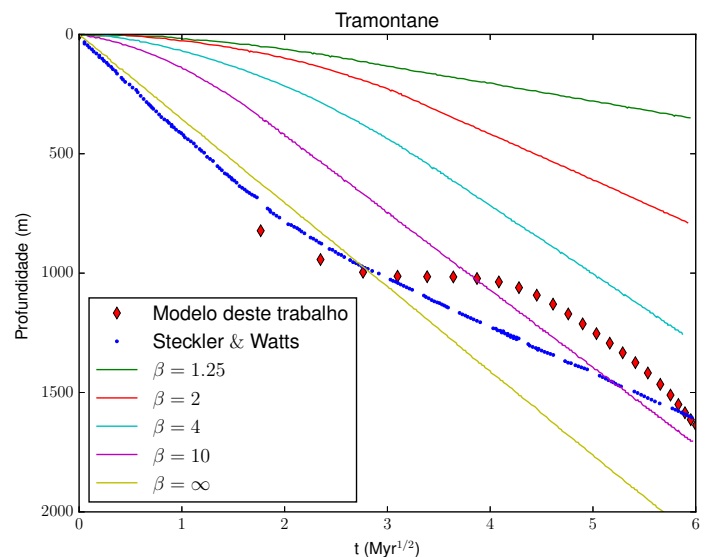

(a) Curvas de subsidência para o poço de Tramontane.

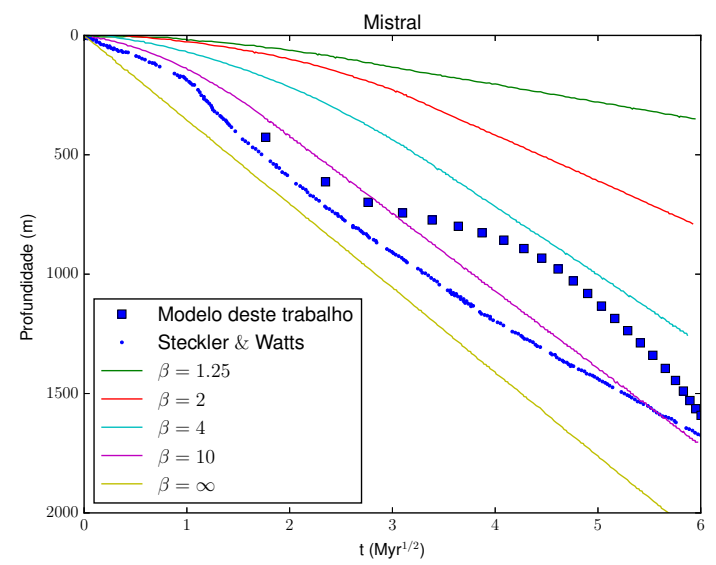

(b) Curvas de subsidência para o poço de Mistral.

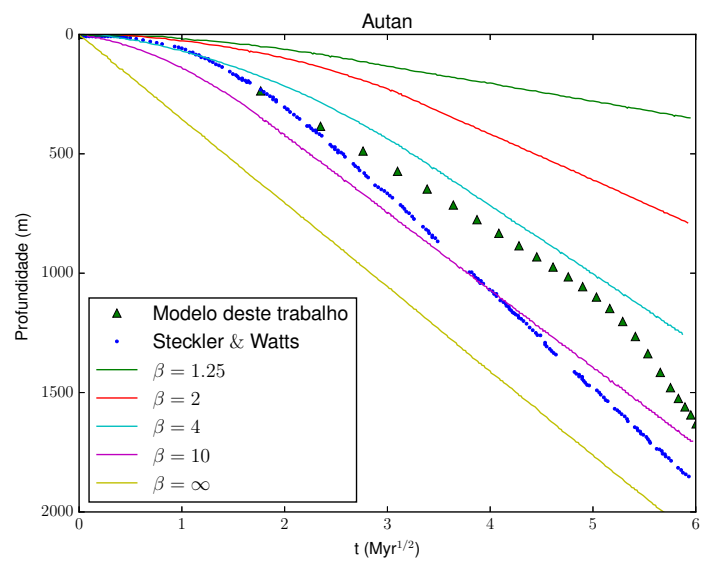

(c) Curvas de subsidência para o poço de Autan.

Figura 8.3: Comparação das curvas de subsidência entre os modelos de Mckenzie (1978), Steckler e Watts (1980) e os apresentados neste trabalho para o modelo com $\eta_{0}=1 \times 10^{20}$, $E^{\prime}=20$ e $V^{\prime}=5$. 


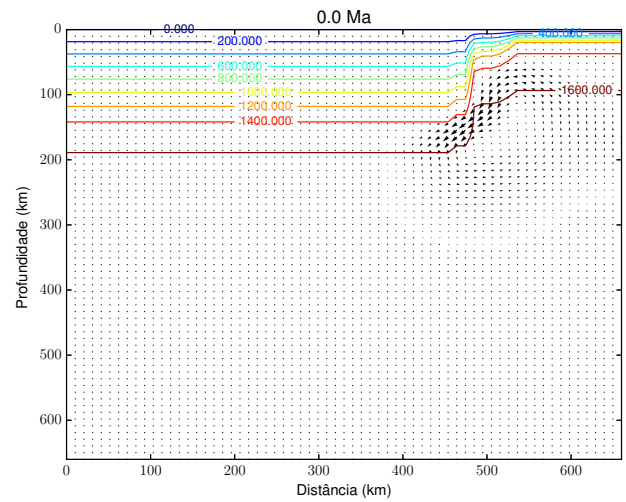

(a)

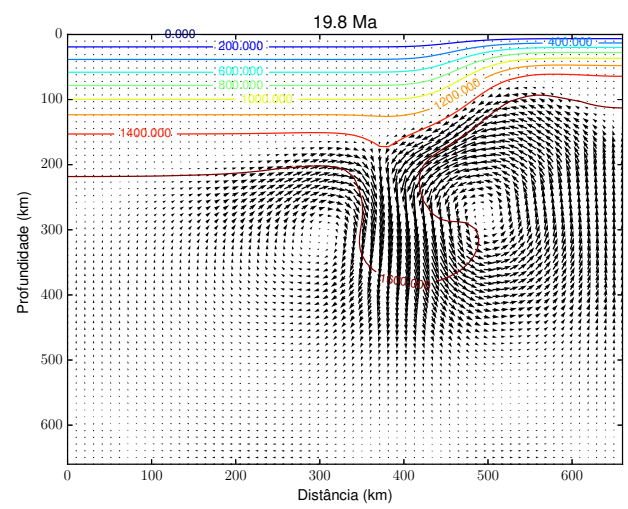

(c)

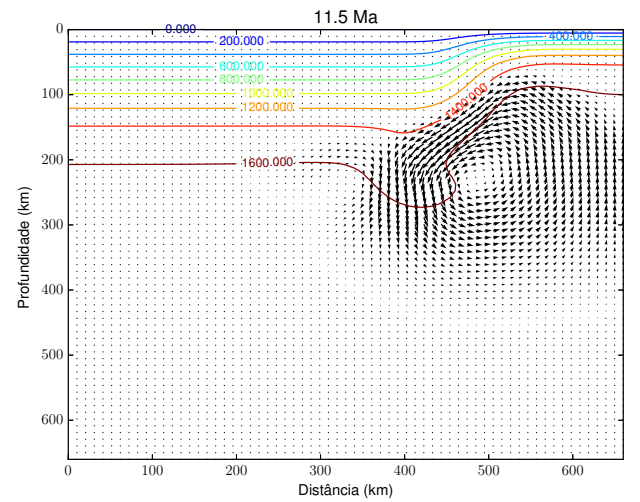

(b)

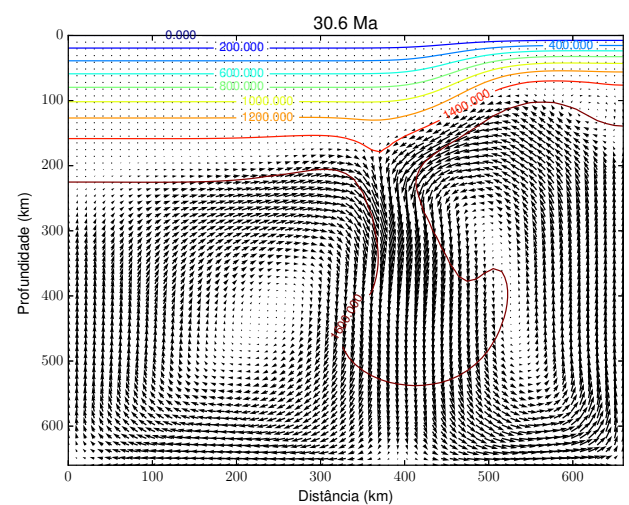

(d)

Figura 8.4: Estrutura térmica e campo de velocidades para o modelo com $\eta_{0}=1 \times 10^{20}, E^{\prime}=20$ e $V^{\prime}=5$. 


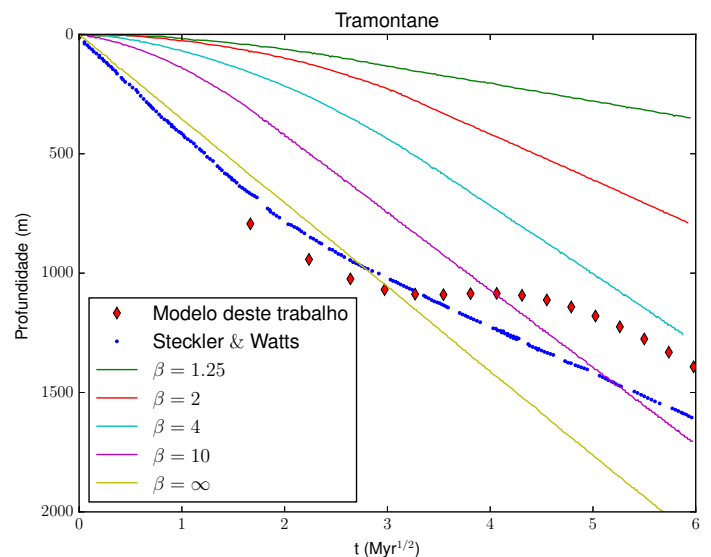

(a) Curvas de subsidência para o poço de Tramontane.

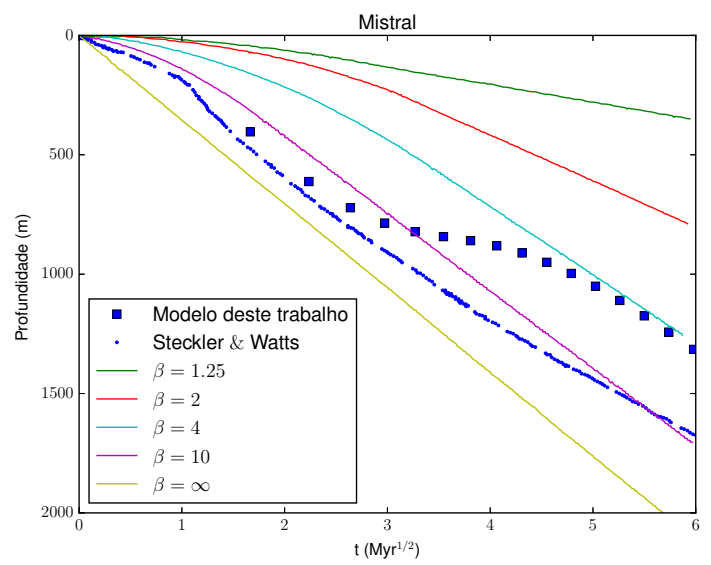

(b) Curvas de subsidência para o poço de Mistral.

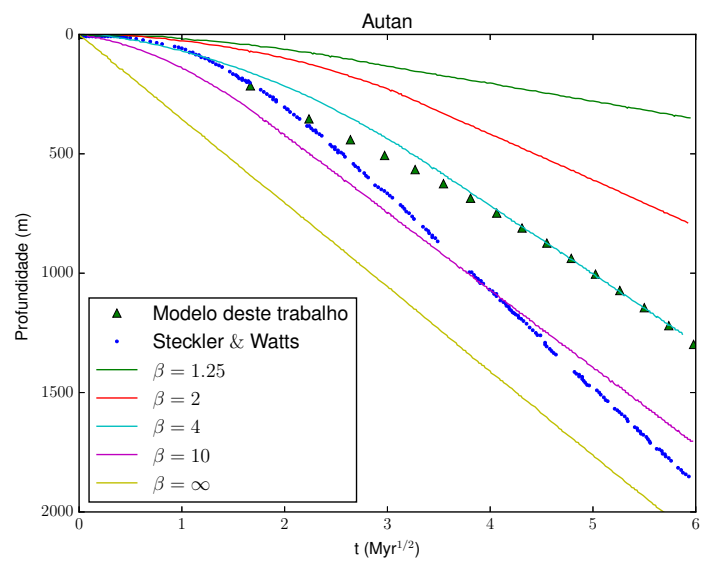

(c) Curvas de subsidência para o poço de Autan.

Figura 8.5: Comparação das curvas de subsidência entre os modelos de Mckenzie (1978), Steckler e Watts (1980) e os apresentados neste trabalho para o modelo com $\eta_{0}=4 \times 10^{20}$, $E^{\prime}=20$ e $V^{\prime}=7.5$. 


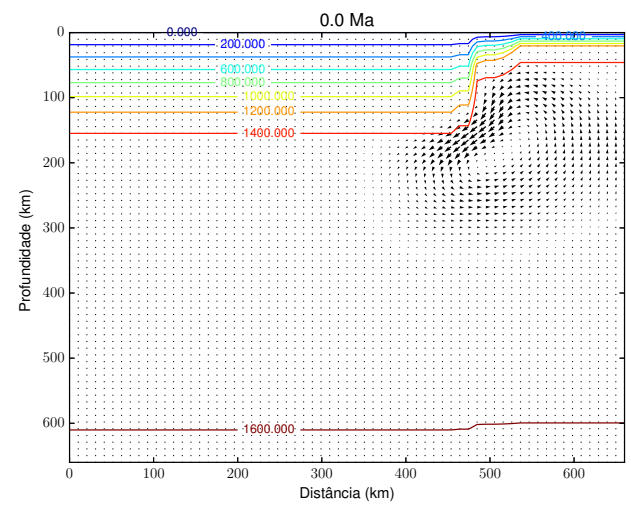

(a)

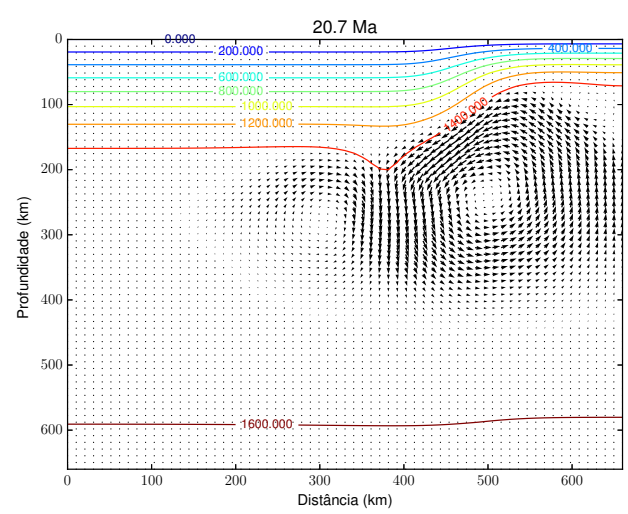

(c)

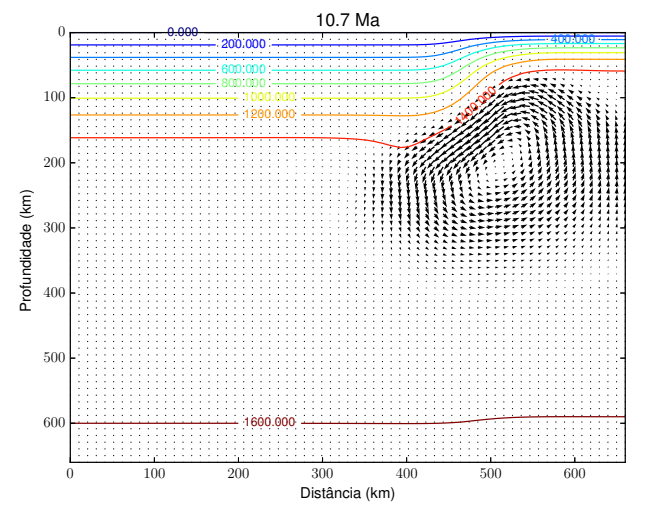

(b)

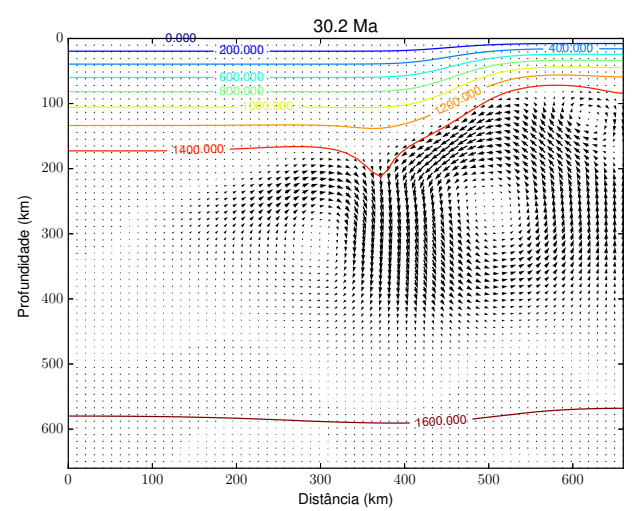

(d)

Figura 8.6: Estrutura térmica e campo de velocidades para o modelo com $\eta_{0}=4 \times 10^{20}, E^{\prime}=20$ e $V^{\prime}=7.5$. 
de velocidades para este modelo.

A comparação das curvas de subsidência para o modelo com $\eta_{0}=3 \times 10^{20}, E^{\prime}=30$ e $V^{\prime}=5$ estão apresentadas nas Figuras 8.9(a-c). Este modelo foi simulado a partir de uma litosfera com espessura inicial de $267 \mathrm{~km}$.

Assim como no modelo da Figura 8.3 a subsidência ocorreu mais rapidamente devido a maior interface de contato lateral.

Nas Figuras 8.10(a-d) são apresentadas as estruturas térmicas juntamente com o campo de velocidades. Pode-se perceber que neste modelo o movimento convectivo é muito pequeno e, portanto, o processo de subsidência é predominantemente controlado pela condução térmica. Entretanto, mesmo com o modelo sendo predominantemente condutivo foi possível obter uma subsidência menor do que a obtida por Steckler e Watts (1980) no poço mais distal como apresentado na Figura 8.9(c). 


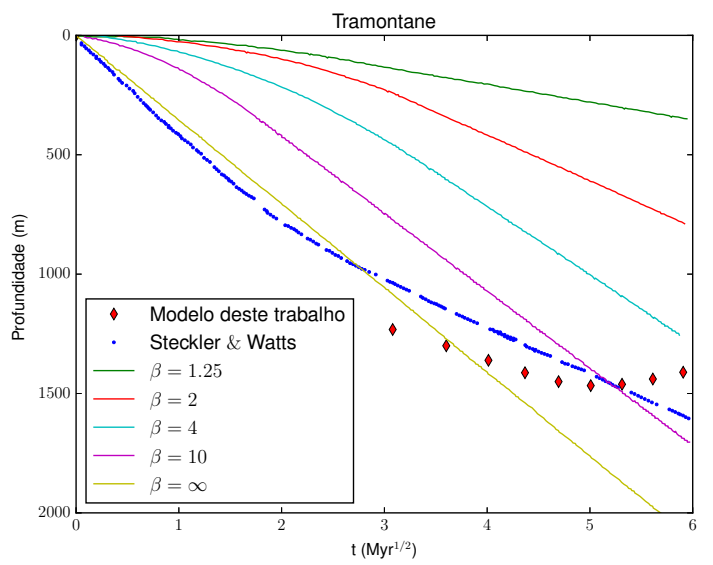

(a) Curvas de subsidência para o poço de Tramontane.

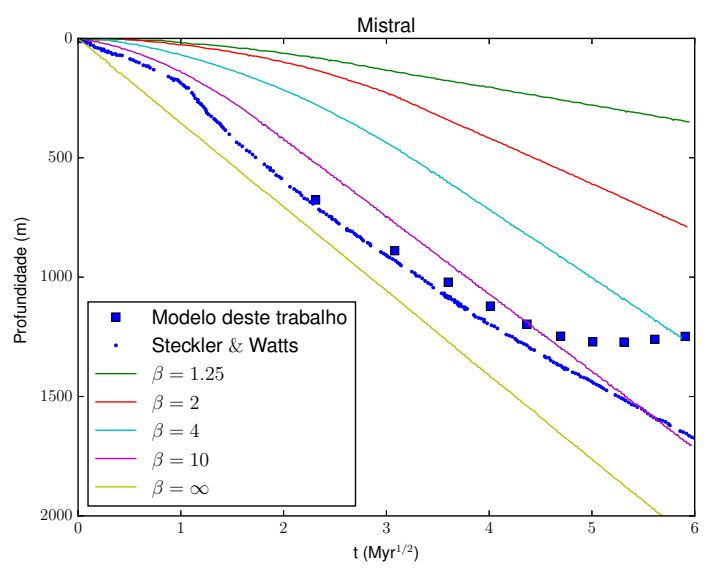

(b) Curvas de subsidência para o poço de Mistral.

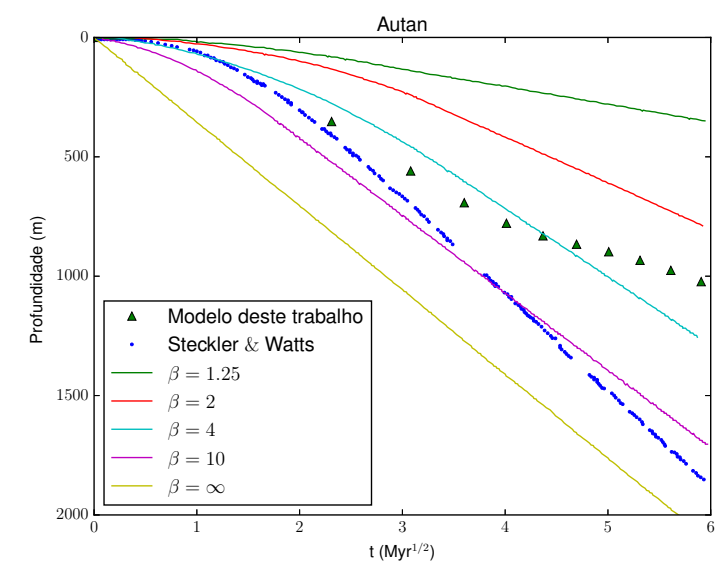

(c) Curvas de subsidência para o poço de Autan.

Figura 8.7: Comparação das curvas de subsidência entre os modelos de Mckenzie (1978), Steckler e Watts (1980) e os apresentados neste trabalho para o modelo com $\eta_{0}=5 \times 10^{20}$, $E^{\prime}=20$ e $V^{\prime}=7.5$. 


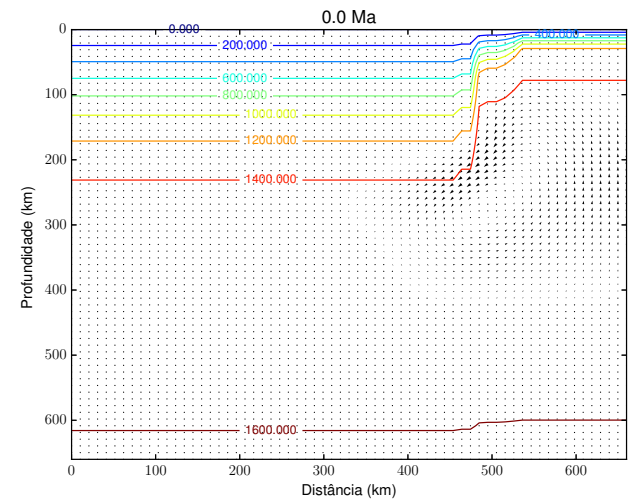

(a)

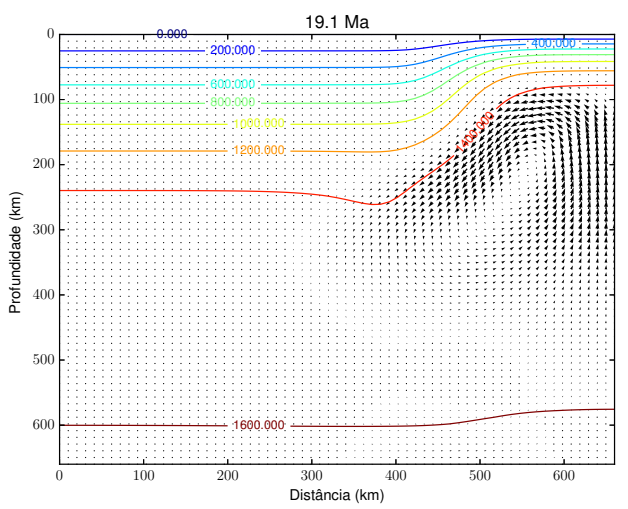

(c)

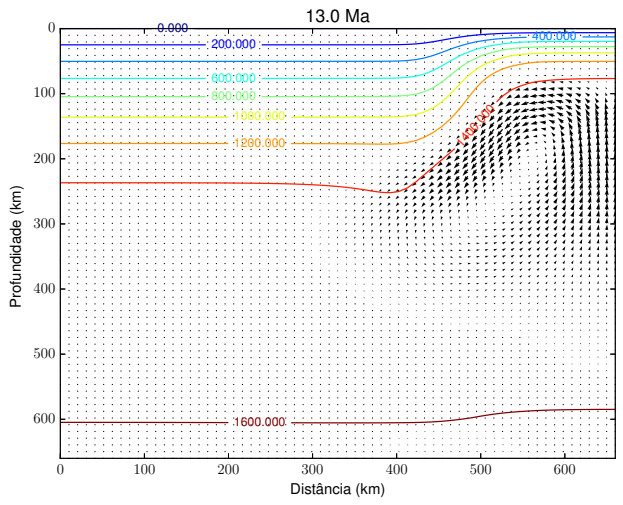

(b)

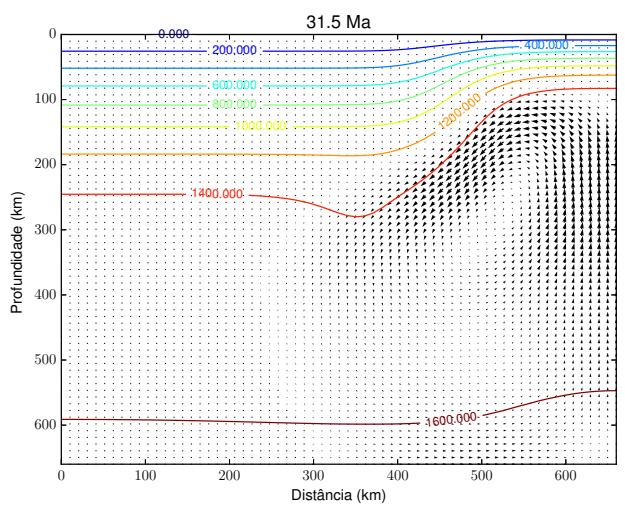

(d)

Figura 8.8: Estrutura térmica e campo de velocidades para o modelo com $\eta_{0}=5 \times 10^{20}, E^{\prime}=20$ e $V^{\prime}=7.5$. 


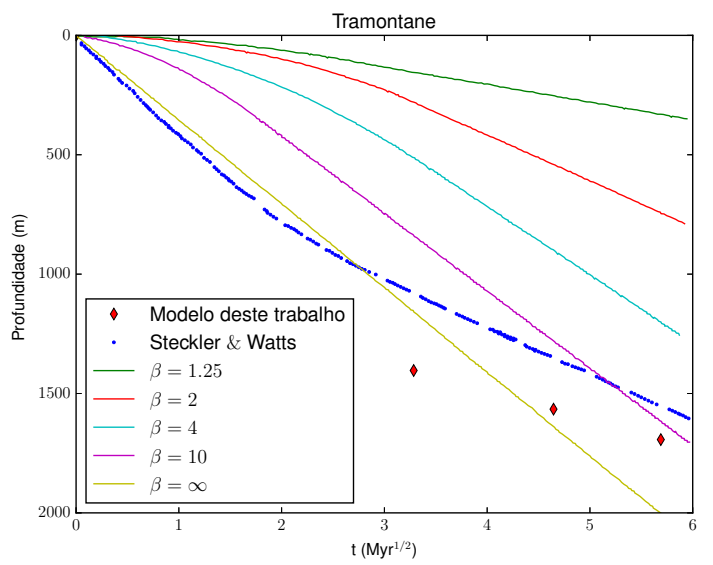

(a) Curvas de subsidência para o poço de Tramontane.

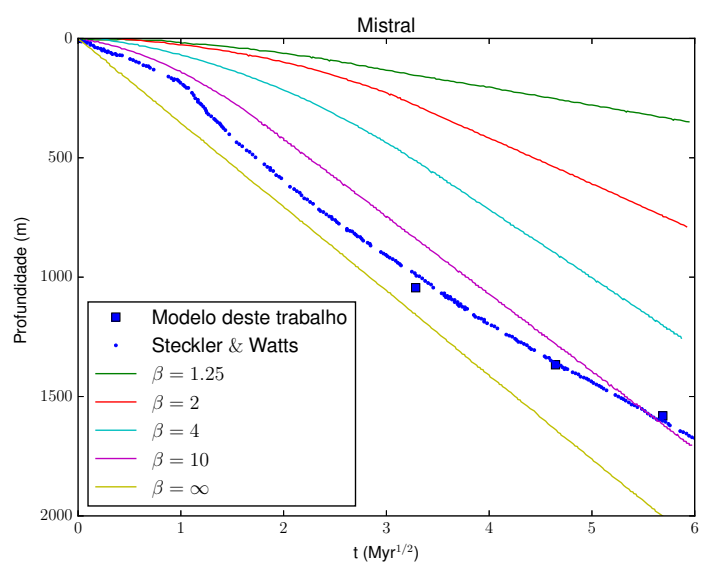

(b) Curvas de subsidência para o poço de Mistral.

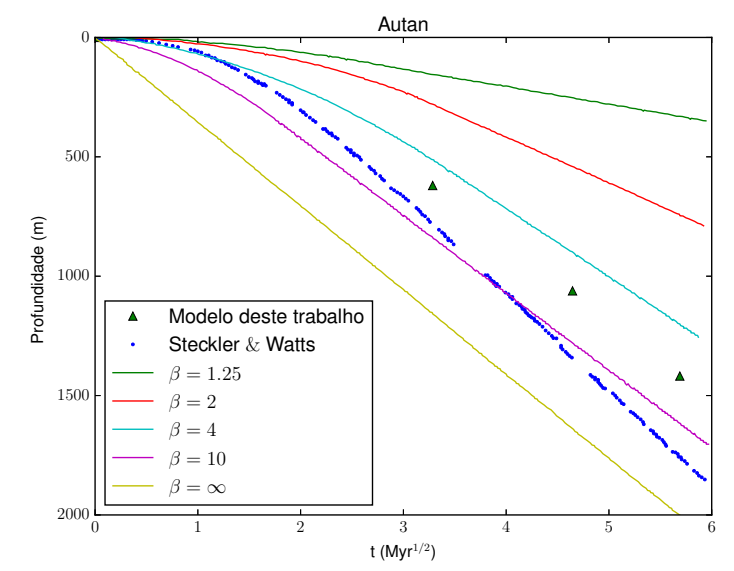

(c) Curvas de subsidência para o poço de Autan.

Figura 8.9: Comparação das curvas de subsidência entre os modelos de Mckenzie (1978), Steckler e Watts (1980) e os apresentados neste trabalho para o modelo com $\eta_{0}=3 \times 10^{20}$, $E^{\prime}=30$ e $V^{\prime}=5$. 


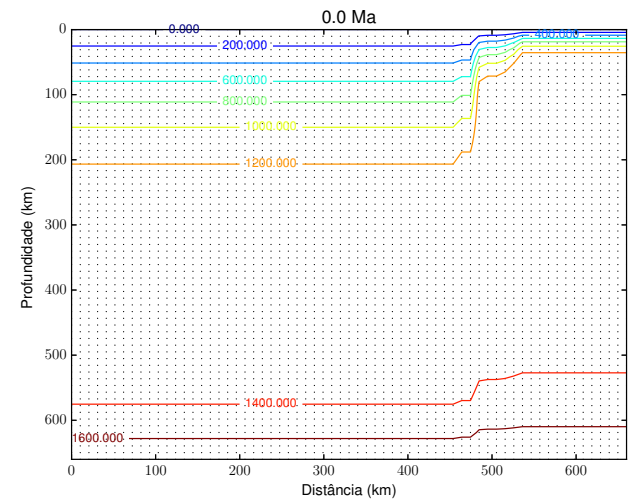

(a)

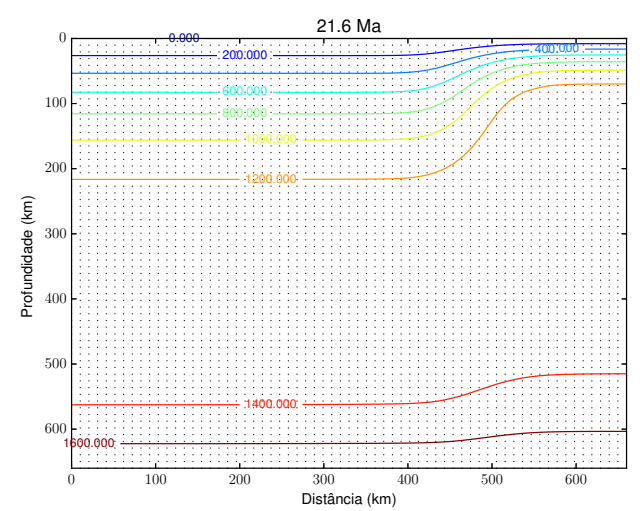

(c)

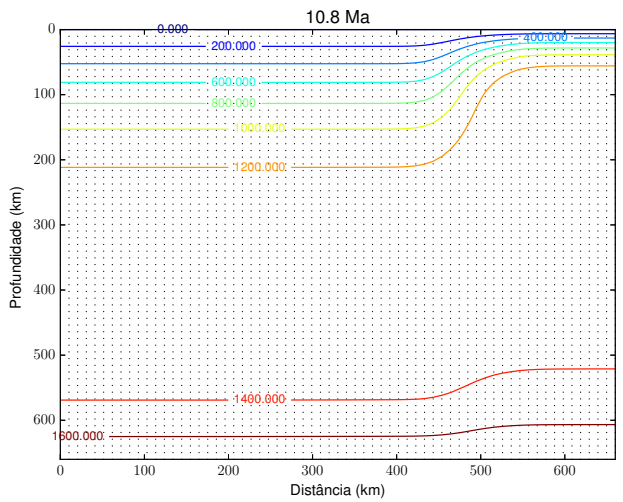

(b)

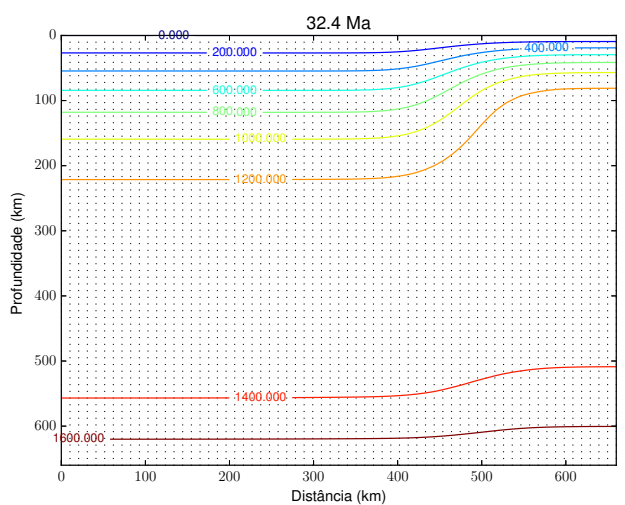

(d)

Figura 8.10: Estrutura térmica e campo de velocidades para o modelo com $\eta_{0}=3 \times 10^{20}, E^{\prime}=30$ e $V^{\prime}=5$. 


\subsection{Discussão}

Com os quatro cenários numéricos da dinâmica convectiva comparados com os modelos puramente condutivos da evolução da história de subsidência da bacia sedimentar do Golfo do Leão, observa-se que tanto os presentes modelos quanto o modelo condutivo $2 \mathrm{D}$ de Steckler e Watts (1980) foram capazes de reproduzir uma alta taxa de subsidência tectônica inicial com valores de $\beta$ mais realistas e inferiores aos previstos pelo modelo $1 \mathrm{D}$ de Mckenzie (1978). Desse modo, a análise dos parágrafos a seguir se concentrará na comparação dos modelos convectivos deste trabalho com o modelo condutivo de Steckler e Watts (1980).

Esses quatro cenários numéricos são representativos para os diferentes padrões de subsidência descritos nesta seção. Outros cenários compatíveis com estruturas reológicas diferentes são apresentados no Apêndice A.

Para os modelos convectivos com espessura inicial da litosfera de 129 e 136 km, a subsidência nos três pontos foi predominantemente inferior ao modelo de Steckler e Watts (1980). Isto ocorre pois, apesar de terem valores de espessura da litosfera equivalente, a componente convectiva no manto astenosférico traz calor para a base da litosfera afinada, fazendo com que a estrutura térmica da litosfera afinada permaneça aquecida por mais tempo do que no modelo puramente condutivo.

O aumento da espessura da litosfera, nos modelos com 198 e 267 km, resultou em uma maior superfície litosférica lateral em contato com a astenosfera, contribuindo para o aumento da subsidência do poço mais proximal, Tramontane. Nesses dois modelos, o poço intermediário (Mistral), obteve um melhor ajuste, porém o mais distal (Autan) continuou com uma taxa de subsidência inferior ao modelo de Steckler e Watts (1980) devido a uma estrutura térmica mais aquecida pelo movimento convectivo ascendente da astenosfera, atuando em oposição a perda de calor por condução.

Nas Figuras 8.3(a-c), 8.5(a-c) e 8.7(a-c) pode-se perceber uma grande variação na taxa de subsidência entre 9 e 16 Myr, chegando até a ocorrer um pequeno soerguimento na Figura 8.5(a). Essa variação coincide com a mesma época da discordância erosiva causada pela crise de salinidade ocorrida no final do Mioceno como apontada por Steckler e Watts (1980). Isso pode indicar que a dinâmica convectiva possa ter contribuído para o soerguimento dos sedimentos durante esta época e consequentemente contribuído para a perda de sedimentos pela erosão conforme mostra a Figura 8.11. 


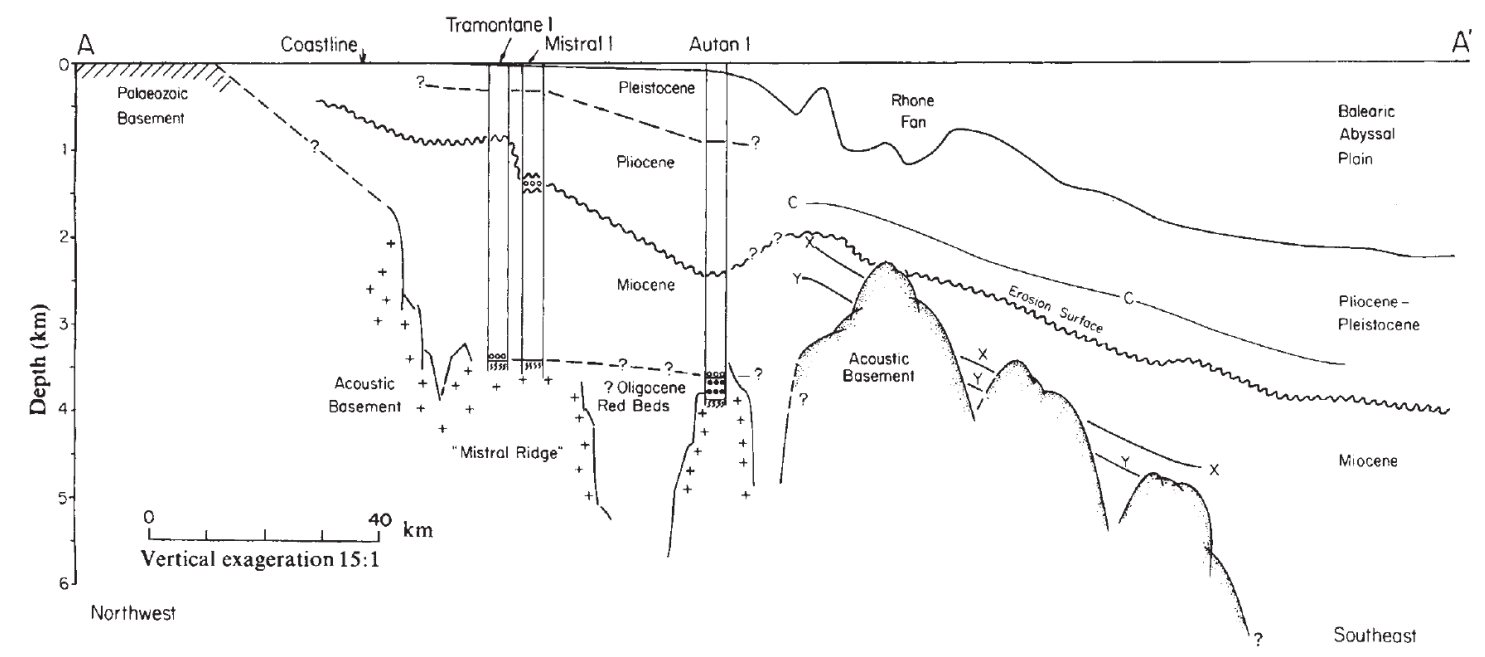

Figura 8.11: Geologia de um perfil através do Golfo de Leão. Modificada de Steckler e Watts (1980).

Artemieva (2006), através de um modelo térmico global, estimou que a espessura da litosfera na margem sudeste da França na porção não-estirada está entre $100-150$ km, compatível com o valor utilizado por Steckler e Watts (1980) e com os dois primeiros modelos convectivos do presente trabalho que obtiveram taxas de subsidência sistematicamente inferiores ao observado. Para compensar a baixa taxa de subsidência desses dois modelos, a seguir são apresentados alguns possíveis mecanismos: (1) geometria 3D da margem: a forma côncava da margem do Golfo de Leão poderia contribuir para o aumento da perda de calor para o continente, aumentando a taxa de subsidência da margem (Sacek e Ussami, 2013); (2) variação composicional da viscosidade: dados laboratoriais e experimentos numéricos indicam que o manto litosférico empobrecido em voláteis pode ser mais viscoso do que o manto astenosférico, alterando a dinâmica convectiva na borda do continente, podendo contribuir para o aumento da taxa de subsidência mesmo com litosferas mais finas (Doin et al., 1997); (3) diferença entre espessura litosférica térmica e reológica: a porção da litosfera que comporta-se como um sólido no tempo geológico não coincide necessariamente com a isoterma de $1300^{\circ} \mathrm{C}$, mas pode ser superior à litosfera térmica.

É importante notar que todos os modelos não consideraram a rigidez flexural para quantificar o deslocamento vertical da litosfera. Ao se considerar uma litosfera rígida, é 
de se esperar que estas feições sejam suavizadas. Além disso, ao se incorporar a rigidez flexural seria difícil explicar uma subsidência térmica tão expressiva do poço mais próximo do continente em uma distância menor do que $10 \mathrm{~km}$ da porção continental não estirada.

Assim uma melhor representação da evolução geodinâmica desta margem divergente deve incorporar uma complexidade geológica e geométrica maior do que a explorada neste trabalho, levando-se em consideração a geometria 3D real da margem, assim como uma estrutura reológica dependente da composição, além da compensação flexural da margem.

Isto mostra que, após décadas de estudo da evolução de margens divergentes, grandes desafios ainda existem para uma correta representação da física que rege a dinâmica dessas bacias. 
Capítulo 9

\section{Conclusão}

Os modelos numéricos apresentados aqui se mostraram úteis no estudo da evolução de margens divergentes. Através desses modelos foi possível avaliar a importância dos processos convectivos da astenosfera no processo de evolução de margens divergentes.

A análise da estabilidade da estrutura térmica da litosfera apresentada na Seção 7.2 foi de grande importância para o desenvolvimento do trabalho, garantindo que a estrutura térmica da litosfera não-estirada esteja em equilíbrio térmico. Além disso, esse estudo mostrou como os parâmetros reológicos como a viscosidade, energia de ativação e volume de ativação influenciam a espessura em que a litosfera se estabiliza.

Os resultados dos modelos numéricos apresentados na Seção 8.3 mostraram como a presença de processos convectivos no manto terrestre influenciam na evolução térmica e isostática de margens divergentes.

Nas Figuras 8.3(a-c), 8.5(a-c) e 8.7(a-c) pode-se verificar uma diminuição na taxa de subsidência do modelo convectivo comparando-se com os modelos puramente condutivos, apesar de terem uma espessura litosférica semelhante. Essa diminuição é decorrente do fato da litosfera permanecer aquecida por mais tempo devido as células de convecção presentes na astenosfera que carregam o material mais quente para a base da litosfera como pode-se perceber nas figuras 8.4(a-d),8.6(a-d) e 8.8(a-d).

É importante ressaltar que a única diferença dos modelos apresentados neste trabalho para os modelos puramente condutivos é a incorporação dos processos de convecção. Este modelo pode ser modificado futuramente para considerar a geometria tridimensional da margem do Golfo do Leão, que por possuir uma geometria côncava, pode contribuir para uma maior subsidência da margem (Sacek e Ussami, 2013) e também a incorporação da rigidez flexural para a litosfera que tende a suavizar as oscilações de pequenos comprimentos 
de onda presentes nos modelos convectivos.

Adicionalmente, testes numéricos que incorporem a variação composicional da viscosidade entre o manto litosférico e astenosférico poderão contribuir para melhorar a representação físico-matemática da dinâmica convectiva do manto e interação litosfera/astenosfera. 


\section{Referências Bibliográficas}

Allen P. A., Allen J. R., Basin Analysis - Principles and Applications 2nd edition, 2005, 562

Artemieva I. M., Global $1^{\circ} \times 1^{\circ}$ thermal model TC1 for the continental lithosphere: Implications for lithosphere secular evolution, Tectonophysics, 2006, vol. 416, p. 245

Braun J., Deschamps F., Rouby D., Dauteuil O., Flexure of the lithosphere and the geodynamical evolution of non-cylindrical rifted passive margins: Results from a numerical model incorporating variable elastic thickness, surface processes and 3D thermal subsidence, Tectonophysics, 2013, vol. 604, p. 72

Buck W. R., Small-scale convection induced by passive rifting: the cause for uplift of rift shoulders, Earth and Planetary Science Letters, 1986, vol. 77, p. 362

Christensen U., Heat transport by variable viscosity convection and implications for the Earth's thermal evolution, Physics of the Earth and Planetary Interiors, 1984, vol. 35, p. 264

Christensen U. R., The influence of trench migration on slab penetration into the lower mantle, Earth and Planetary Science Letters, 1996, vol. 140, p. 27

Christensen U. R., Influence of chemical buoyancy on the dynamics of slabs in the transition zone, Journal of Geophysical Research: Solid Earth, 1997, vol. 102, p. 22435

Doin M.-P., Fleitout L., Christensen U., Mantle convection and stability of depleted and undepleted continental lithosphere, Journal of Geophysical Research, 1997, vol. 102, p. 2771 
Farrington R. J., Stegman D. R., Moresi L. N., Sandiford M., May D. A., Interactions of 3D mantle flow and continental lithosphere near passive margins, Tectonophysics, 2010, vol. 483 , p. 20

Ismail-Zadeh A., Tackley P., Computational Methods for Geodynamics. No. 1, 2014, 1

Jarvis G. T., Mckenzie D. P., Sedimentary basin formation with finite extension rates, Earth and Planetary Science Letters, 1980, vol. 48, p. 42

King S. D., Anderson D. L., Edge-driven convection, Earth and Planetary Science Letters, 1998, vol. 160, p. 289

Landau L. D., Lifshitz E. M., Fluid Mechanics. vol. 6, 1987, 539

Lucazeau F., Leroy S., Bonneville A., Goutorbe B., Rolandone F., D'Acremont E., Watremez L., Düsünur D., Tuchais P., Huchon P., Bellahsen N., Al-Toubi K., Persistent thermal activity at the Eastern Gulf of Aden after continental break-up, Nature Geoscience, 2008, vol. 1, p. 854

Mckenzie D., Some remarks on the development of sedimentary basins, Earth and Planetary Science Letters, 1978, vol. 40, p. 25

Moresi L., Gurnis M., Constraints on lateral strength of slabs from 3-D dynamic flow models, Earth and Planetary Science Letters, 1996, vol. 138, p. 15

Petersen K. D., Nielsen S. B., Clausen O. R., Stephenson R., Gerya T. V., Small-scale mantle convection produces stratigraphic sequences in sedimentary basins, Science (New York, N.Y.), 2010, vol. 329, p. 827

Ranalli G., Rheology of the Earth. Springer Netherlands, 1995

Ricard Y., In Schubert G., (Ed.), Treatise on Geophysics, Volume 7. Mantle Dynamics 2nd edition, 2015 Elsevier Oxford pp $23-71$

Royden L., Keen C. E., Rifting Processes and thermal evolution of the continental margin of eastern Canada determined from subsidence curves, Earth and Planetary Science Letters, 1980, vol. 51, p. 343 
Sacek V., Ussami N., Upper mantle viscosity and dynamic subsidence of curved continental margins, Nature Communications, 2013, vol. 4, p. 1

Schubert G., Turcotte D. L., Olson P., Mantle convection in the earth and planets 1st edition. Cambridge Monographs on Mechan, Cambridge University Press, 2001

Sleep N. H., Thermal effects of the formation of Atlantic continental margins by continental break-up, Geophysical Journal of the Royal Astronomical Society, 1971, vol. 24, p. 325

Solomatov V. S., Scaling of temperature and stress dependent viscosity convection, Physics of Fluids, 1995, vol. 7, p. 266

Steckler M. S., Watts A. B., The Gulf of Lion: subsidence of a young continental margin, Nature, 1980, vol. 287, p. 425

Stüwe K., Geodynamics of the Lithosphere, 2002, 221

Tozer D. C., The present thermal state of the terrestrial planets, Physics of the Earth and Planetary Interiors, 1972, vol. 6, p. 182

Turcotte D., Schubert G., Geodynamics 3rd edition, 2014, 636

Zhong S., Constraints on thermochemical convection of the mantle from plume heat flux, plume excess temperature and upper mantle temperature, Journal of Geophysical Research, 2006, vol. 111

Ziegler W. H., In Woodland A. W., (Ed.), Petroleum and the Continental Shelf of NorthWest Europe, 1975 J. Wiley and Sons New York 
Apêndice 

Apêndice $\mathrm{A}$

\section{Subsidência e Estrutura Térmica dos Modelos com Litosfera Inicial Entre 120 - $270 \mathrm{~km}$}

Neste apêndice serão apresentados as taxas de subsidência e a estrutura térmica juntamente com o vetor de velocidades para todos os modelos em que foi possível obter uma litosfera estabilizada entre $120-270 \mathrm{~km}$. Os valores de $E^{\prime}, V^{\prime}$ e $\eta_{0}$ estão indicados na legenda de cada um dos modelos. 


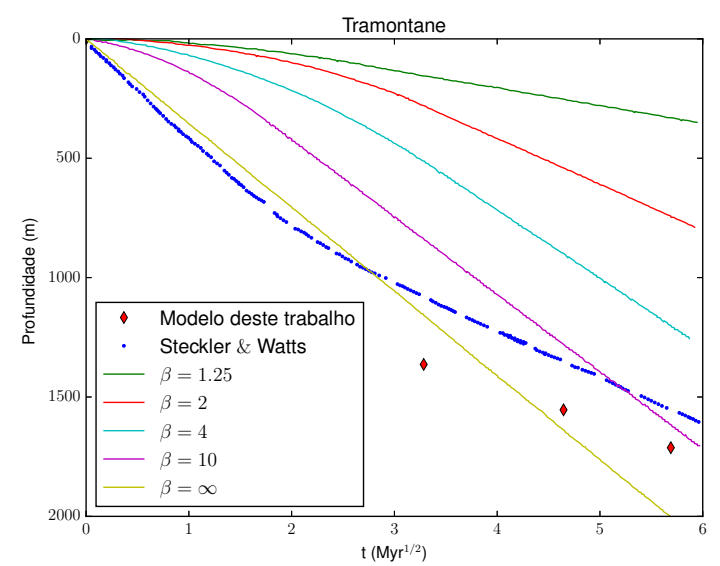

(a) Curvas de subsidência para o poço de Tramontane.

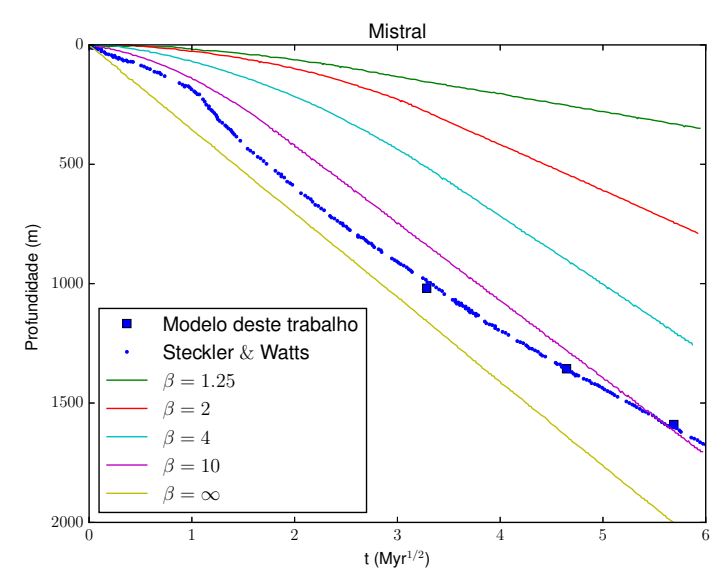

(b) Curvas de subsidência para o poço de Mistral.

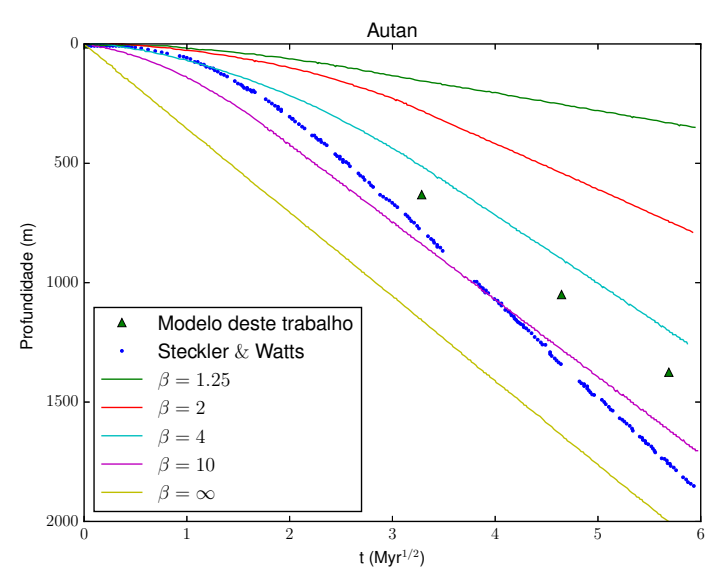

(c) Curvas de subsidência para o poço de Autan.

Figura A.1: Curvas de subsidência para o modelo com $\eta_{0}=4 \times 10^{20}, E^{\prime}=30$ e $V^{\prime}=7.5$. 


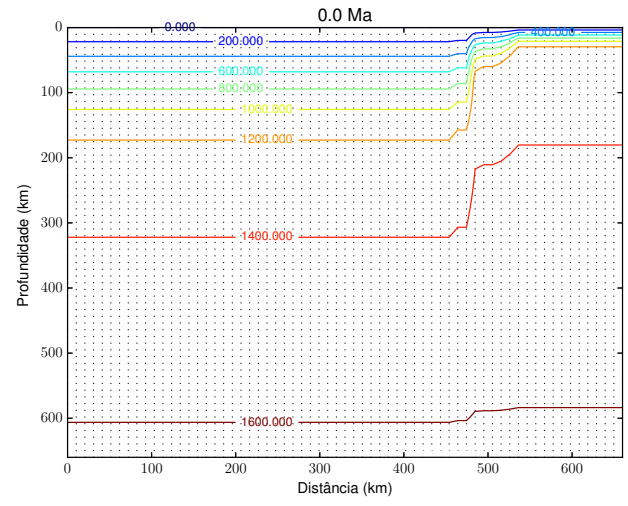

(a)

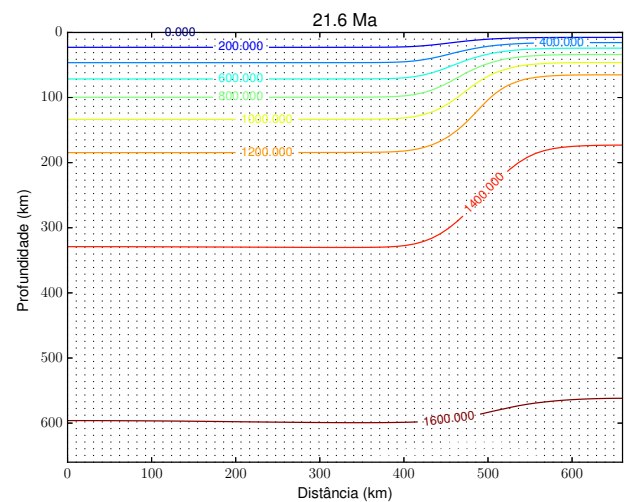

(c)

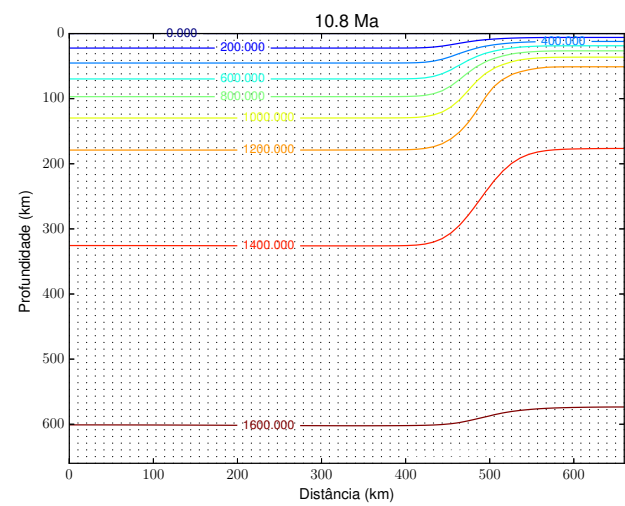

(b)

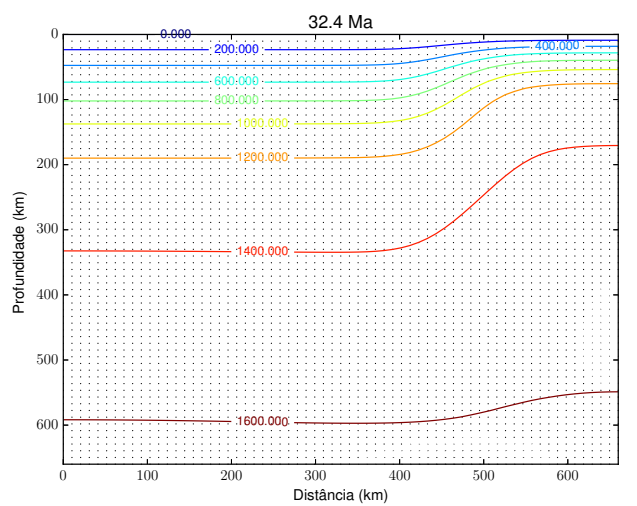

(d)

Figura A.2: Estrutura térmica e campo de velocidades para o modelo com $\eta_{0}=4 \times 10^{20}, E^{\prime}=30$ e $V^{\prime}=7.5$. Os vetores de velocidade foram reescalonados a cada intervalo de tempo e apenas fornecem uma representação qualitativa da tendência do movimento. 


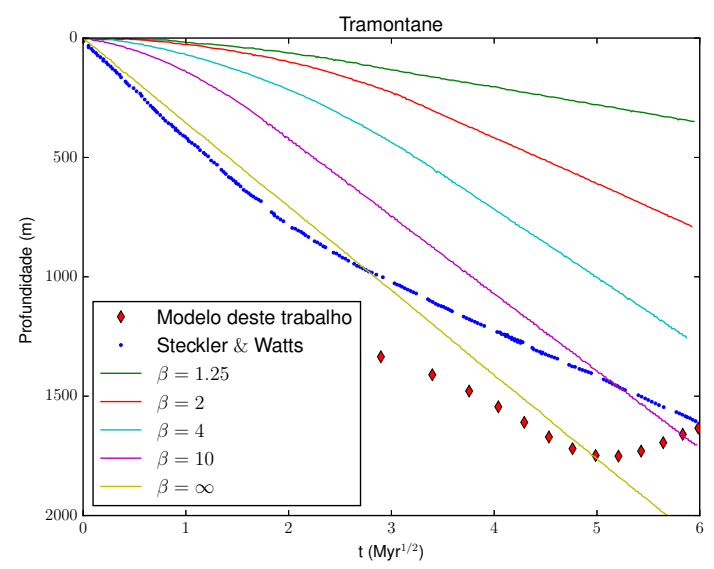

(a) Curvas de subsidência para o poço de Tramontane.

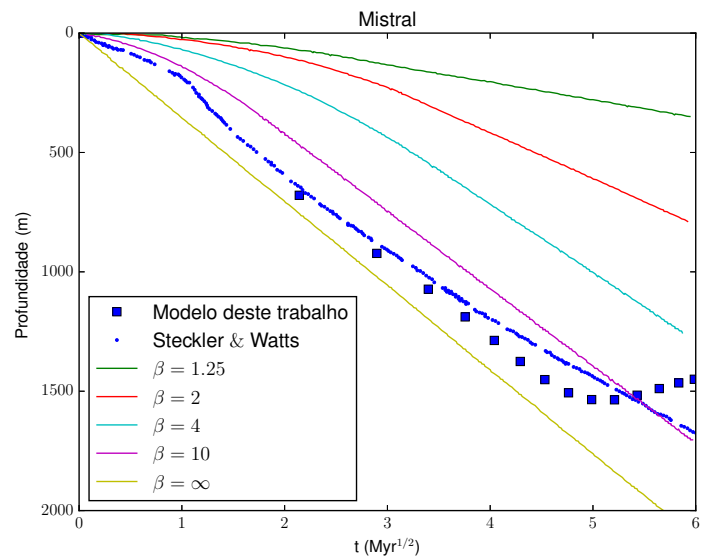

(b) Curvas de subsidência para o poço de Mistral.

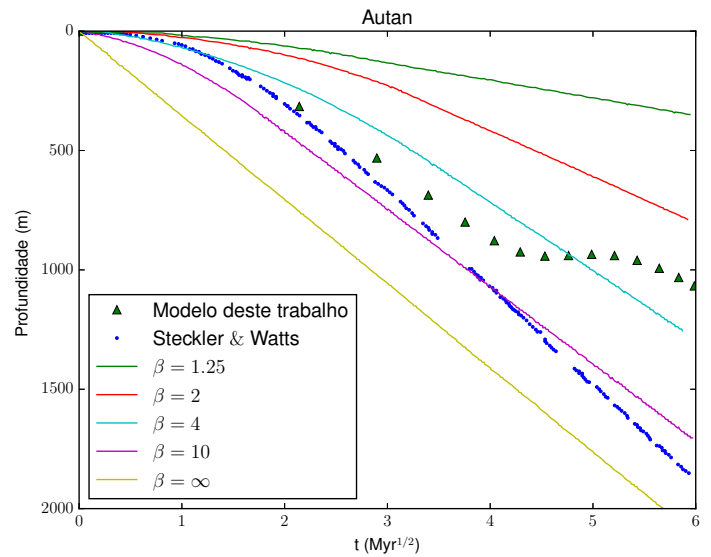

(c) Curvas de subsidência para o poço de Autan.

Figura A.3: Curvas de subsidência para o modelo com $\eta_{0}=3 \times 10^{20}, E^{\prime}=30$ e $V^{\prime}=7.5$. 


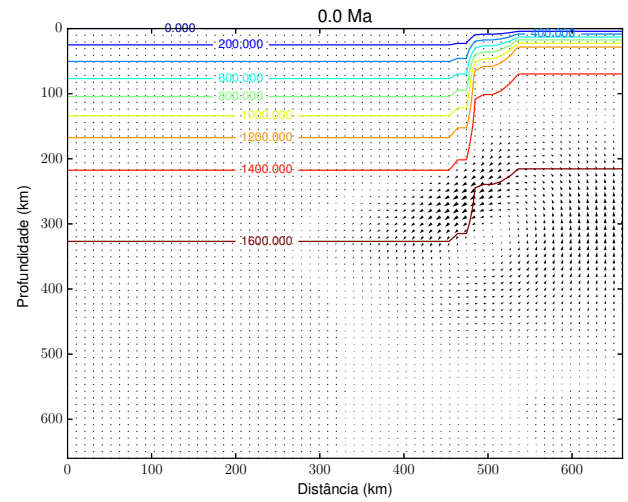

(a)

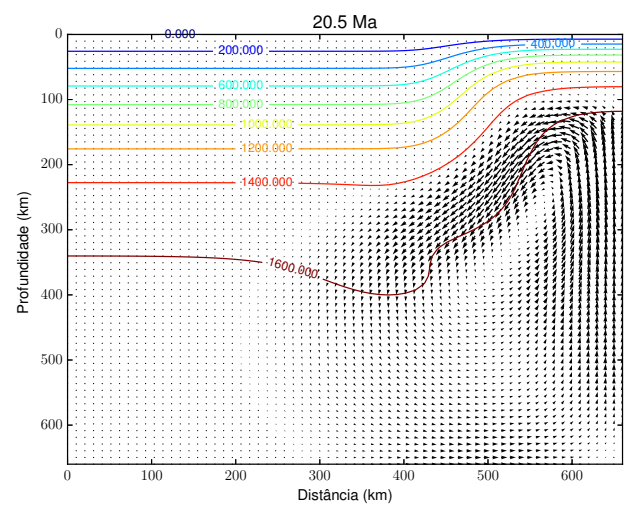

(c)

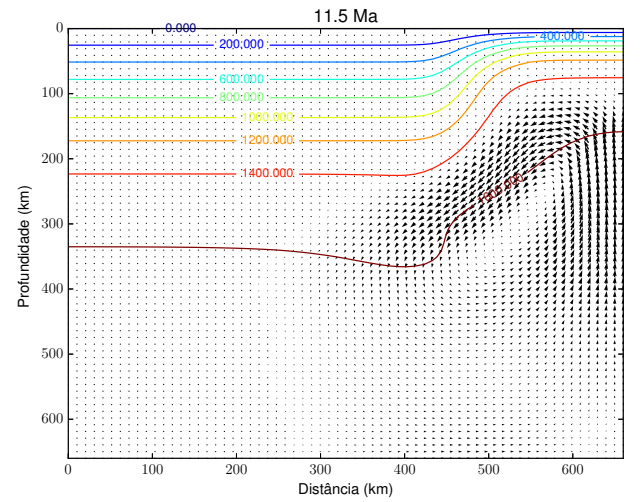

(b)

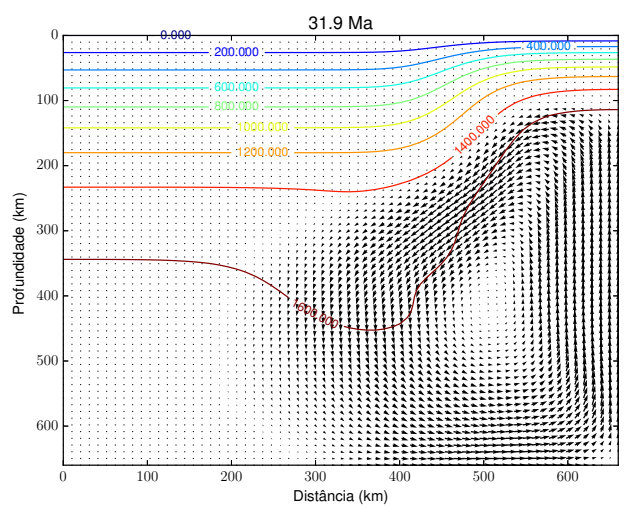

(d)

Figura A.4: Estrutura térmica e campo de velocidades para o modelo com $\eta_{0}=3 \times 10^{20}, E^{\prime}=30$ e $V^{\prime}=7.5$. Os vetores de velocidade foram reescalonados a cada intervalo de tempo e apenas fornecem uma representação qualitativa da tendência do movimento. 


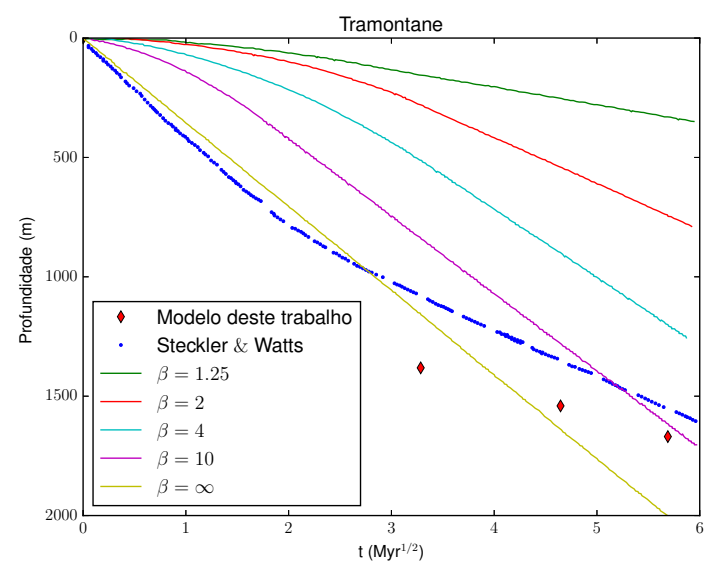

(a) Curvas de subsidência para o poço de Tramontane.

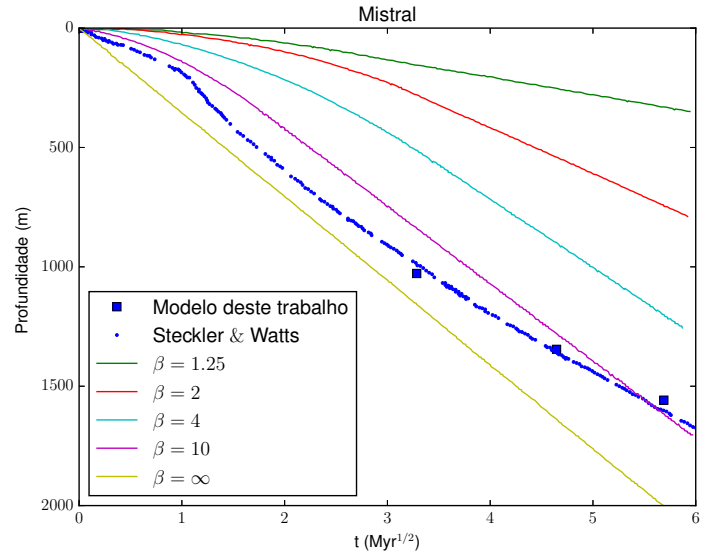

(b) Curvas de subsidência para o poço de Mistral.

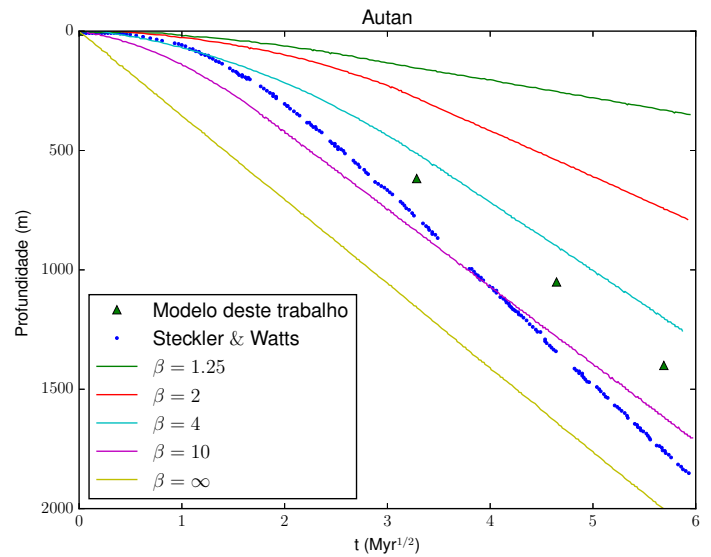

(c) Curvas de subsidência para o poço de Autan.

Figura A.5: Curvas de subsidência para o modelo com $\eta_{0}=1 \times 10^{20}, E^{\prime}=30$ e $V^{\prime}=0$. 


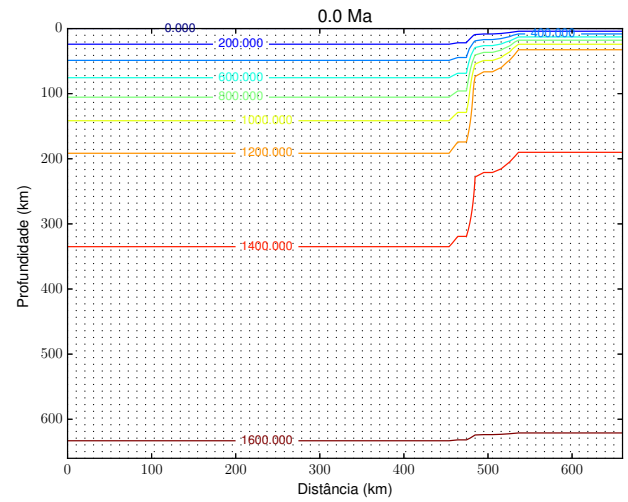

(a)

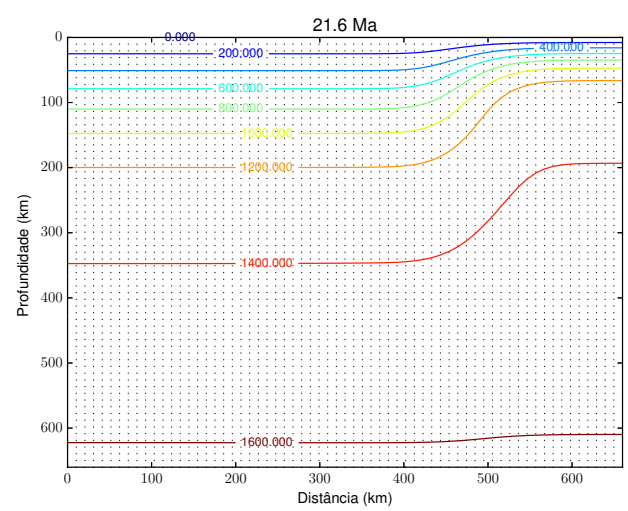

(c)

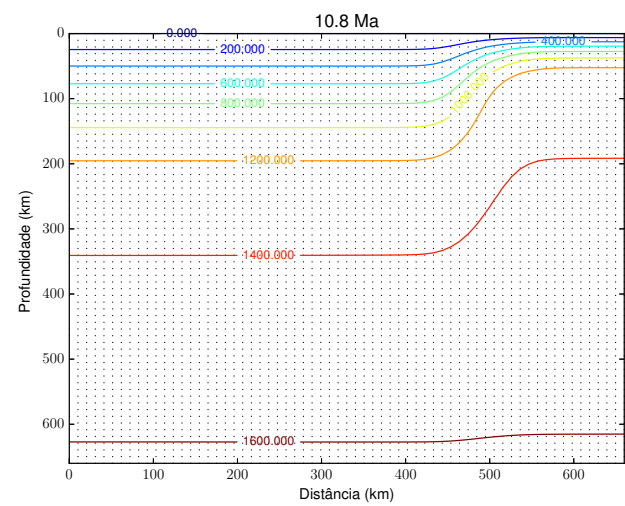

(b)

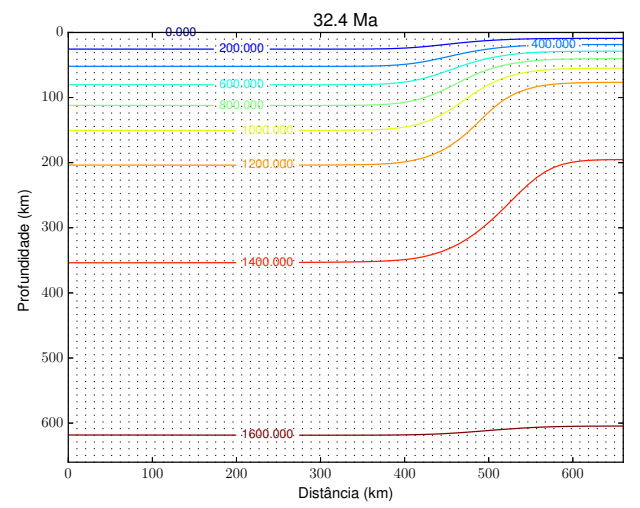

(d)

Figura A.6: Estrutura térmica e campo de velocidades para o modelo com $\eta_{0}=1 \times 10^{20}, E^{\prime}=30$ e $V^{\prime}=0$. Os vetores de velocidade foram reescalonados a cada intervalo de tempo e apenas fornecem uma representação qualitativa da tendência do movimento. 


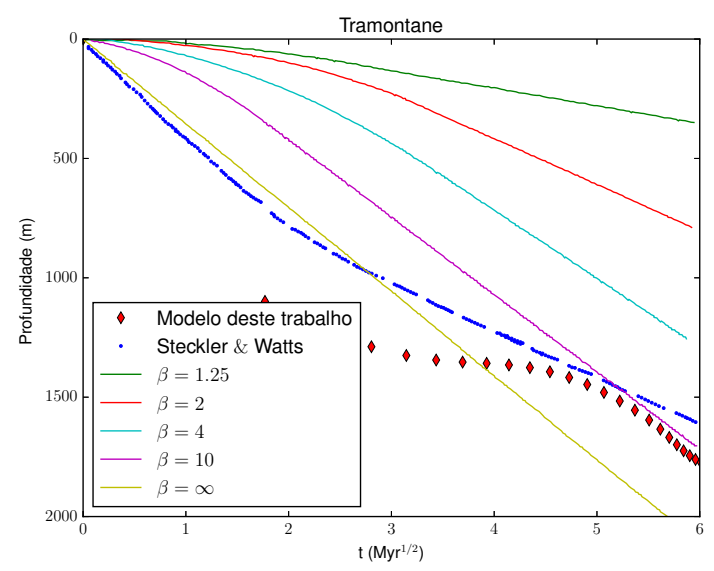

(a) Curvas de subsidência para o poço de Tramontane.

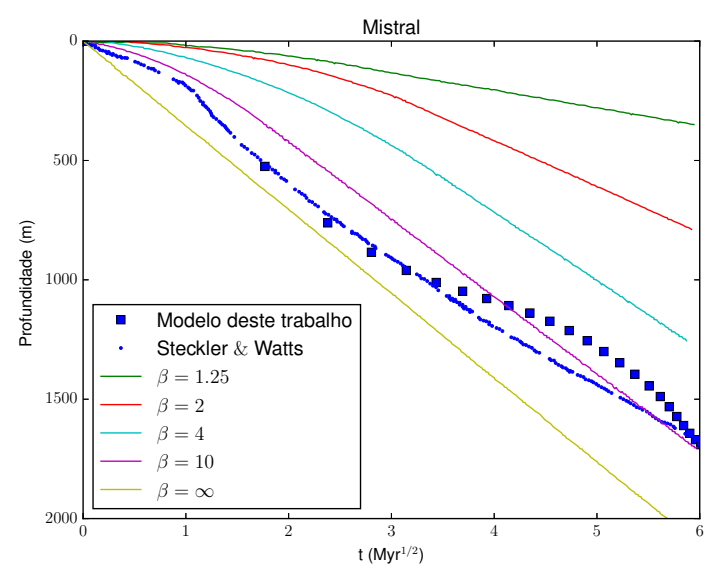

(b) Curvas de subsidência para o poço de Mistral.

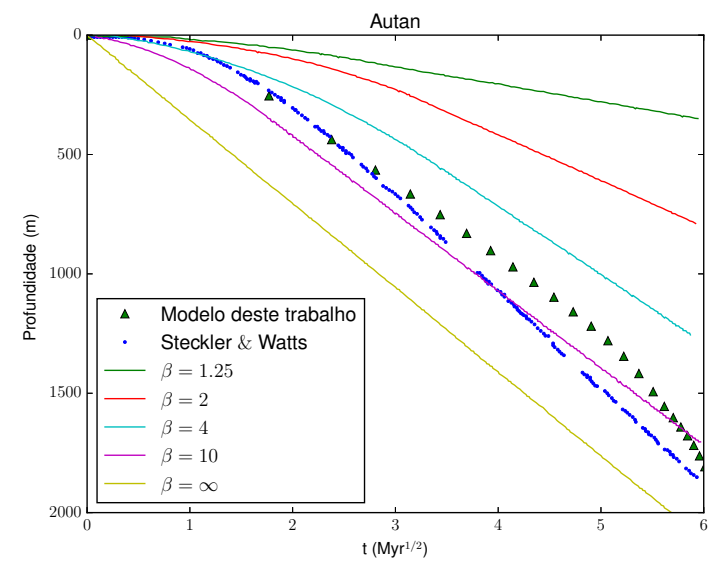

(c) Curvas de subsidência para o poço de Autan.

Figura A.7: Curvas de subsidência para o modelo com $\eta_{0}=1 \times 10^{20}, E^{\prime}=30$ e $V^{\prime}=5$. 


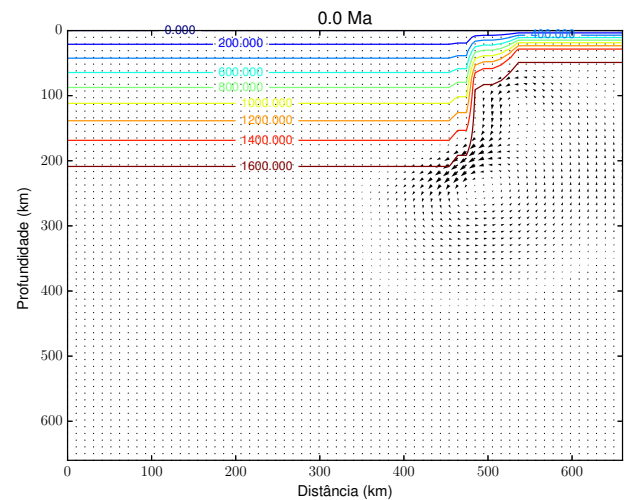

(a)

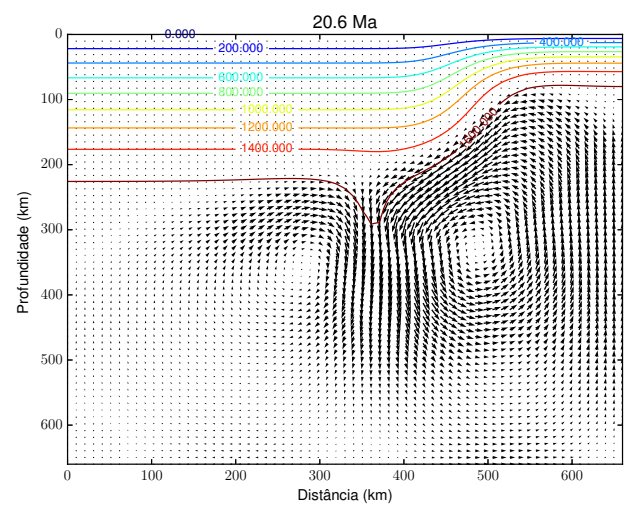

(c)

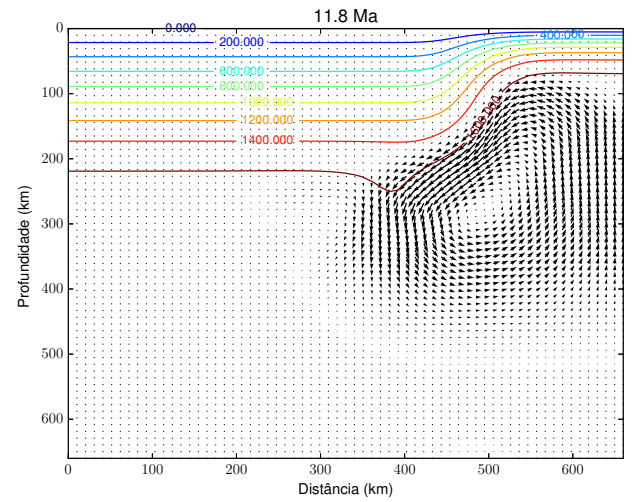

(b)

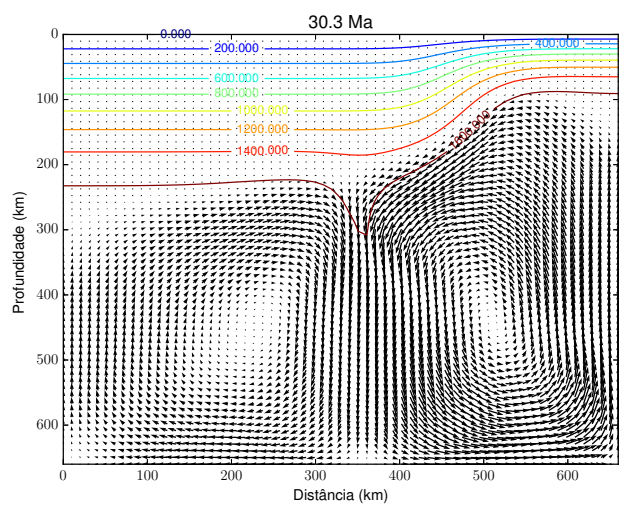

(d)

Figura A.8: Estrutura térmica e campo de velocidades para o modelo com $\eta_{0}=1 \times 10^{20}, E^{\prime}=30$ e $V^{\prime}=5$. Os vetores de velocidade foram reescalonados a cada intervalo de tempo e apenas fornecem uma representação qualitativa da tendência do movimento. 


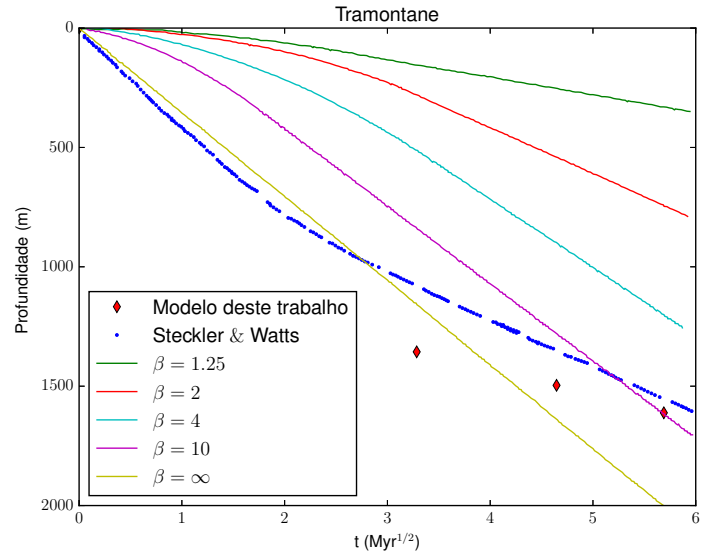

(a) Curvas de subsidência para o poço de Tramontane.

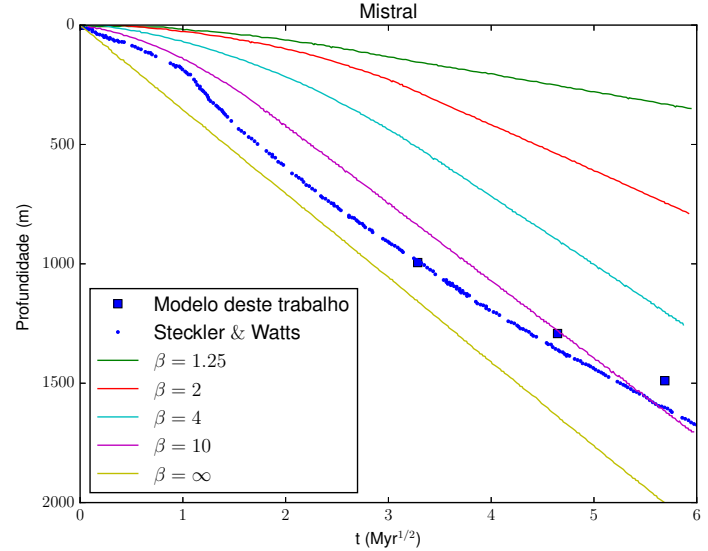

(b) Curvas de subsidência para o poço de Mistral.

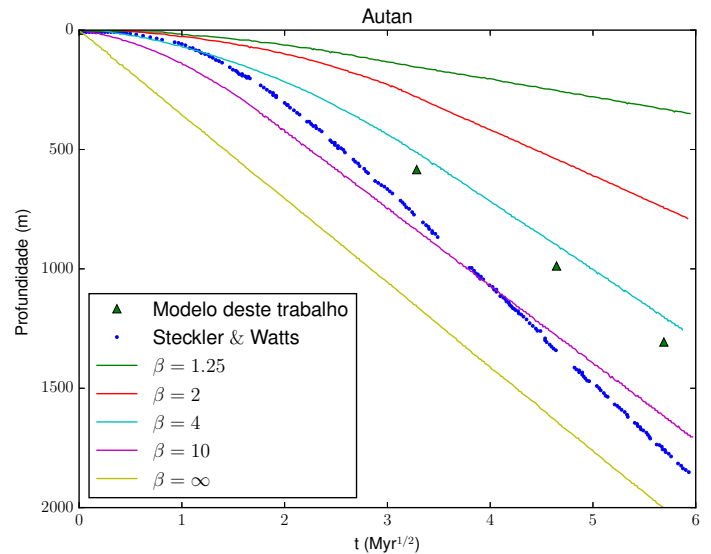

(c) Curvas de subsidência para o poço de Autan.

Figura A.9: Curvas de subsidência para o modelo com $\eta_{0}=5 \times 10^{20}, E^{\prime}=20$ e $V^{\prime}=5$. 


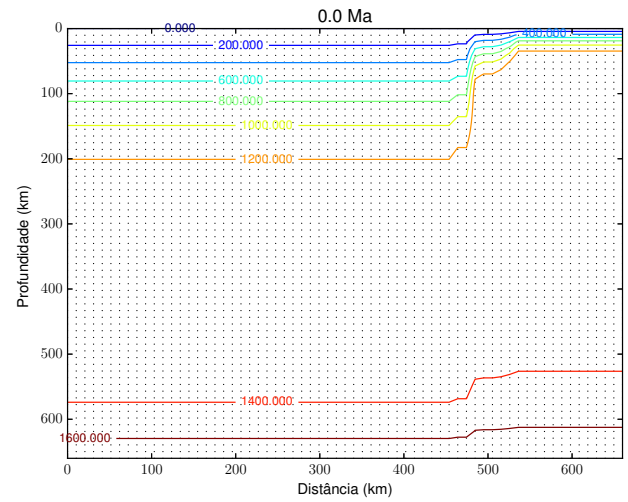

(a)

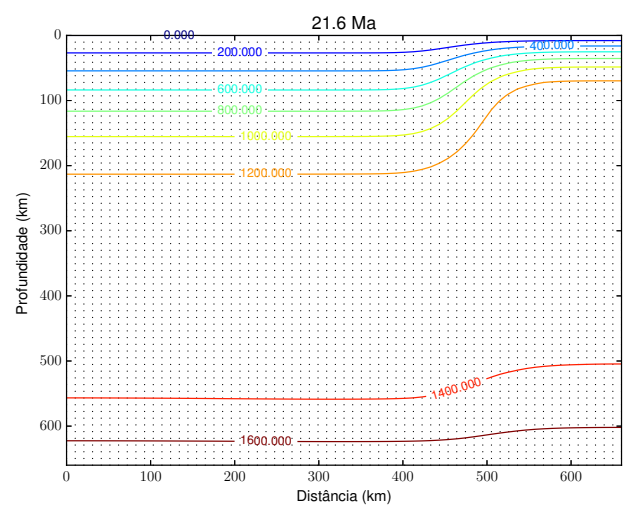

(c)

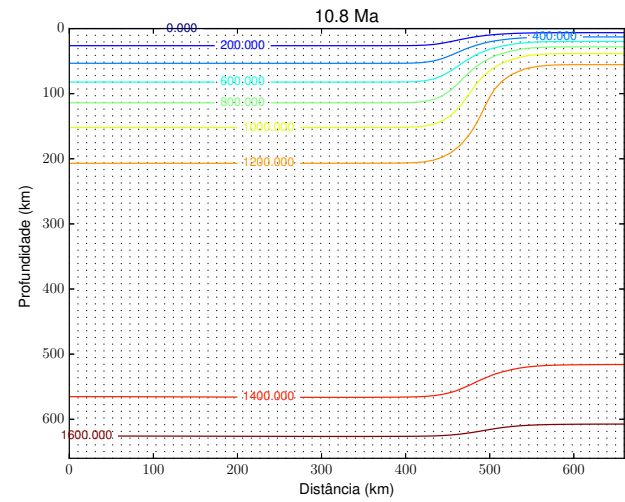

(b)

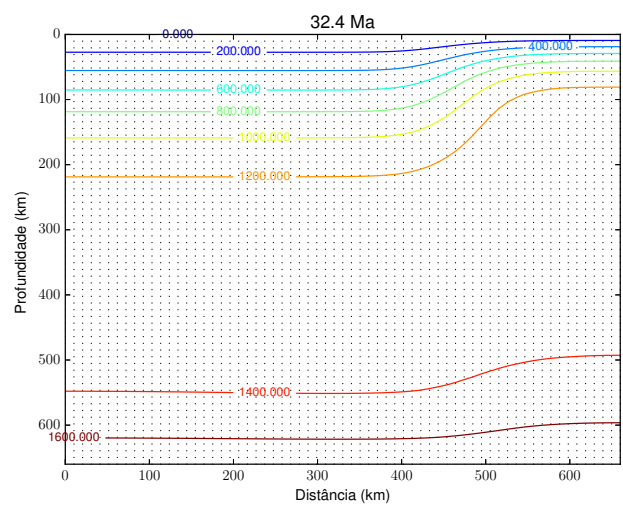

(d)

Figura A.10: Estrutura térmica e campo de velocidades para o modelo com $\eta_{0}=5 \times 10^{20}, E^{\prime}=20$ e $V^{\prime}=5$. Os vetores de velocidade foram reescalonados a cada intervalo de tempo e apenas fornecem uma representação qualitativa da tendência do movimento. 


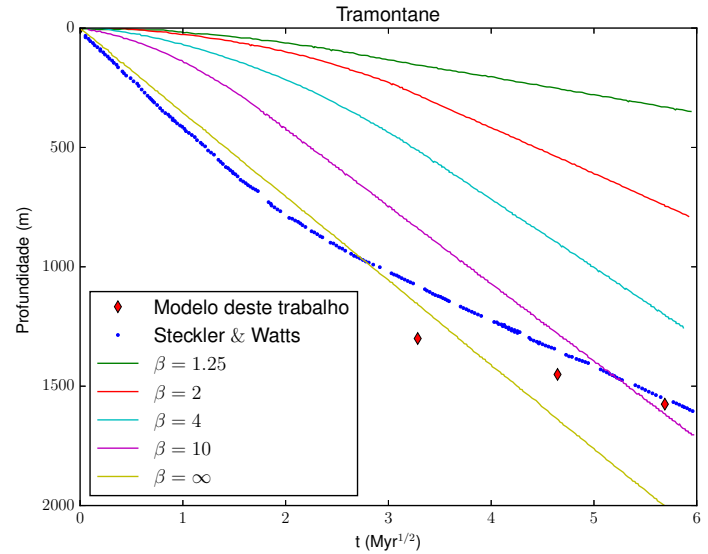

(a) Curvas de subsidência para o poço de Tramontane.

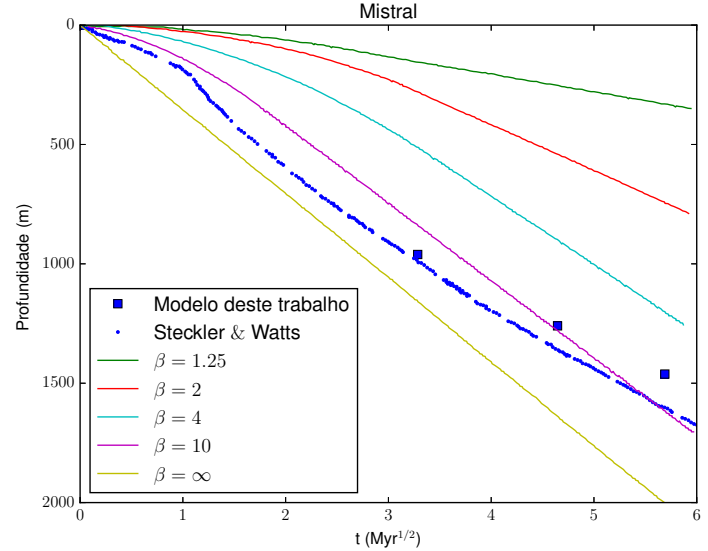

(b) Curvas de subsidência para o poço de Mistral.

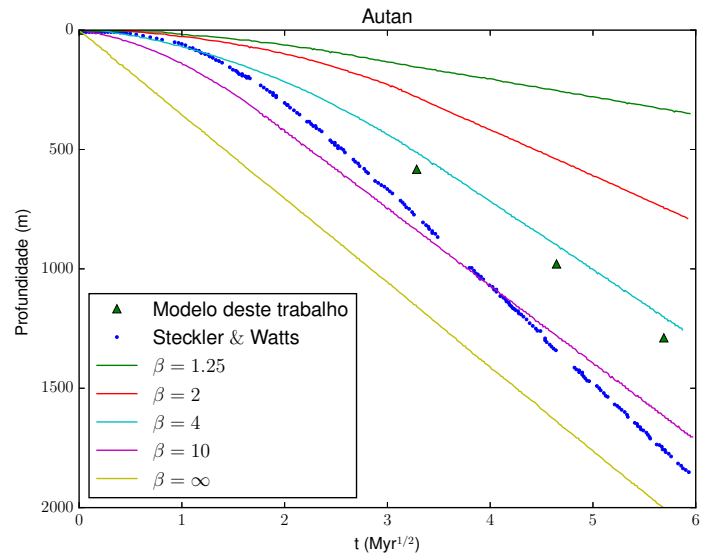

(c) Curvas de subsidência para o poço de Autan.

Figura A.11: Curvas de subsidência para o modelo com $\eta_{0}=4 \times 10^{20}, E^{\prime}=20$ e $V^{\prime}=5$. 


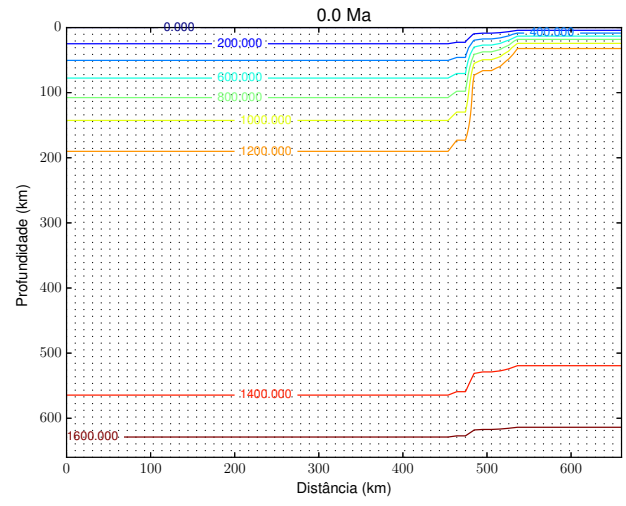

(a)

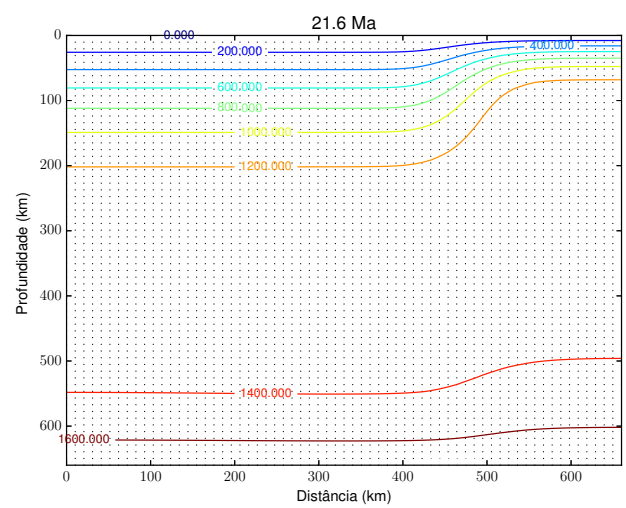

(c)

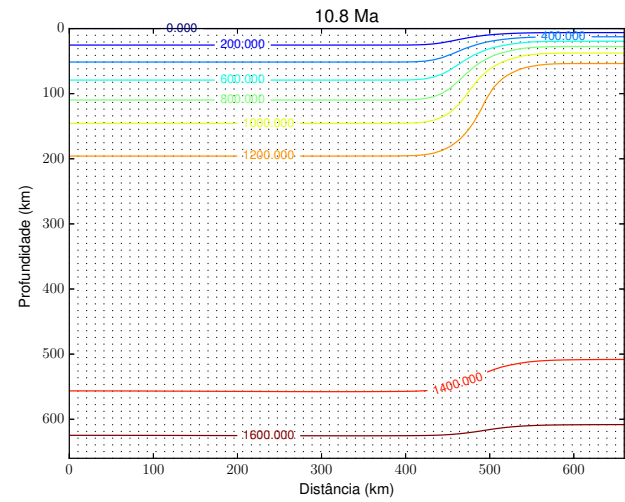

(b)

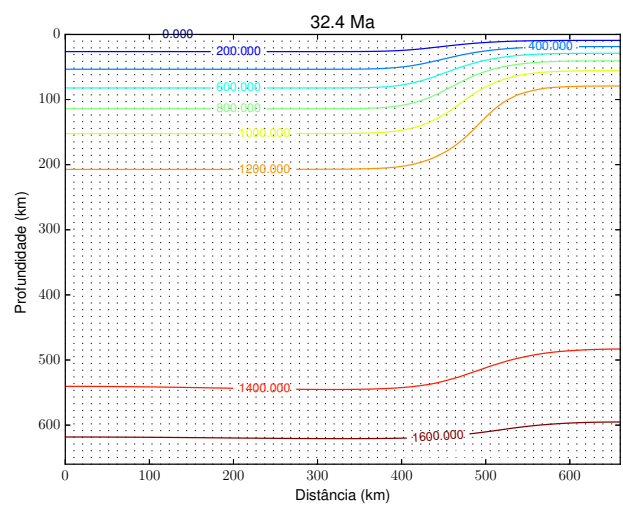

(d)

Figura A.12: Estrutura térmica e campo de velocidades para o modelo com $\eta_{0}=4 \times 10^{20}, E^{\prime}=20$ e $V^{\prime}=5$. Os vetores de velocidade foram reescalonados a cada intervalo de tempo e apenas fornecem uma representação qualitativa da tendência do movimento. 


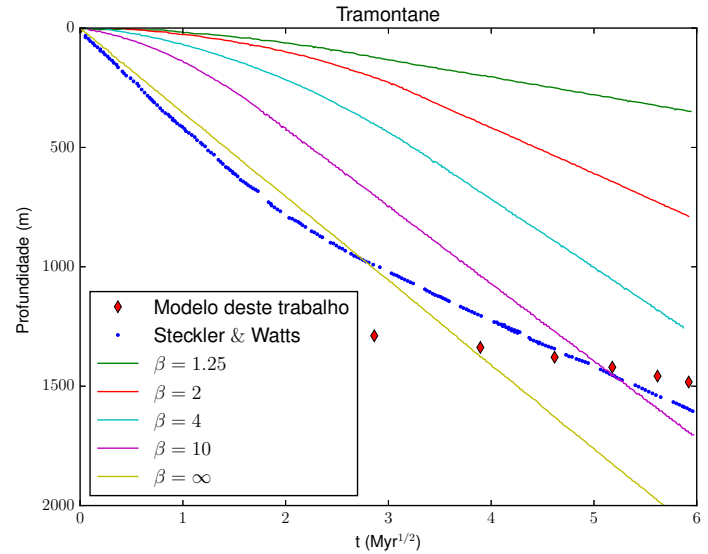

(a) Curvas de subsidência para o poço de Tramontane.

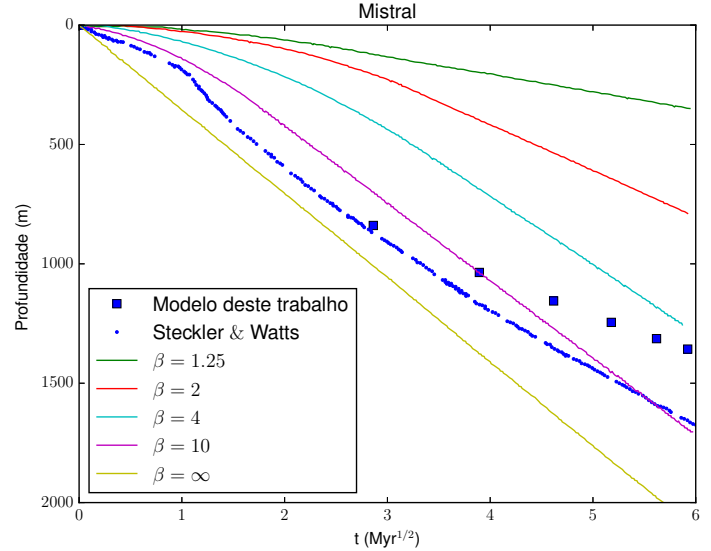

(b) Curvas de subsidência para o poço de Mistral.

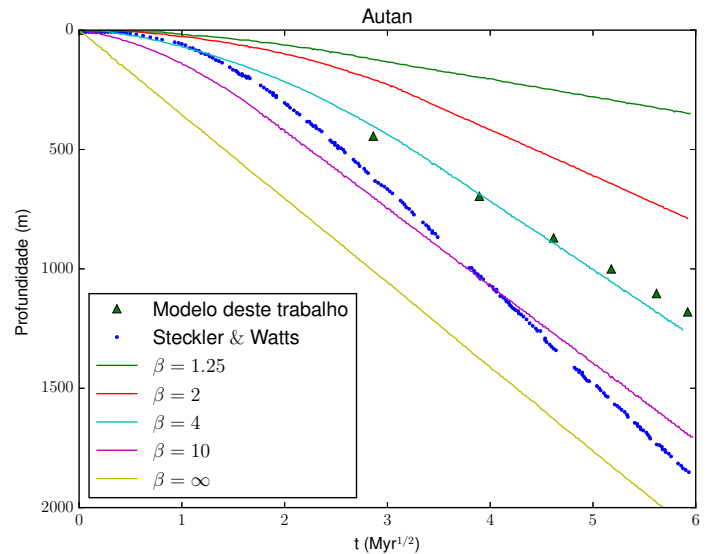

(c) Curvas de subsidência para o poço de Autan.

Figura A.13: Curvas de subsidência para o modelo com $\eta_{0}=3 \times 10^{20}, E^{\prime}=20$ e $V^{\prime}=5$. 


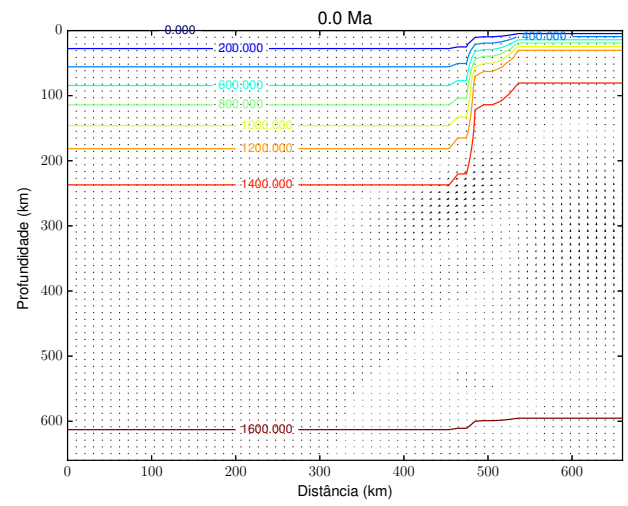

(a)

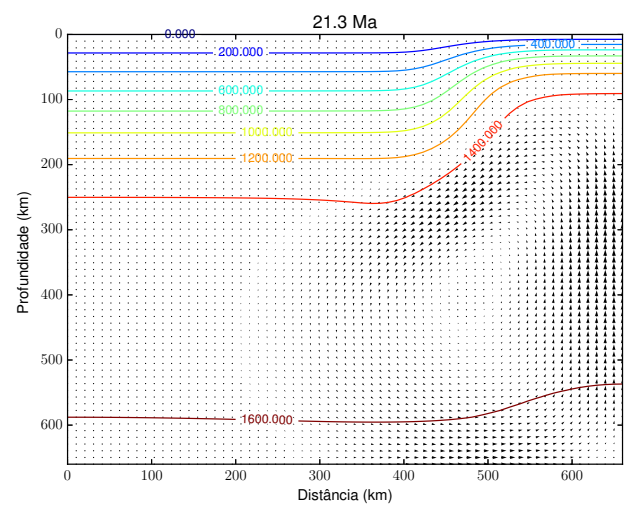

(c)

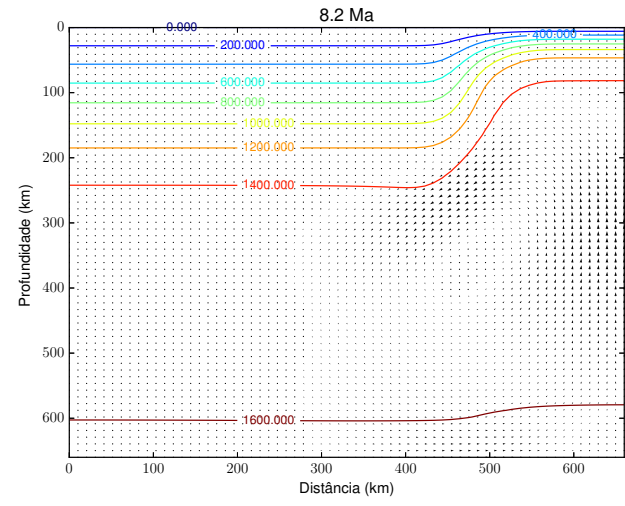

(b)

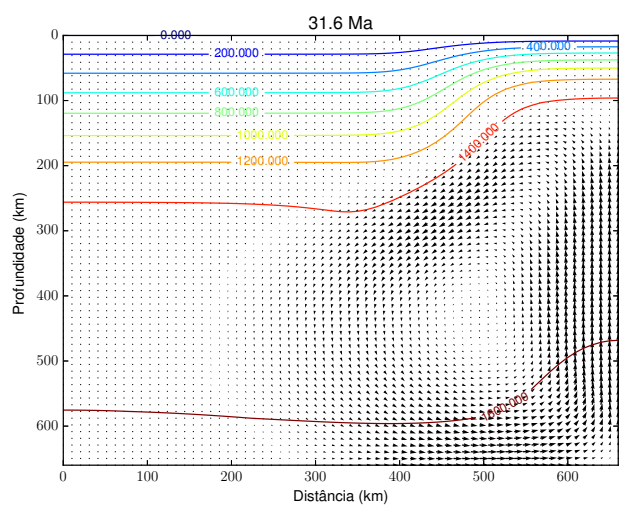

(d)

Figura A.14: Estrutura térmica e campo de velocidades para o modelo com $\eta_{0}=3 \times 10^{20}, E^{\prime}=20$ e $V^{\prime}=5$. Os vetores de velocidade foram reescalonados a cada intervalo de tempo e apenas fornecem uma representação qualitativa da tendência do movimento. 


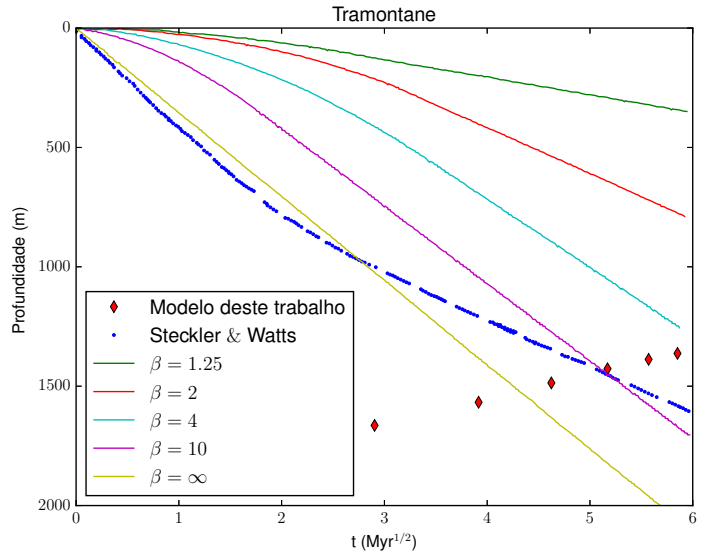

(a) Curvas de subsidência para o poço de Tramontane.

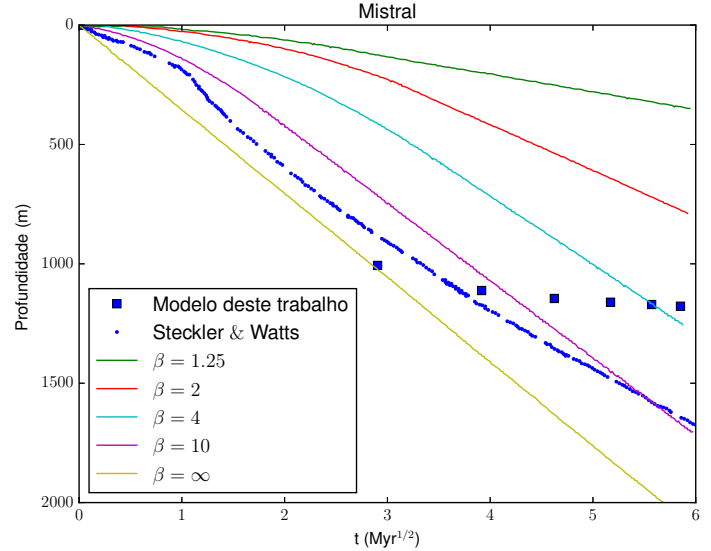

(b) Curvas de subsidência para o poço de Mistral.

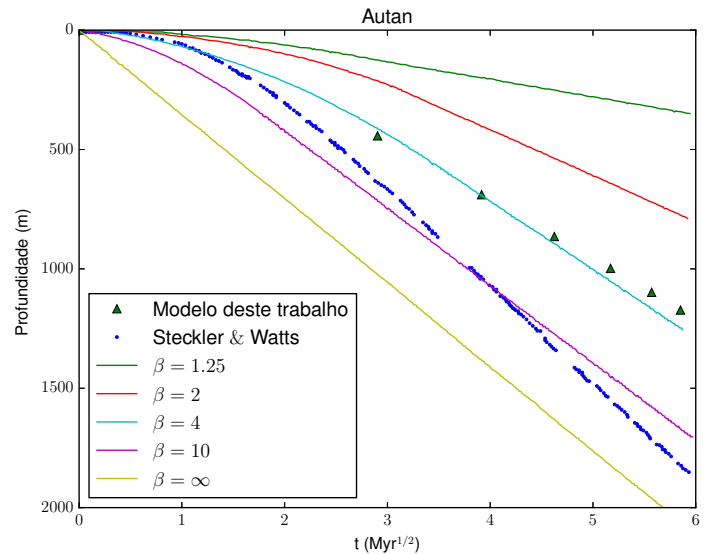

(c) Curvas de subsidência para o poço de Autan.

Figura A.15: Curvas de subsidência para o modelo com $\eta_{0}=1 \times 10^{20}, E^{\prime}=20$ e $V^{\prime}=0$. 


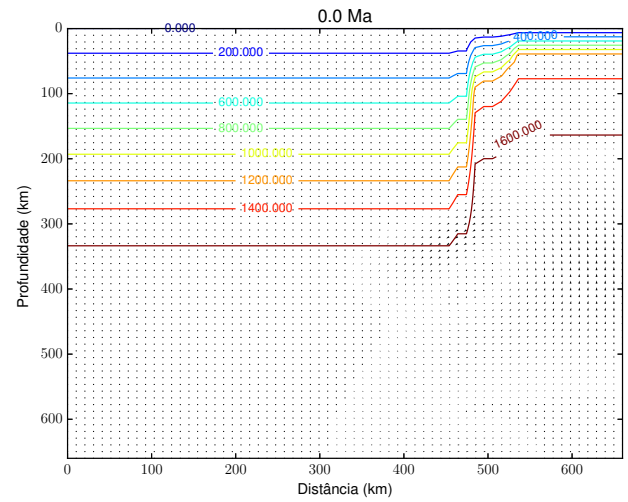

(a)

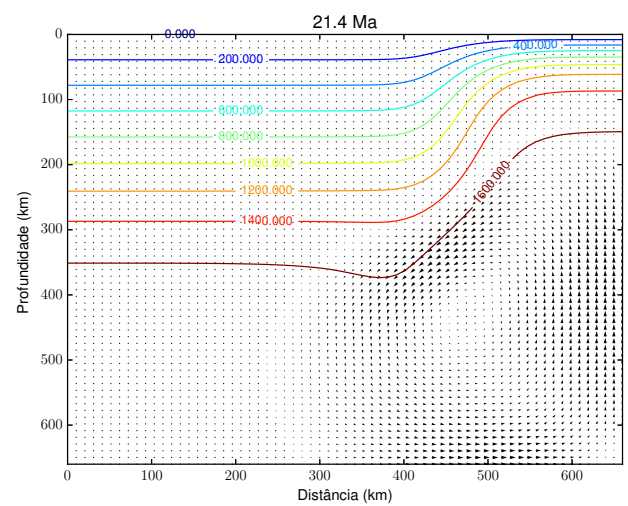

(c)

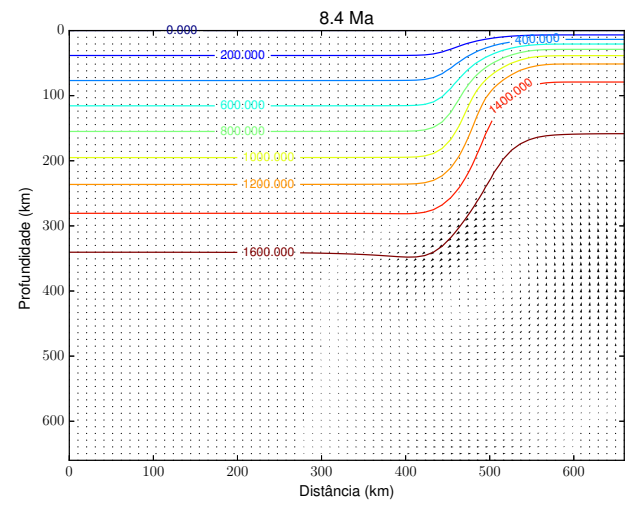

(b)

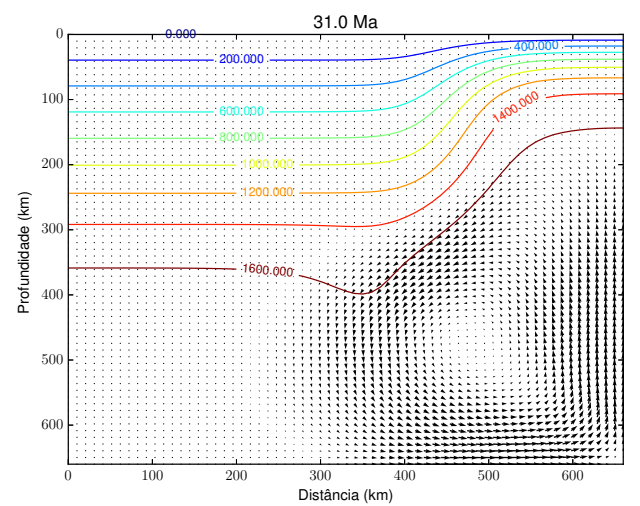

(d)

Figura A.16: Estrutura térmica e campo de velocidades para o modelo com $\eta_{0}=1 \times 10^{20}, E^{\prime}=20$ e $V^{\prime}=0$. Os vetores de velocidade foram reescalonados a cada intervalo de tempo e apenas fornecem uma representação qualitativa da tendência do movimento. 